WHC-EP-0816

UC-600

\title{
Ferrocyanide Safety Program: An Assessment of the Possibility of Ferrocyanide Sludge Dryout
}

\author{
M. Epstein \\ H. K. Fauske \\ Fauske and Associates, Inc. \\ D. R. Dickinson \\ M. D. Crippen \\ J. D. McCormack \\ R. J. Cash \\ J. E. Meacham \\ Westinghouse Hanford Company \\ C. S. Simmons \\ Pacific Northwest Laboratory
}

Date Published

September 1994

Prepared for. the U.S. Department of Energy Office of Environmental Restoration and Waste Management

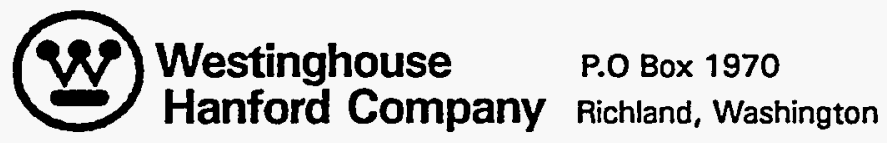

Hanford Operations and Engineering Contractor for the

U.S. Department of Energy under Contract DE-AC06-87RL10930

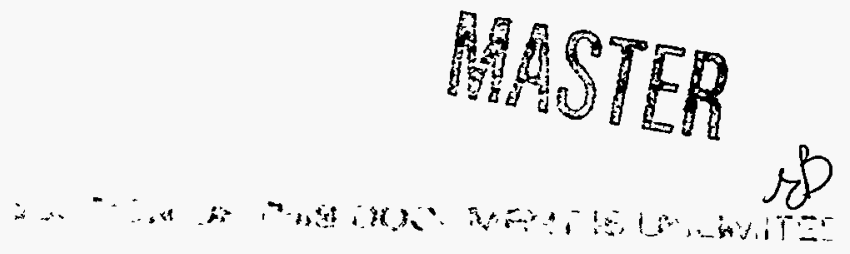

Approved for Public Release 


\section{RELEASE AUTHORIZATION}

Document Number: WHC-EP-0816

Document Title: $\quad$ Ferrocyanide Safety Progarm: An Assessment of the Possibility of Ferrocyanide Sludge Dryout

Release Date: $\quad$ September 30, 1994

***************

This document was reviewed following the procedures described in WHC-CM-3-4 and is:

APPROVED FOR PUBLIC RELEASE

***************

WHC Information Release Administration Specialist:

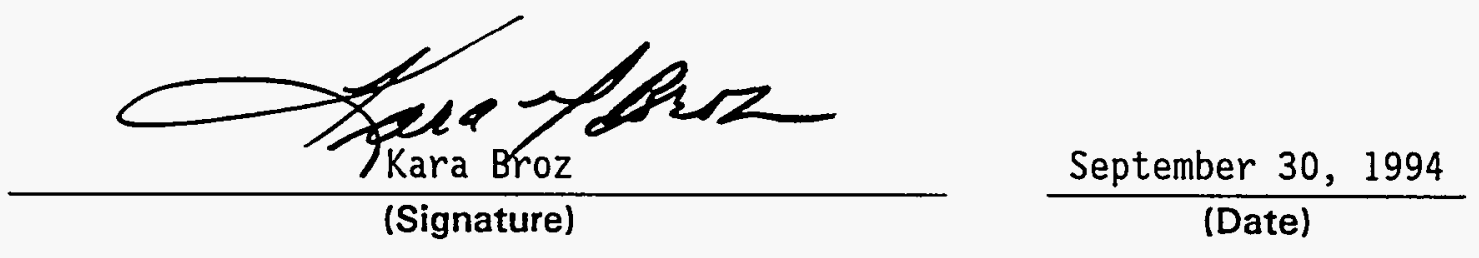




\section{DISCLAIMER}

This report was prepared as an account of work sponsored by an agency of the United States Government. Neither the United States Government nor any agency thereof, nor any of their employees, make any warranty, express or implied, or assumes any legal liability or responsibility for the accuracy, completeness, or usefulness of any information, apparatus, product, or process disclosed, or represents that its use would not infringe privately owned rights. Reference herein to any specific commercial product, process, or service by trade name, trademark, manufacturer, or otherwise does not necessarily constitute or imply its endorsement, recommendation, or favoring by the United States Government or any agency thereof. The views and opinions of authors expressed herein do not necessarily state or reflect those of the United States Government or any agency thereof. 


\section{DISCLAIMER}

Portions of this document may be illegible in electronic image products. Images are produced from the best available original document. 


\section{SUMMARY}

Much attention has been focused on the Hanford Site radioactive waste storage tanks as a result of problems that have been envisioned for them. One problem is the potential chemical reaction between ferrocyanide precipitate particles and nitrates in the absence of water. This report addresses the question of whether dryout of a portion of ferrocyanide sludge would render it potentially reactive.

Various sludge dryout mechanisms were examined to determine if any of them could occur. The mechanisms are: 1) bulk heating of the entire sludge inventory to its boiling point; 2) loss of liquid to the atmosphere via sludge surface evaporation; 3) local drying by boiling in a "hot spot" region; 4) sludge drainage through a leak in the tank wall; and 5) local drying by evaporation from a warm segment of surface sludge. From the simple analyses presented in this report and more detailed published analyses, it is evident that global loss of water from bulk heating of the sludge to its boiling point or from surface evaporation and vapor transport to the outside air is not credible. Also, from the analyses presented in this report and experimental and analytical work presented elsewhere, it is evident that formation of a dry local or global region of sludge as a result of tank leakage (draining of interstitial liquid) is not possible. Finally, and most importantly, it is concluded that formation of dry local regions in the ferrocyanide sludge by local hot spots or warm surface regions is not possible.

Local dryout cannot occur because a structure of fine (micron-size) precipitate particles comprises the sludge; this structure is capable of holding within its pores large quantities of water. Much like in natural soils or clays (fine sediment), water in ferrocyanide sludge is strongly held by the sludge solids as a result of electrostatic forces. The tenacity with which the sludge precipitate particle matrix maintains its "grip" on the sludge water component is clearly illustrated by data taken on the response of ferrocyanide simulant sludge to bubble growth and sustained local heat sources in test volumes as large as $1.0 \mathrm{~m}$.

The conclusion that local or global dryout is incredible is consistent with four decades of waste storage history, during which sludge temperatures have gradually decreased or remained constant and the sludge moisture content has been retained. 
WHC-EP-0816

This page intentionally left blank. 


\section{TABLE OF CONTENTS}

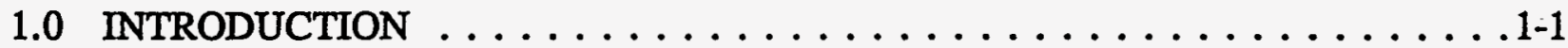

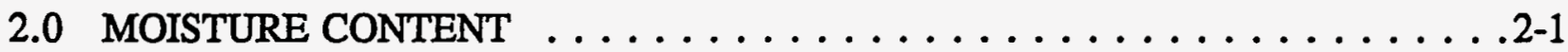

2.1 MOISTURE CONTENTS OF WASTE SIMULANTS $\ldots \ldots \ldots \ldots \ldots .2-1$

2.2 MOISTURE CONTENTS OF TANK WASTE SAMPLES $\ldots \ldots \ldots \ldots 2-2$

2.3 MOISTURE INVENTORY OF FERROCYANIDE TANKS . . . . . . . . 2-2

2.4 DEPENDENCE OF VAPOR PRESSURE OF WATER IN SLUDGE ON

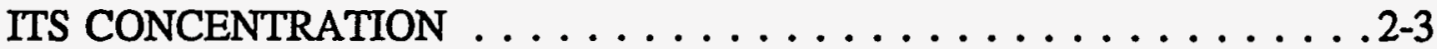

3.0 MOISTURE CONTENT REQUIRED TO PREVENT PROPAGATING REACTIONS . . . . . . . . . . . . . . . . .

3.1 ADIABATIC CALORIMETRY TESTS $\ldots \ldots \ldots \ldots \ldots \ldots \ldots \ldots . \ldots \ldots$

3.2 PROPAGATION RATE TESTS $\ldots \ldots \ldots \ldots \ldots \ldots \ldots \ldots \ldots$. . . . . .

4.0 GLOBAL MECHANISMS OF DRYOUT $\ldots \ldots \ldots \ldots \ldots \ldots . \ldots \ldots$ 4 1

4.1 TANK HEAT LOADS AND THERMAL CONDUCTIVITY OF

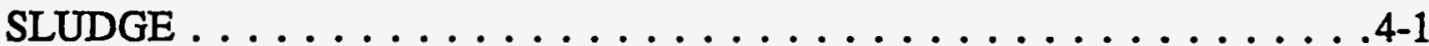

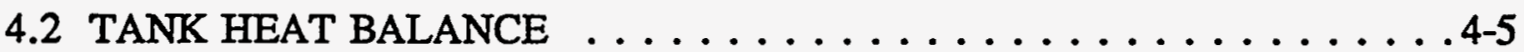

4.3 AIR-EXCHANGE-CONTROLLED SLUDGE EVAPORATION RATE . . 4-10

5.0 RHEOLOGY OF WATER-SATURATED FERROCYANIDE SLUDGE . . . . . . 5-1

5.1 LIQUID DRAINAGE EXPERIMENT AND INTERPRETATION . . . . . . 5-1

5.2 EXPERIMENTS ON SIMULANT WASTE TANK SLUDGE RESPONSE TO VOID GROWTH . . . . . . . . . . . . . . . . 5-4

5.3 SMALL-SCALE EXPERIMENTAL RESULTS ON DRYOUT IN SIMULANT WASTE SLUDGE HEATED LOCALLY . . . . . . . . . 5-14

5.4 LARGE-SCALE EXPERIMENTAL RESULTS ON DRYOUT IN SIMULANT . . . . . . . . . . . . . . . . . . . . . . . 5-30

5.5 RHEOLOGICAL PROPERTIES OF FERROCYANIDE WASTE TANK SIMULANTS COMPARED WITH PROPERTIES OF WASTE TANK

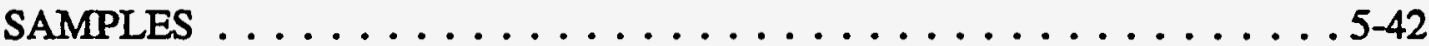

6.0 WATER RETENTION CAPABILITY OF SLUDGE AND THE UNLIKELIHOOD OF LOCAL DRYOUT $\ldots \ldots \ldots \ldots \ldots \ldots \ldots \ldots \ldots$

6.1 CONSOLIDATION PRINCIPLES $\ldots \ldots \ldots \ldots \ldots \ldots \ldots \ldots \ldots \ldots$

6.2 THE HOT SPOT $\ldots \ldots \ldots \ldots \ldots \ldots \ldots \ldots \ldots \ldots \ldots \ldots$

6.3 DRAINAGE OF INTERSTITIAL LIQUID $\ldots \ldots \ldots \ldots \ldots \ldots \ldots$. . . . . .

6.4 LOCAL EVAPORATION AND BOILING . . . . . . . . . . 6-17

6.5 POSSIBLE CONCENTRATION OF HEAT GENERATION IN TANKS . . 6-23

7.0 CONCLUDING REMARKS $\ldots \ldots \ldots \ldots \ldots \ldots \ldots \ldots \ldots \ldots \ldots \ldots \ldots$

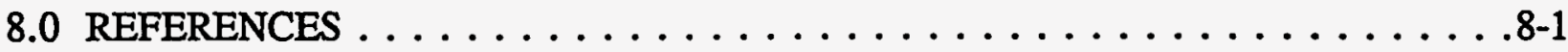




\section{LIST OF FIGURES}

4-1. Illustration of Flow Configuration Through Clustered Tanks

$\left(Q_{p}\right.$ is dry instrument air purge flow) $\ldots \ldots \ldots \ldots \ldots \ldots \ldots \ldots \ldots \ldots \ldots \ldots .16$

5-1. Drainage Weight of Interstitial Liquid versus Time from a $0.2-m$ Column of In Farm 2 Sludge . . . . . . . . . . . . 5-3

5-2. Schematic of Bubble Formation Apparatus $\ldots \ldots \ldots \ldots \ldots \ldots$ 5-6

5-3. Photograph of Gas Bubble and Overlying 4.45-cm-Diameter Column of Ferrocyanide In Farm 1 Flowsheet Simulant Material . . . . . . . . . 5-7

5-4. Photograph of Gas Bubble Showing the Overlying 50/50 Weight Percent Kaolin Particle-Water in the 12.7-cm-Diameter Column . . . . . . . . . 5-8

5-5. Schematic of Apparatus for Vapor Bubble Formation in Sludge via Slow Depressurization $\ldots \ldots \ldots \ldots \ldots \ldots \ldots \ldots \ldots \ldots$. . . . . . . .

5-6. Photograph of Vapor Bubble Growing in 50/50 Weight Percent Kaolin Particle-Water Mixture . . . . . . . . . . . . . . . . . 5-12

5-7. Photograph of Vapor Bubble Growing in Ferrocyanide In Farm 1 Flowsheet Simulant Material . . . . . . . . . . . . 5-13

5-8. Schematic of 3-Liter Beaker Test Indicating Locations of Cylindrical Immersion Heater and Thermocouples . . . . . . . . . . . 5-18

5-9. Thermal Response of 50/50 Kaolin/Water Mixture by Mass to 67 -Watt Cylindrical Immersion Heater . . . . . . . . . . . . . . . . . . . 5-19

5-10. Thermal Response of Kaolin/Aqueous Sodium Nitrate Salt Solution to a 4-Watt Cylindrical Immersion Heater $\ldots \ldots \ldots \ldots$. . . . . . . . . . .

5-11. Thermal Response of 50/50 Kaolin/Water Mixture to 4-Watt Cylindrical Immersion Heater . . . . . . . . . . . . . . . . 5-23

5-12. Schematic of "Two-Dimensional Test Section" for Observing Simulant Waste Material Response to a Local Heat Source . . . . . . . . . . 5 5-26

5-13. Photograph of Simulant Waste (Kaolin) Morphology in Vicinity of 8.6-Watt Cylindrical Heater . . . . . . . . . . . 5-27

5-14. Photograph of U Plant Simulant in Vicinity of $8.1-$ Watt Cylindrical Heater $\ldots \ldots \ldots \ldots \ldots \ldots \ldots . . \ldots 5$ 


\section{LIST OF FIGURES (Continued)}

5-15. Large-Scale Test Section Indicating Locations

of Coiled Immersion Heaters and Thermocouples . . . . . . . . . . . . . 5-31

5-16. Photograph of Heater and Thermocouple Arrangements in Large-Scale Kaolin Tank . . . . . . . . . . . . . . . . . . . . . 5-32

5-17. Measured Temperature-Time Histories at Various Vertical Locations Along Centerline of Large-Scale Tank During Calibration Run . . . . . . . 5-34

5-18. Measured Temperature-Time Histories at Various Radial Locations in Large-Scale Tank During Calibration Run . . . . . . . . . . 5-35

5-19. Measured Temperature-Time Histories at Various Locations Along Centerline of Large-Scale Tank During Boiling Experiment . . . . . . 5-36

5-20. Measured Temperature-Time Histories at Various Radial Locations in Large-Scale Tank During Boiling Experiment . . . . . . . . . . 5-37

5-21. Measured Temperature-Time Histories at Various Vertical Locations Along Centerline of Large-Scale Tank During Water Migration Test . . . . . . 5-40

5-22. Measured Temperature-Time Histories at Various Radial Locations in Large-Scale Tank During Water Migration Test . . . . . . . . . . . . 5 5-41

6-1. Schematic of Consolidation Cell for Measurement of Effective Stress $\sigma=\mathrm{P}-\mathrm{p} \ldots$ 6-3

6-2. Analytical Consolidation Curve for In Farm 2 Simulant Based on Centrifuge Measurements . . . . . . . . . . . . . . 6-4

6-3. Conversion Curve for Translating Void Ratios into Weight Percent Water Content of In Farm 2 Simulant Sludge . . . . . . . . 6-6

6-4. Consolidation Curve for U Plant 1 Simulant Sludge Based on Tempe Cell Water Retention Measurements . . . . . . . . . . . . 6-6

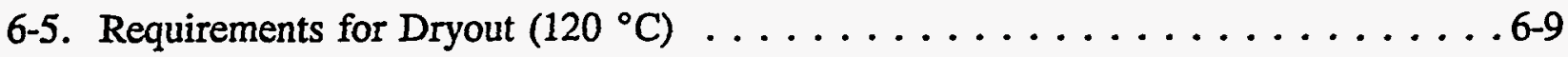

6-6. Sludge Suspension Response to Bubble Growth $\ldots \ldots \ldots \ldots \ldots$. . . . . . . .

6-7. Comparison of Suspension Settling and Liquid Conduction Models for the Drainage from the Small In Farm 2 Sludge Column . . . . . . . . 6-16

6-8. Physical Model of Water Migration to Surface Region Hot Spot . . . . . . . 6-18 


\section{LIST OF TABLES}

2-1. Moisture Content of Simulant Ferrocyanide Sludges . . . . . . . . . . 2-2

2-2. Measured Moisture Content of Tank Samples . . . . . . . . . . . 2-4

2-3. Estimated Free Water in Ferrocyanide Waste Tanks . . . . . . . . . . 2-5

4-1. Comparison of Estimates of Heat Loads $(\mathrm{kW})$ of Ferrocyanide Tanks . . . . . 4-3

4-2. Estimation of Thermal Conductivity in Ferrocyanide Tanks . . . . . . . . . 4-4

4-3. Thermal Characteristics of Ferrocyanide Tanks . . . . . . . . . . . 4-6

4-4. Physical Properties Used in Calculation of Maximum Sludge Temperature . . . . . . . . . . . . . . . . . . 4-9

4-5. Rate of Water Loss from Ferrocyanide Tanks $\ldots \ldots \ldots \ldots$. . . . . . 4-15

5-1. Summary of Important Characteristics of Waste-Sludge-Local Heating Tests Presented in Sections 5.3 and $5.4 \ldots \ldots \ldots \ldots \ldots \ldots$ 5-15

5-2. Sample Results in Water Migration Experiment:

Weight Percent Water . . . . . . . . . . . . . . . 5-38

5-3. Particle Sizes of Tank and Simulant Sludges $\ldots \ldots \ldots \ldots \ldots$ 5-43

5-4. Composition of Liquids in Tank and Simulant Sludges (Normality) . . . . . 5-43

6-1. Comparison of Sludge Height and Interstitial Liquid Level . . . . . . . . . 6-17

6-2. Analyses of $\mathrm{C}-112$ Core Samples, $\mu \mathrm{Ci} / \mathrm{g} \ldots \ldots \ldots \ldots \ldots \ldots \ldots \ldots .6 \ldots$

6-3. Analyses of $\mathrm{C}-109$ Core Samples, $\mu \mathrm{Ci} / \mathrm{g} \ldots \ldots \ldots \ldots \ldots \ldots . \ldots \ldots$ 6 . . . . . . .

6-4. Analyses of T-107 Core Samples, $\mu \mathrm{Ci} / \mathrm{g} \ldots \ldots \ldots \ldots \ldots \ldots \ldots .6 \ldots .26$

6-5. Historic High Temperatures in Hanford Waste Tanks . . . . . . . . 6-27 


\section{LIST OF TERMS}

FAI Fauske and Associates, Inc.

FeCN Ferrocyanide

HEPA High-Efficiency Particulate Air [Filter]

ID Internal Diameter

ILL Interstitial Liquid Level

L/D Length-to-Diameter Ratio

LOW Liquid Observation Well

RH Relative Humidity

RSST Reactive System Screening Tool (Small-Scale Calorimeter at FAI)

TRAC Track Radioactive Components

VSP

Vent Sizing Package (Large-Scale Calorimeter at FAI) 
WHC-EP-0816

This page intentionally left blank. 


\subsection{INTRODUCTION}

A number of Hanford Site waste tanks contain ferrocyanide compound precipitate particles mixed with an aqueous solution containing principally nitrate and nitrite salts. This mixture is often referred to as ferrocyanide sludge. Ferrocyanide compounds in the presence of oxidizing materials, such as nitrates and nitrites, are known to undergo energetic chemical reactions if sufficiently concentrated, dry, and heated to elevated temperatures; thus, the ferrocyanide tanks are regarded as potentially hazardous.

It is important to recognize that, while ferrocyanide and oxidizer salts have been stored together in these tanks since the 1950s, the energetic reaction mentioned above has not materialized. One may ask the question: Why hasn't the reaction occurred? An obvious answer is that it is impossible for the ferrocyanide compound to react with the oxidizer salts as long as the aqueous phase (water) is present; that is, the reaction cannot occur in a wet environment. In a wet environment, the temperature of the sludge remains well below the ignition temperature of about $250{ }^{\circ} \mathrm{C}$ for the reactants of interest.

At present, the ferrocyanide-containing sludges in Hanford Site waste tanks contain ample water to prevent chemical reaction. This water has been in the tanks since the introduction of ferrocyanide in the 1950s. Although the waste sludge is generating heat via radioactive decay of $\mathrm{Cs}$ and $\mathrm{Sr}$ isotopes, significant water loss has not occurred during the last $40+$ years, and unless it occurs in the future, the ferrocyanide sludge will remain dormant. Whether there is some mechanism that can ultimately result in significant water loss," and perhaps self-heating of the stored ferrocyanide sludge to its ignition temperature, is the subject of this report.

The analysis of potential dryout mechanisms is essentially divided into two parts: one part deals with potential global mechanisms of dryout, and the other with hypothetical (postulated) mechanisms of local waste drying. Three potential global processes of waste drying have been identified: 1) bulk heating of the entire sludge inventory to the boiling point of the interstitial aqueous solution; 2) loss of liquid via surface evaporation and vapor transport to the atmospheric air that enters and leaves the free board volume of the tank in response to atmospheric pressure fluctuations or a density difference between the tank gas and the outside air; and 3) drainage of interstitial liquid from a leak in the tank wall.

Mechanism 1 is readily dismissed by demonstrating that passive heat removal processes can keep up with the decay-heat-generation rate within the sludge while the temperature of the sludge remains well below the boiling point of the interstitial liquid. Mechanism 2 is

"Significant water loss results in the sludge becoming uniformly desiccated (unsaturated) and forming a solid-like material. Laboratory observations of simulant sludge drying indicates that this occurs when the water content falls below about 20 wt\% (see Section 5.0). 
eliminated as a potential mode of waste drying by showing that the rate at which the tank exchanges air passively with the outside is much too slow to result in significant water loss from the sludge. For convenience, Mechanism 3 is discussed below under the heading of local dryout mechanisms. It is noteworthy that the long-term safe history of approximately four decades of ferrocyanide waste storage is by itself a significant demonstration of the effective natural heat dissipation and minimal moisture loss from the ferrocyanide tanks. A discussion on global mechanisms of sludge drying appears in Section 4.0 of this report.

Three mechanisms of local dryout of sludge material have been postulated: 1) sludge drying by boiling of interstitial liquid in a "hot spot" region that has attracted a large concentration of heat-generating material; 2) drainage of interstitial liquid from a leak in the tank wall or to pumping, and 3) evaporation of interstitial liquid from a relatively warm segment of surface sludge and concomitant vapor transport to cooler regions. All of these mechanisms have one feature in common in that their credibility depends on the idea that the liquid component of the ferrocyanide sludge can readily separate from the particle component in the presence of imposed heat sources or mechanical forces. That is, the physical picture implicitly conveyed by these postulated local dryout mechanisms is one in which a drying wave (moving liquid-vapor phase front) appears locally beneath or at the surface of the sludge and propagates through a medium of sludge particulate. The moving phase boundary thus leaves behind a voided (dry) and perhaps uncoolable region of solid, heat-generating material. However, recent analytical work and experimental data on the rheological behavior of ferrocyanide simulant sludge presented in this report, together with information available in the literature on aqueous solutions containing very high concentrations of fine particles (clays, soils, etc.), suggests that the liquid and solid components of the sludge are intimately bound to one another by electrostatic (ionic) forces.

Some of the postulated local dryout mechanisms are probably based on observations of local dryout in water-saturated sand or other particle systems with grain sizes above approximately $100 \mu \mathrm{m}$. However, the surface and electrostatic forces acting on the $1-\mu \mathrm{m}$ scale particles in waste tank sludge are much larger than those present in sand and, as shall be seen later in this report, give rise to entirely different behavior (rheology). More to the point, it will be shown by experiment and first-order analysis that the mutual attraction of water and sludge particles is strong and that this mutual attraction neutralizes all the postulated local dryout mechanisms as issues of concern.

bThe draining of interstitial liquid through a break in the tank wall is usually classified as a global dryout mechanism. However, it is convenient to postpone the discussion of liquid draining until after the information on sludge rheology is presented. For this reason, drainage from a tank is placed in both the local and global dryout categories in this report. The safety arguments relative to draining are not affected by this dual classification. 
A large portion of this report (Section 5.0) is devoted to presenting experimental observations of ferrocyanide sludge rheology. The report begins in Section 2.0 with a discussion of tank moisture content; this sets the stage for the sections that follow on sludge rheology and dryout mechanisms. It is also worth noting that even if one insists on postulating the appearance of a dry region, the moisture content in the ferrocyanide tanks exceeds what is required to prevent a chemical reaction from propagating beyond the boundary of the hypothetical dry region. A summary of existing data on the combustion of ferrocyanide in the presence of water appears in Section 3.0. Section 4.0 deals with global mechanisms of sludge dryout. In Section 6.0, the last "technical" section of the report, the observations of sludge rheology (Section 5.0), together with soil consolidation theory, are used to show that local dryout is not credible.

The scope of this report covers all mechanisms by which all or part of the ferrocyanide sludge in any waste tank might lose sufficient water to render it capable of undergoing a rapid, sustained chemical reaction. It addresses continued long-term storage under a continuation of present tank management strategy. Major engineered changes in tank condition, such as retrieval or forced ventilation, are outside the scope and should be addressed in separate analyses. 
WHC-EP-0816

This page intentionally left blank. 


\subsection{MOISTURE CONTENT}

The presence of water in ferrocyanide sludge is of key importance in assessing the potential for a propagating exothermic reaction. Ferrocyanide sludge, such as that stored in 18 underground tanks at the Hanford Site, is formed by the precipitation of micron-sized particles in aqueous solution. After settling and consolidating into a sludge layer, significant moisture is retained, as illustrated by measured weight losses following drying of both waste simulants and actual retrieved tank samples.

\subsection{MOISTURE CONTENTS OF WASTE SIMULANTS}

Nonradioactive simulants have been prepared based on process flowsheets used at the Hanford Site, including U Plant, T Plant and In Farm flowsheets (Jeppson and Wong 1993). $\mathrm{U}$ Plant and T Plant flowsheets produced precipitates that contained relatively large percentages of inert diluents, and thus produced sludge that contained relatively low concentrations of ferrocyanide. Some $74 \%$ of the ferrocyanide consumed at the Hanford Site was used by these two flowsheets. The In Farm flowsheets contained lower concentrations of inert diluents, and therefore resulted in sludge that contained relatively higher concentrations of ferrocyanide. Roughly $26 \%$ of the total ferrocyanide consumed was used in the In Farm flowsheet.

Preparation of these simulants followed the same procedures used in the original Hanford Site waste treatment. Compaction of the tank sludge by gravity during 30 years was simulated by centrifuging the settled simulant sludge for about 6 days at 1820 gravities in a closed-bottom centrifuge. The sludge reached close to its final volume in less than $10 \%$ of the centrifuge time, indicating that equilibrium was reached at the end of centrifuging. Tests with simulant sludge have shown that the equilibrium water content decreases with increased acceleration in the centrifuge (Meacham et al. 1994). Thus, the centrifuged sludge may have a lower water content than would be present in gravity-compacted material.

The water contents of the simulant sludges were measured by weight loss on vacuum drying at $60^{\circ} \mathrm{C}$ for 24 hours (subsequent work has shown that higher moisture contents are measured by heating at atmospheric pressure at $105^{\circ} \mathrm{C}$; thus, these values are low or conservative). These data are given in Table 2-1. The moisture content varies from $48 \%$ to $69 \%$, with one exception. The bottom $10 \%$ of the $\mathrm{T}$ Plant simulant sludge had a water content of only $35 \%$. Bismuth phosphate, which was not present in the U Plant and In Farm processes, was found to be heavily concentrated in this layer, whereas the concentration of $\mathrm{Na}_{2} \mathrm{NiFe}(\mathrm{CN})_{6}$ was depleted to $1.08 \%$ in this bottom layer, compared to $2.72 \%$ in the top $90 \%$ of the sludge height. 
Table 2-1. Moisture Content of Ferrocyanide Simulant Sludges.

\begin{tabular}{|c|c|c|}
\hline \multirow{2}{*}{ Sludge Type } & \multicolumn{2}{|c|}{ Weight Percent Water } \\
\cline { 2 - 3 } & Top & Bottom \\
\hline U Plant 2 & 67 & 64 \\
\hline In Farm 1 & 51 & 48 \\
\hline In Farm 2 & 52 & 50 \\
\hline T Plant & $69 *$ & $35^{*}$ \\
\hline
\end{tabular}

*Apply to top $90 \%$ and bottom $10 \%$, respectively, of total height of centrifuged $\mathrm{T}$ Plant sludge.

\subsection{MOISTURE CONTENTS OF TANK WASTE SAMPLES}

Measurements of moisture content have been made on several samples removed from five ferrocyanide tanks. Moisture was determined by weight loss on heating at $105^{\circ} \mathrm{C}$ for 18 hours. These data are given in Table 2-2. Tanks C-109 and C-112 contain In Farm sludge; TY-101, TY-103, and TY-104 received T Plant sludge. Tank C-109 shows low moisture (19\% and 20\%) at the top of two cores (Subsegment B). Cladding waste was added on top of the ferrocyanide in this tank, and these low readings may not apply to ferrocyanide sludge.

Samples will be taken from the other ferrocyanide tanks; analyses will include moisture content.

\subsection{MOISTURE INVENTORY OF FERROCYANIDE TANKS}

The moisture content of the waste in each ferrocyanide tank has been estimated using saltcake and sludge volumes and liquid level data from Grigsby et al. (1992). For tanks that have recent core sample results available, the average moisture and density values from the samples were used.

For unsampled tanks, the sludge water content was based on the values given in Table 2-1 for the appropriate waste type in the tank. For the saltcake below the interstitial liquid level (ILL), a conservatively low water content of $280 \mathrm{~kg} / \mathrm{m}^{3}$ was used; for saltcake above the ILL, a conservative free water content of $20 \mathrm{~kg} / \mathrm{m}^{3}$ was used. Both of these water contents were suggested by Grigsby et al. (1992). The free water inventories thus estimated for each tank are summarized in Table 2-3. From Table 2-3, tank BY-112 is estimated to contain the 
least water because of the small amount of sludge and the relatively large fraction of saltcake above the ILL.

\subsection{DEPENDENCE OF VAPOR PRESSURE OF WATER IN SLUDGE ON ITS CONCENTRATION}

As the water content of the ferrocyanide sludge is reduced, its vapor pressure falls off. This dependence has been measured (Armstrong et al. 1993) by exposing samples of In Farm simulant sludge to constant relative humidity at $25^{\circ} \mathrm{C}$ and measuring its water content after equilibrium was reached. The results may be summarized as:

\begin{tabular}{|l|c|c|c|c|}
\hline Relative Humidity, \% & 30 & 50 & 75 & 90 \\
\hline Water Content, wt\% & 4.1 & 10.6 & 31.3 & 65.4 \\
\hline
\end{tabular}


WHC-EP-0816

Table 2-2. Measured Moisture Content of Tank Samples.

\begin{tabular}{|c|c|c|c|c|c|}
\hline Tank & Riser & Core & Subsegment & $\begin{array}{l}\text { Wt\% } \\
\text { Water }\end{array}$ & Reference \\
\hline C-109 & $\begin{array}{l}6 \\
7 \\
2\end{array}$ & $\begin{array}{l}47 \\
48 \\
49\end{array}$ & $\begin{array}{l}\text { B (top) } \\
\text { C } \\
\text { D } \\
\text { C } \\
\text { D } \\
\text { B } \\
\text { C } \\
\text { D }\end{array}$ & $\begin{array}{l}19 \\
28 \\
39 \\
53 \\
52 \\
20 \\
38 \\
40\end{array}$ & $\begin{array}{c}\text { Simpson et al. } \\
1993 \mathrm{~b}\end{array}$ \\
\hline$C-112$ & $\begin{array}{l}2 \\
7 \\
8\end{array}$ & $\begin{array}{l}34 \\
\\
35 \\
36\end{array}$ & $\begin{array}{c}\text { 1D (top) } \\
2 \mathrm{~B} \\
2 \mathrm{C} \\
2 \mathrm{D} \\
\text { Composite } \\
\text { 1C } \\
1 \mathrm{D} \\
2 \mathrm{~A} \\
2 \mathrm{~B} \\
2 \mathrm{C} \\
2 \mathrm{D}\end{array}$ & $\begin{array}{l}45 \\
53 \\
58 \\
52 \\
34 \\
49 \\
58 \\
57 \\
41 \\
64 \\
56\end{array}$ & $\begin{array}{c}\text { Simpson et al. } \\
\text { 1993a }\end{array}$ \\
\hline TY-101 & & & & 44 & Grigsby et al. 1992 \\
\hline TY-103 & & & & 52 & Grigsby et al. 1992 \\
\hline TY-104 & & & & 56 & Grigsby et al. 1992 \\
\hline $\mathrm{T}-107$ & & $\begin{array}{l}50 \\
51 \\
52\end{array}$ & $\begin{array}{c}1 \mathrm{R} \\
2 \\
3 \\
4 \\
2 \\
3 \mathrm{U} \\
3 \mathrm{~L} \\
4 \mathrm{U} \\
4 \mathrm{~L} \\
1 \\
2 \\
3 \mathrm{U} \\
3 \mathrm{~L} \\
4\end{array}$ & $\begin{array}{l}18 \\
42 \\
\text { IS } \\
\text { IS } \\
60 \\
55 \\
53 \\
55 \\
50 \\
17 \\
48 \\
51 \\
54 \\
\text { IS }\end{array}$ & $\begin{array}{c}\text { Sasaki and } \\
\text { Valenzuela } 1994\end{array}$ \\
\hline
\end{tabular}

IS $=$ Insufficient sample for analysis. 
WHC-EP-0816

Table 2-3. Estimated Free Water in Ferrocyanide Waste Tanks.

\begin{tabular}{|c|c|c|c|}
\hline \multirow{2}{*}{ Tank Number } & \multicolumn{3}{|c|}{ Water Content, Mg } \\
\cline { 2 - 4 } & In Saltcake & In Sludge & Total \\
\hline BY-103 & 105 & 740 & 845 \\
\hline BY-104 & 11 & 908 & 919 \\
\hline BY-105 & 350 & 335 & 685 \\
\hline BY-106 & 382 & 796 & 1178 \\
\hline BY-107 & 8 & 552 & 560 \\
\hline BY-108 & 2 & 726 & 728 \\
\hline BY-110 & 13 & 786 & 799 \\
\hline BY-111 & 221 & 49 & 270 \\
\hline BY-112 & 86 & 24 & 110 \\
\hline C-108 & 0 & 178 & 178 \\
\hline C-109 & 0 & 138 & 138 \\
\hline C-111 & 0 & 154 & 154 \\
\hline C-112 & 0 & 236 & 236 \\
\hline T-107 & 0 & 425 & 425 \\
\hline TX-118 & 144 & 15 & 159 \\
\hline TY-101 & 0 & 322 & 322 \\
\hline TY-103 & 0 & 541 & 541 \\
\hline TY-104 & 0 & 154 & 154 \\
\hline
\end{tabular}


WHC-EP-0816

This page intentionally left blank. 


\subsection{MOISTURE CONTENT REQUIRED TO PREVENT PROPAGATING REACTIONS}

As indicated earlier, a number of Hanford Site waste tanks are known to hold sludge-like material containing various quantities of ferrocyanides and nitrates. In order to reduce storage volume, ferrocyanide $\left[\mathrm{Na}_{4} \mathrm{Fe}(\mathrm{CN})_{6}\right]$, along with $\mathrm{NiSO}_{4}$, was added to the liquid waste to precipitate ${ }^{137} \mathrm{Cs}$ out of solution. The forms of insoluble ferrocyanides in the resulting sludge include $\mathrm{Na}_{2} \mathrm{NiFe}(\mathrm{CN})_{6}$ and $\mathrm{NaCsNiFe}(\mathrm{CN})_{6}$. Sodium nitrate is a major waste component as a result of also adding $\mathrm{NaOH}$ to the liquid waste in order to neutralize the nitric acid $\left(\mathrm{HNO}_{3}\right)$. Given the right conditions, an intimate mixture of such chemicals could react, resulting in rapid heat release and gas production. Fortunately, a rather small moisture content well below the moisture retention characteristics of ferrocyanide sludge (as discussed in Section 2.0) will prevent propagating reactions even with the largest anticipated ferrocyanide concentrations; i.e., the In Farm flowsheet simulants.

Two types of experimental procedures have been used to study the propagation characteristics of waste simulants: adiabatic calorimetry and propagation rate tests (Fauske 1992 and Fauske 1993a). Waste simulants used in the propagation tests included U Plant, In Farm and T Plant flowsheet materials.

\subsection{ADIABATIC CALORIMETRY TESTS}

In these tests, sizeable samples (10 and 70 grams) are externally heated under essentially zero heat loss conditions, as provided by the reactive system screening tool (RSST) (Creed and Fauske 1990) and the vent sizing package (VSP) (Fauske and Leung 1985). As the sample is heated to above the reaction onset temperature, the thermal energy produced by the reaction causes the sample to self-heat. Based on these adiabatic calorimetry tests, it was found that: 1) the onset temperature for a propagating reaction is about $250^{\circ} \mathrm{C}$; and 2) propagating reactions were not observed for sodium nickel ferrocyanide concentrations below about $15 \mathrm{wt} \%$ on a zero free water basis (Fauske 1992). This finding is consistent with theoretical interpretations (Epstein et al. 1994) and rules out propagating reactions for all Hanford Site ferrocyanide flowsheet materials with the exception of the In Farm flowsheets, even if all free water is lost.

\subsection{PROPAGATION RATE TESTS}

In these tests, a confined cylinder of simulated waste was ignited at the open upper end, and the rate of propagation (if any) was measured by noting the time when the reaction front passed imbedded thermocouples. Parameter variations included cylinder size, ambient pressure, moisture content, initial temperature, and ferrocyanide concentration. Key results included: 1) confirmation that at least a $15 \mathrm{wt} \% \mathrm{Na}_{2} \mathrm{NiFe}(\mathrm{CN})_{6}$ concentration was required in order to sustain propagation in the complete absence of free water; and 2) propagation 
ceased when the free moisture content was in excess of about $12 \mathrm{wt} \%$ for the highest concentration of ferrocyanide ( $26 \mathrm{wt} \%$ In Farm flowsheet material) (Fauske 1992).

A more conservative requirement of $24 \mathrm{wt} \%$ moisture to prevent a propagating reaction in In Farm sludge was set as the criterion for classifying a tank containing $26 \mathrm{wt} \%$ $\mathrm{Na}_{2} \mathrm{NiFe}(\mathrm{CN})_{6}$ on a dry basis (the highest ferrocyanide concentration added to any tank) as SAFE (Postma et al. 1994). This limit was based on a thermodynamic calculation of the conditions necessary to raise the temperature adiabatically to the threshold temperature of $250^{\circ} \mathrm{C}$. This thermodynamic limit is conservative because kinetic factors are ignored; i.e., the reactions are not instantaneous. This conservatism between a $24 \mathrm{wt} \%$ water-calculated SAFE limit and the $12 \mathrm{wt} \%$ water-measured limit represents a safety factor in classifying tanks as SAFE. 


\subsection{GLOBAL MECHANISMS OF DRYOUT}

This section discusses two global mechanisms of sludge dryout that have been identified: 1) dryout by decay heating; and 2) loss of liquid to the atmosphere by evaporation. Discussion of a third global mechanism, loss of liquid from a combination of draining and tank leakage, is postponed until Section 6.0, because the downflow process of the liquid component of the sludge cannot be divorced from the subject of sludge rheology.

\subsection{TANK HEAT LOADS AND THERMAL CONDUCTIVITY OF SLUDGE}

Some of the mechanisms that might tend to dry out the sludge involve the effects of internally generated heat. Estimation of the heat loads in each of the ferrocyanide tanks has been the subject of several studies, which used different approaches, as described below.

- "Historic" heat loads are the estimates that existed before the start of the present emphasis on ferrocyanide safety in 1990 and were listed in the monthly Tank Farm Surveillance and Waste Status Summary Report prior to 1993. These were rough estimates or upper bounds, calculated from tank temperatures and from the rate of moisture loss from those tanks with active exhausters during the late 1960s to late 1970s. These values are high, in that they resulted in overly conservative assumptions and were not corrected for recent decay or removal of liquid. The values are considered to be less accurate than the recent, more careful estimates.

- Heat loads calculated (Grigsby et al. 1992) from inventories of ${ }^{137} \mathrm{Cs}$ and ${ }^{90} \mathrm{Sr}$, as given by track radioactive component (TRAC) records. After 30 years of storage, heat generation is almost entirely from these two radionuclides. These estimates suffer from the poor accuracy of the TRAC records (Jungfleisch 1984).

- Heat loads calculated (Grigsby et al. 1992) from the inventories of ${ }^{137} \mathrm{Cs}$ and ${ }^{90} \mathrm{Sr}$, as estimated by Borsheim and Simpson (1991) for the ferrocyanide tanks. These estimates were more carefully obtained than the TRAC values, but do not account for nuclides added or removed after 1958.

- Heat loads calculated by thermal analysis based on measured tank temperatures. A heat-transfer model of the tank and the soil above, below, and around it was created. The heat load and the conductivity of the tank solids, and in many cases, the vertical distribution of the heat load, were adjusted to get the best fit to measured tank temperatures. The heat loads calculated in this manner were found to be strongly dependent on the thermal conductivity assumed for the soil surrounding the tanks. Two sets of thermal analyses have been performed. The first were steady-state calculations for selected tanks (McLaren 1991, 1993a). The latter updated thermal analysis (McLaren 1993b, 1994a, 1994b) employed a transient calculation starting at the time of original tank filling. It also used revised values of thermal conductivity of 
the soil based on better, more recent data. The updated analyses are, therefore, considered more accurate than the older ones. The updated analyses also make estimates of upper and lower bounds, based on estimated uncertainties in soil conductivity and tank temperature measurements.

- Crowe et al. (1993) has calculated tank heat loads from the difference between the tank airspace temperature and the ambient atmospheric temperature. Analysis of the amplitude and phase shift of the annual variation of airspace temperature relative to that of the ambient temperature permits calculation of the thermal diffusivity of the soil independent of the heat load and thus reduces errors caused by uncertainties in values for soil conductivity.

These various estimates of tank heat loads are compared in Table 4-1.

The tank heat loads calculated by Crowe are judged to be probably the most accurate available. They are being reported in the present monthly Tank Farm Surveillance and Waste Status Summary Reports. Crowe's estimates are generally conservative (high) compared to others in Table 4-1, if the "historic" and TRAC estimates are discounted as less reliable.

Thermal conductivity of the ferrocyanide sludge is also an important parameter in several calculations relevant to sludge dryout. Three sources of data are available:

1) Measurements of centrifuged In Farm 2 and U Plant 1 simulant sludge give conductivities of 1.8 and $2.0 \mathrm{~W} / \mathrm{m}{ }^{\circ} \mathrm{C}$ at $38^{\circ} \mathrm{C}$ and higher values at higher temperatures (Jeppson and Wong 1993).

2) Bouse (1975) reports measurements of thermal conductivity of samples from several non-ferrocyanide tanks. Three of these samples (from S-110, SX-104, and SX-105) were described as "mud" (as opposed to "crystals" or "lumps") and may thus be comparable to the ferrocyanide sludges. Conductivities of the as-received samples at $24{ }^{\circ} \mathrm{C}$ were $0.8,1.1$, and $1.6 \mathrm{~W} / \mathrm{m}^{\circ} \mathrm{C}$, respectively.

3) McLaren's thermal analysis, discussed above, generated estimates of thermal conductivity as well as heat loads for tanks deep enough to have several thermocouples in the waste. These estimates are shown in Table 4-2. 
Table 4-1. Comparison of Estimates of Heat Loads $(\mathrm{kW})$ of Ferrocyanide Tanks.

\begin{tabular}{|l|c|c|c|c|c|c|}
\hline \multicolumn{1}{|c|}{ Tank } & Historic & TRAC & $\begin{array}{c}\text { Borsheim } \\
\text { and Simpson }\end{array}$ & $\begin{array}{c}\text { McLaren } \\
\text { (old) }\end{array}$ & $\begin{array}{c}\text { McLaren } \\
\text { (new) }\end{array}$ & Crowe \\
\hline BY-103 & 2.5 & 4.7 & 2.3 & & 1.2 & 1.6 \\
\hline BY-104 & 5.0 & 4.1 & 2.9 & 2.3 & 2.3 & 2.6 \\
\hline BY-105 & 11 & 3.8 & 1.3 & 1.2 & 2.2 & 2.6 \\
\hline BY-106 & 3.6 & 4.7 & 3.2 & 1.6 & 2.5 & 3.0 \\
\hline BY-107 & 4.2 & 1.9 & 2.1 & & 1.8 & 2.6 \\
\hline BY-108 & 6.7 & 1.6 & 2.7 & 1.3 & 2.0 & 2.7 \\
\hline BY-110 & 7.4 & 4.7 & 2.9 & 1.2 & 2.1 & 2.0 \\
\hline BY-111 & 10 & 4.7 & 0.2 & 0.7 & 1.3 & 1.6 \\
\hline BY-112 & $<3$ & 0.9 & 0.1 & & 1.5 & 1.8 \\
\hline C-108 & $<3$ & 0.2 & 0.3 & & 1.8 & 1.8 \\
\hline C-109 & $<3$ & 0.02 & 0.6 & 1.0 & 1.9 & 2.1 \\
\hline C-111 & $<3$ & 0.6 & 0.1 & & 1.6 & 1.9 \\
\hline C-112 & $<3$ & 0.3 & 0.6 & & 2.1 & 2.2 \\
\hline T-107 & $<3$ & 0.2 & 0.1 & & 0.7 & 0.9 \\
\hline TX-118 & 1.4 & 11 & - & & 1.3 & 1.3 \\
\hline TY-101 & $<3$ & 0.1 & 0.4 & & 0.7 & 0.9 \\
\hline TY-103 & $<3$ & 1.4 & 0.6 & & 0.5 & 1.2 \\
\hline TY-104 & $<3$ & 0.1 & 0.2 & & 1.0 & 0.9 \\
\hline
\end{tabular}


Table 4-2. Estimation of Thermal Conductivity in Ferrocyanide Tanks.

\begin{tabular}{|c|c|c|c|c|c|c|}
\hline \multirow{2}{*}{ Tank } & \multicolumn{3}{|c|}{ Height $^{a}(m)$} & \multirow[b]{2}{*}{$\begin{array}{l}\text { Region }^{\mathrm{d}} \\
\text { (m) }\end{array}$} & \multicolumn{2}{|c|}{$\begin{array}{c}\text { Thermal Conductivity } \\
\left(\mathrm{W} / \mathrm{m}{ }^{\circ} \mathrm{C}\right)\end{array}$} \\
\hline & $\begin{array}{l}\text { Total } \\
\text { Solids }\end{array}$ & $\begin{array}{l}\text { FeCN } \\
\text { Sludge }\end{array}$ & ILL $^{c}$ & & $\begin{array}{c}\text { In } \\
\text { Region }\end{array}$ & $\begin{array}{c}\text { Sludge } \\
\text { Average }\end{array}$ \\
\hline BY-103 & 3.9 & 2.1 & 3.6 & $\begin{array}{l}y<3.1 \\
y>3.1\end{array}$ & $\begin{array}{l}2.2 \\
0.4\end{array}$ & - \\
\hline BY-104 & 3.9 & 2.6 & 2.1 & $\begin{array}{l}\mathrm{y}<1.22 \\
1.22<\mathrm{y} \\
<2.56 \\
\mathrm{y}>2.56\end{array}$ & $\begin{array}{l}1.2 \\
\\
0.7 \\
0.3 \\
\end{array}$ & 1.0 \\
\hline BY-105 & 4.8 & 1.1 & 4.1 & $\begin{array}{l}\mathrm{y}<3.1 \\
\mathrm{y}>3.1\end{array}$ & $\begin{array}{l}1.1 \\
0.8\end{array}$ & - \\
\hline BY-106 & 6.1 & 2.3 & 5.6 & $\begin{array}{l}y<2.7 \\
y>2.7\end{array}$ & $\begin{array}{l}1.7 \\
0.8\end{array}$ & 1.7 \\
\hline BY-107 & 2.7 & 1.6 & 1.6 & $\begin{array}{l}y<1.5 \\
y>1.5\end{array}$ & $\begin{array}{l}1.0 \\
0.5 \\
\end{array}$ & 1.0 \\
\hline BY-108 & 2.3 & 2.1 & - & $\begin{array}{l}y<0.7 \\
0.7<y \\
<1.38 \\
y>1.38\end{array}$ & $\begin{array}{l}0.8 \\
\\
0.6 \\
0.5\end{array}$ & 0.7 \\
\hline BY-110 & 3.9 & 2.3 & 1.9 & $\begin{array}{l}y<0.7 \\
0.7<y \\
<2.68 \\
y>2.68\end{array}$ & $\begin{array}{l}1.0 \\
0.7 \\
0.4\end{array}$ & 0.8 \\
\hline BY-111 & 4.4 & 0.3 & 2.1 & $\begin{array}{l}y<2.7 \\
y>2.7\end{array}$ & $\begin{array}{l}1.4 \\
0.9\end{array}$ & - \\
\hline
\end{tabular}

- Height from bottom of tank

b $\mathrm{FeCN}$ is an abbreviation for ferrocyanide

c $\mathrm{ILL}=$ Interstitial liquid level

d $y=$ Distance from bottom of tank, $m$

The tanks included in Table 4-2 contain a layer of saltcake on top of the ferrocyanide sludge. Table 4-2 gives the total solids height (Grigsby et al. 1992) and the depth of the ferrocyanide sludge, as estimated by Borsheim and Simpson (1991). McLaren's thermal analysis divided the tank solids arbitrarily into two or three layers, as shown in Table 4-2, and adjusted the conductivity of each to fit the measured temperatures. Because several parameters were adjusted to fit a limited set of temperature measurements, the results may not be a unique set 
of parameters that fits the temperature measurements. The data may be best used to obtain a generic estimate of the conductivity of ferrocyanide sludge, rather than to characterize given regions of specific tanks. The last column of Table 4-2 contains an average for the ferrocyanide sludge region when such a calculation was possible. Conductivities range from 0.7 to $1.7 \mathrm{~W} / \mathrm{m}{ }^{\circ} \mathrm{C}$, with an average of $1.0 \mathrm{~W} / \mathrm{m}{ }^{\circ} \mathrm{C}$.

From the above data, a conductivity of $1.0 \mathrm{~W} / \mathrm{m}{ }^{\circ} \mathrm{C}$ for the ferrocyanide sludge is judged to be reasonable for the heat-transfer calculations in this report, and Crowe's values of tank heat load are the most appropriate.

\subsection{TANK HEAT BALANCE}

This section considers whether global dryout of the ferrocyanide sludge can occur by heating the entire sludge inventory to its boiling point. Because the liquid compound of the ferrocyanide sludge is a concentrated solution of $\mathrm{NaNO}_{3}$, its boiling point may be approximated as the boiling point of a saturated $\mathrm{NaNO}_{3}$ solution, or about $120^{\circ} \mathrm{C}$ at atmospheric pressure. Heating the sludge to such an elevated temperature is shown to be impossible by the following considerations:

1) The peak measured sludge temperatures $\left(54^{\circ} \mathrm{C}\right.$ or less) are all well below the boiling point (see Table 4-3).

2) Historic temperature data show that sludge temperatures are slowly decreasing with time in a manner consistent with the decay of ${ }^{137} \mathrm{Cs}$ and ${ }^{90} \mathrm{Sr}$ with 30 -year half lives (Postma et al. 1994, Appendix D).

3) The tank decay heat loads are low; the maximum is $3.0 \mathrm{~kW}$ in BY-106 (see Table 4-3). These heat loads are distributed over a tank $23 \mathrm{~m}$ in diameter, so the heat fluxes are very low.

4) Heat removal is entirely by the passive mechanisms of conduction through the sludge and soil and natural convection and radiation through the airspace. There is no forced coolant flow or any active cooling mechanism that could fail and thereby give a rise in temperature.

5) Evaporation of water is not required to remove the decay heat, and evaporation plays only a minor role in heat dissipation. Thermal analyses of selected tanks (McLaren 1993a) show good agreement with measured tank temperature profiles using an analytical model which neglected cooling by evaporation and included only conduction, natural convection and radiation. 
Table 4-3. Thermal Characteristics of Ferrocyanide Tanks.

\begin{tabular}{|l|c|c|c|c|}
\hline \multirow{2}{*}{ Tank } & \multirow{2}{*}{$\begin{array}{c}\text { Depth of Solids } \\
(\mathrm{m})\end{array}$} & $\begin{array}{c}\text { Maximum Temperature } \\
\left({ }^{\circ} \mathrm{C}\right)\end{array}$ & \multicolumn{2}{|c|}{ Estimate of Heat Load } \\
\cline { 3 - 5 } & 3.9 & 28 & $\mathrm{~kW}^{\mathrm{c}}$ & $\mathrm{W} / \mathrm{m}^{3}$ \\
\hline BY-103 & 3.9 & 54 & 2.6 & 1.0 \\
\hline BY-104 & 4.8 & 50 & 2.6 & 1.5 \\
\hline BY-105 & 6.1 & 54 & 3.0 & 1.1 \\
\hline BY-106 & 2.7 & 35 & 2.6 & 2.3 \\
\hline BY-107 & 2.3 & 43 & 2.7 & 2.8 \\
\hline BY-108 & 3.9 & 48 & 2.0 & 1.2 \\
\hline BY-110 & 4.4 & 30 & 1.6 & 0.8 \\
\hline BY-111 & 2.9 & 32 & 1.8 & 1.5 \\
\hline BY-112 & 0.8 & 22 & 1.8 & 6.4 \\
\hline C-108 & 0.8 & 26 & 2.1 & 7.9 \\
\hline C-109 & 0.7 & 21 & 1.9 & 7.9 \\
\hline C-111 & 1.2 & 26 & 2.2 & 5.0 \\
\hline C-112 & 1.8 & 18 & 0.9 & 1.2 \\
\hline T-107 & 3.4 & 25 & 1.3 & 0.9 \\
\hline TX-118 & 1.3 & 18 & 0.9 & 1.8 \\
\hline TY-101 & 0.6 & 1.2 & 1.7 \\
\hline TY-103 & & & 4.9 \\
\hline TY-104 & 36 & & \\
\hline
\end{tabular}

'Grigsby et al. 1992, Table 4-34

bHanlon 1993

'Crowe et al. 1993 
Because the ferrocyanide tanks are not actively ventilated, the net evaporation and evaporative cooling are low, as discussed further in Section 4.3. The upper-bound evaporation rate for tank BY-106 of $480 \mathrm{~kg} / \mathrm{yr}$, calculated in Section 4.3 , would absorb 35 watts $(W)$ of heat. This is only $1.2 \%$ of the total heat load.

The maximum sludge temperature that could be reached can be estimated by considering a simple heat-transfer model in which the bottom of the tank is an adiabatic boundary so that all the heat generated in the sludge is conducted upward toward the tank airspace. Because the thicknesses of the sludge layer and the soil layer above the tank are small in comparison with the tank diameter, heat conduction in the horizontal direction can be ignored. Thus, the heat transfer model is concerned with vertical heat flow through four regions in series each with its own characteristic thermal properties. In order of increasing vertical height these regions are the sludge layer, the tank airspace, the soil above the tank, and the atmosphere.

The heat transfer coefficient $h_{\text {tunk }}$ for natural convection within the tank airspace may be determined by representing the space as a layer of gas (air) confined between two horizontal surfaces, namely the surface of the sludge and the tank dome. The correlation recommended by Turner (1973) for highly turbulent natural convection within this geometry yields

$$
h_{\text {tank }}=0.09 \mathrm{k}\left[\frac{\mathrm{g} \beta\left(\Delta \mathrm{T}_{\mathrm{tank}}\right.}{v \alpha}\right]^{1 / 3}
$$

where $\mathrm{k}, \nu, \beta$ are the thermal conductivity, kinematic viscosity, and coefficient of expansion of the airspace gas (air), respectively, $g$ is the gravitational constant, and $(\Delta \mathrm{T})_{\text {tent }}$ is the temperature drop in the vertical direction across the tank airspace.

The heat transfer coefficient $h_{\infty}$ for the heat exchange between the ground and the atmosphere in the absence of wind may be taken from Katsaros et al. (1977) for turbulent natural convection from a horizontal surface; i.e.,

$$
\mathrm{h}_{\infty}=0.15 \mathrm{k}\left[\frac{\mathrm{g} \beta(\Delta \mathrm{T})_{-}}{v \alpha}\right]^{1 / 3} .
$$

The upward heat flux through each region is the product of sludge volumetric decay-heat generation rate $Q$ and the sludge depth $\mathrm{H}_{\mathrm{sl}}$. Thus, from the definition of the heat transfer coefficient and Equation (4-1), the temperature drop across the tank airspace is

$$
\left(\Delta \mathrm{T}_{\mathrm{tank}}=6.1\left(\frac{\mathrm{Q} \mathrm{H}_{\mathrm{s}}}{\mathrm{k}}\right)^{3 / 4}\left(\frac{v \alpha}{\mathrm{g} \beta}\right)^{1 / 4}\right.
$$


Similarly, the temperature difference between the surface of the soil and the atmosphere is, from Equation (4-2),

$$
\left(\Delta \mathrm{T}_{\infty}=4.1\left(\frac{\mathrm{Q} \mathrm{H}_{\mathrm{gl}}}{\mathrm{k}}\right)^{3 / 4}\left(\frac{v \alpha}{\mathrm{g} \beta}\right)^{1 / 4}\right.
$$

where for the sake of simplicity the assumption has been made that the physical properties of the atmosphere are equal to those of the airspace gas. In addition, there are the two statements regarding the temperature decrease through the heat-generating sludge and the soil

$$
\begin{aligned}
& \left(\Delta T_{\mathrm{gl}}=\frac{Q H_{\mathrm{sl}}^{2}}{2 \mathrm{k}_{\mathrm{sl}}}\right. \\
& \left(\Delta \mathrm{T}_{\mathrm{soil}}=\frac{Q \mathrm{H}_{\mathrm{sl}} \mathrm{H}_{\text {soil }}}{\mathrm{k}_{\text {soil }}}\right.
\end{aligned}
$$

where $k_{11}$ and $k_{\text {ooil }}$ are the thermal conductivities of the sludge and soil, respectively, and $\mathrm{H}_{\text {soil }}$ is the effective thickness of the soil layer above the tank. In writing Equation (4-5) the assumption has been made of a uniform distribution of heat sources throughout the tank solids.

Addition of Equations (4-3) to (4-6) gives the following expression for the maximum sludge temperature $\mathrm{T}_{\max }$, which is achieved at the bottom of the tank:

$$
T_{\max }=T_{\infty}+Q H_{s l}\left(\frac{H_{s l}}{2 k_{s l}}+\frac{H_{s o i l}}{k_{\text {soil }}}\right)+10.2\left(\frac{Q H_{s l}}{k}\right)^{3 / 4}\left(\frac{v \alpha}{g \beta}\right)^{1 / 4}
$$

Note that heat transported across the tank airspace by thermal radiation and by evaporated water has been neglected. One-dimensional vapor (latent heat) transport may be visualized as taking place through the airspace gas from the surface of the warm sludge to the cooler underside of the tank dome. However, separate analyses have shown that when the sludge salt $\left(\mathrm{NaNO}_{3}\right)$ concentration (salt mass/water mass) exceeds about 0.3 , the water vapor pressure at the sludge surface falls below the vapor pressure exerted by the condensate film on the underside of the tank dome, thereby precluding the latent heat transport mechanism. 
Calculation of the maximum sludge temperature can be made as soon as the appropriate physical properties are collected. The physical properties used in the calculation are given in Table 4-4.

The thermal conductivity $k_{a 1}$ is taken from the discussion of Section 4.1, while the thermal conductivity of the soil $k_{\text {soil }}$ is derived from annual temperature cycling of the tank airspace (Crowe et al. 1993). The sludge depth and volumetric power level values in Table 4-4 correspond to those of the hottest tank, BY-106. The effective depth of the soil is the value recommended by Crowe et al. (1993). Substituting the values from Table 4-4 into Equation (4-7) yields $T_{\max }=73^{\circ} \mathrm{C}$. It is worth noting that the soil layer above the tank represents the primary resistance to upward heat transport as $52 \%$ of the total temperature drop $\left(T_{\max }-T_{\infty}=61^{\circ} \mathrm{C}\right)$ occurs across this layer.

Table 4-4. Physical Properties Used in Calculation of Maximum Sludge Temperature.

\begin{tabular}{|lll|l|}
\hline $\mathrm{k}$ & $=$ & $0.026 \mathrm{~W} \mathrm{~m}^{-1} \mathrm{~K}^{-1}$ & gas (air) thermal conductivity \\
\hline$\beta$ & $=$ & $3.3 \times 10^{-3} \mathrm{~K}^{-1}$ & gas coefficient of expansion \\
\hline$\nu$ & $=$ & $1.6 \times 10^{-5} \mathrm{~m}^{2} \mathrm{~s}^{-1}$ & gas kinematic viscosity \\
\hline$\alpha$ & $=$ & $2.2 \times 10^{-5} \mathrm{~m}^{2} \mathrm{~s}^{-1}$ & gas thermal diffusivity \\
\hline $\mathrm{k}_{\mathrm{sl}}=1.0 \mathrm{~W} \mathrm{~m}^{-1} \mathrm{~K}^{-1}$ & sludge thermal conductivity \\
\hline $\mathrm{k}_{\mathrm{soil}}=$ & $0.93 \mathrm{~W} \mathrm{~m}^{-1} \mathrm{~K}^{-1}$ & soil thermal conductivity \\
$\mathrm{H}_{\mathrm{sl}}=$ & $6.1 \mathrm{~m}$ & sludge depth \\
\hline $\mathrm{H}_{\mathrm{soil}}=$ & $4.0 \mathrm{~m}$ & soil depth \\
$\mathrm{Q}$ & $=1.2 \mathrm{~W} \mathrm{~m}$ & sludge decay heat generation rate \\
\hline $\mathrm{T}_{\infty}=12{ }^{\circ} \mathrm{C}$ & average temperature of Hanford atmosphere \\
\hline
\end{tabular}

This conservatively calculated peak sludge temperature is higher than the measured peak of $54{ }^{\circ} \mathrm{C}$. This calculation confirms that the passive process of conduction is capable of removing the decay heat while keeping all sludge temperatures well below the boiling point of the sludge liquid. 


\subsection{AIR-EXCHANGE-CONTROLLED SLUDGE EVAPORATION RATE}

The net rate of evaporation of water from the waste surface will be limited by the rate at which flow of saturated air out of the tank can remove moisture.

Each ferrocyanide tank is vented to the atmosphere through a high-efficiency particulate air (HEPA) filter to accommodate changing atmospheric pressure. The measured pressure-drop through these filters is $1.0 \mathrm{in}$. of water $(249 \mathrm{~Pa})$ at a nominal flow rate of $225 \mathrm{cfm}$ $\left(0.106 \mathrm{~m}^{3} / \mathrm{s}\right)$. They open $0.6 \mathrm{~m}$ above grade and typically are connected to a 4-in. $(10.2-\mathrm{cm}$ internal diameter [ID]) riser pipe $5.5 \mathrm{~m}$ long, although the length depends somewhat on the riser location. The waste level in some of the tanks is measured with level gauges that have an air purge to reduce water vapor condensation within the instrument.

Inter-tank cascade connections are above the liquid levels of the stored ferrocyanide waste and provide a between-tank air circulation path. These are 3-in. Schedule 80 pipes, 7.4-cm $\mathrm{ID}$ and $7.6-\mathrm{m}$ long. These pipes have a $4 \%$ slope down to the receiver tank. The ferrocyanide tanks are isolated to prevent intrusion and liquid entry. Review of typical isolation prints shows a careful effort to plug and seal unused tank connections. A possible exception is the 2-in.-diameter floor drain in the access pit, which is intentionally left open. The pits, however, are closed at the top with steel covers with polyurethane weather seal over the concrete shield blocks.

While a detailed tank-by-tank examination has not been made, the breather filters, cascade connections, and the purge air flow are the only defined tank air connections. If leaks are detected, they can be located and repaired.

While the ferrocyanide tanks are not actively ventilated, they can exchange air with the outside through the riser pipes by means of atmospheric pressure fluctuations and/or by natural convection. The latter mechanism of air exchange occurs even when the pressure within the tank is equal to that of the atmosphere. The air in the tank has a temperature and water vapor composition different from that of the air outside, and as a result, the density of the tank atmosphere is less than that of the air outside. Thus, buoyancy forces may cause a flow of air out of the tank and a corresponding flow of air into the tank. The rate of tank moisture loss from barometric pressure variations (tank breathing) is estimated first.

\subsubsection{Tank Breathing}

An analysis by Crippen (1993) of hourly barometric pressure measurements recorded at the Hanford Site weather station over a period of four years showed the sum of all hourly pressure increases (and also of all decreases) to be $1.7 \mathrm{~atm} / \mathrm{yr}$. The tanks' 10-cm (4-in.) vent pipes are large enough to maintain the tanks at the same pressure as the atmosphere during these rather slow changes in atmospheric pressure. Thus, the tank breathing rate $P_{b r}$ is also $1.7 \mathrm{~atm} / \mathrm{yr}$. From the ideal gas law, $\mathrm{P}_{\mathrm{br}}$ can be related to the volumetric exchange rate $\mathrm{Q}\left(\right.$ in $\left.\mathrm{m}^{3} \mathrm{~s}^{-1}\right)$ 


$$
Q=\frac{P_{b_{r}} V}{P_{\infty}}
$$

where $\mathrm{V}$ is the volume of the tank airspace and $\mathrm{P}_{\infty}$ is the ambient pressure. For $\mathrm{V}=$ $1.46 \times 10^{3} \mathrm{~m}^{3}(\operatorname{tank} \mathrm{BY}-106)$ and $\mathrm{P}_{\infty}=1.0 \mathrm{~atm}$, an estimate is made that $\mathrm{Q}=$ $2.5 \times 10^{3} \mathrm{~m}^{3} \mathrm{yr}^{-1}$. The temperature of the airspace gas in tank BY-106 is $27.0^{\circ} \mathrm{C}$ (Crowe et al. 1993), giving a saturated in-tank water-vapor density $\rho_{\mathrm{v}}=0.0261 \mathrm{~kg} \mathrm{~m}^{-3}$. However, the top of this tank contains a layer of saltcake, which is primarily sodium nitrate. Therefore, the relative humidity of the air will be that in equilibrium with solid $\mathrm{NaNO}_{3}$ or its saturated solution, which is $74 \%$. The water vapor density in the tank air space will thus be $.0261 \times 0.74$, or $\rho_{\mathrm{v}}=0.0193 \mathrm{~kg} \mathrm{~m}^{-3}$. The average dry bulb temperature and humidity of the air at the Hanford Site are $12{ }^{\circ} \mathrm{C}$ and $54 \%$, respectively. The corresponding water vapor density in the Hanford Site atmosphere is $\rho_{\mathrm{v}, \infty}=5.6 \times 10^{-3} \mathrm{~kg} \mathrm{~m}^{-3}$. Therefore, the net rate of moisture loss from the tank is

$$
\dot{\mathrm{m}}=\mathrm{Q}\left(\rho_{\mathrm{v}}-\rho_{\mathrm{v}, \mathrm{e}}\right)=34 \mathrm{~kg} \mathrm{yr}^{-1} \text {. }
$$

This evaporation rate from tank breathing is of the order of $0.005 \%$ of the sludge water content per year.

\subsubsection{Natural Convection Exchange Flow Through a Single Riser}

As mentioned previously, the airspace of each tank communicates directly with the atmosphere through a vertical riser pipe. A plenum region is attached to the top of the riser. A HEPA filter occupies the $0.305-\mathrm{m} \times 0.305-\mathrm{m}$ cross-sectional area of the plenum. In the absence of any additional passages between the airspace and the atmosphere, the density difference between the tank airspace and the outside may induce a buoyancy-driven countercurrent downflow of the heavier atmospheric air and an upflow of the lighter tank air through the riser. Epstein (1988) has provided an empirical correlation for such a buoyancy-driven countercurrent exchange flow. The result for the exchange flow rate $Q$ versus the length-to-diameter ratio $(\mathrm{L} / \mathrm{D})$ of the vertical riser is

$$
Q=0.32\left(\frac{D^{5} g \Delta \rho}{\rho_{\infty}}\right)^{1 / 2}\left(\frac{L}{D}\right)^{-3 / 2}
$$

where $\Delta \rho$ is the density difference between the atmosphere and the gas within the tank, $g$ is the gravitational constant, and $\rho_{\infty}$ is the density of the atmosphere.

There are two difficulties connected with the application of Equation (4-10) to the tank riser. First, the correlation is based on data with L/D's in the range 3-20. The riser L/D is about 
50, so the present application requires extrapolation. Secondly, it is not clear how the resistance of the HEPA filter to countercurrent flow should be incorporated. It is probably best to ignore the filter and assume that there are no "obstacles" to flow within the riser.

Based on the average dry bulb temperature and the humidity of air at the Hanford Site, average outside air density is estimated to be $\rho_{\infty}=1.225 \mathrm{~kg} \mathrm{~m}^{-3}$. The density of water saturated air (74\% relative humidity $[\mathrm{RH}]$ ) in tank BY-106 at an average temperature of $27.0^{\circ} \mathrm{C}$ is $\rho=1.162 \mathrm{~kg} \mathrm{~m}^{-3}$. Thus

$$
\Delta \rho=\rho_{\infty}-\rho=0.063 \mathrm{~kg} \mathrm{~m}^{-3}
$$

The remaining parameters required for the problem at hand are: $\mathrm{L}=5.5 \mathrm{~m}, \mathrm{D}=0.102 \mathrm{~m}$. Then, according to Equation (4-10), $Q=60.1 \mathrm{~m}^{3} \mathrm{yr}^{-1}$, which is considerably less than the tank breathing rate of $2.5 \times 10^{3} \mathrm{~m}^{3} \mathrm{yr}^{-1}$ (see previous subsection). Clearly, tank moisture loss from natural convection exchange flow within a single riser is negligible.

\subsubsection{Natural Convection Exchange Flow Through Multiple Risers}

The tank airspaces are generally connected in groups of three by near-horizontal pipes, as shown schematically in Figure 4-1. This situation may give rise to a number of different natural-convection flow patterns, as either upward or downward flow may exist in any one of the risers. Of course, continuity demands that the downward flow in one of the risers plus the total purge flow must be equal in magnitude but opposite in direction to the upward flows in the other two risers. It is relevant to note that, while all the possible flow patterns result in essentially numerically similar air exchange rates, the flow pattern illustrated in Figure 4-1 can be shown to result in the largest inflow of fresh air to a single tank, and hence the greatest water removal from a tank. This is the pattern that will be examined here. The quantity $Q_{p}$ in Figure 4-1 is the known volumetric instrument purge flow of air ( $2 \times 10^{-4} \mathrm{~m}^{3} \mathrm{~s}^{-1}$ for tank BY-106) while $\mathrm{Q}$ is the to-be-determined volumetric inlet flow.

For purposes of developing a simple expression for the air exchange rate between the tank cluster and the atmosphere, the following justifiable assumptions are introduced:

1) The major frictional resistance to flow through the tank array is exerted by the HEPA filters, and the pressure drop $\Delta \mathrm{P}_{\mathrm{f}}$ versus volumetric flow through each filter is well represented by a laminar law. For example, for the middle riser in Figure 4-1,

$$
\Delta P_{f}=R Q
$$


where $R$ is an empirical (filter resistance) coefficient equal to $2.34 \times 10^{3} \mathrm{~Pa} \mathrm{~s} \mathrm{~m}^{-3}$. The small pressure drop through the piping is neglected, which is conservative.

2) The density difference between any two tank airspace atmospheres is small compared with the density difference between the tank atmospheres and the outside air. In other words, the gas density in one tank is assumed to be equal to the gas density in an adjacent tank. The natural convection flow pattern is present in the system shown in Figure 4-1 owing to the difference in density between the light tank gas that enters the peripheral risers and the heavier atmospheric air that enters the central riser.

The steady-state momentum equation is "integrated" around one of the flow loops illustrated in Figure 4-1 to eliminate the pressure term:

$$
R \frac{Q}{2}+R Q+\frac{3}{2} R Q_{p}=\rho_{\infty} g L-\rho g L
$$

Thus, the inlet volumetric air flow rate is

$$
Q=\frac{2 \Delta \rho g L}{3 R}-Q_{p}
$$

where, again, $\Delta \rho=\rho_{\infty}-\rho$. Inserting the appropriate parameter values $\mathrm{R}=$ $2.34 \times 10^{3} \mathrm{~Pa} \mathrm{~s} \mathrm{~m}{ }^{-3}, \Delta \rho=0.063 \mathrm{~kg} \mathrm{~m}^{-3}$ (see Equation 4-11), $\mathrm{L}=5.5 \mathrm{~m}$, and $\mathrm{Q}_{\mathrm{p}}=$ $2 \times 10^{-4} \mathrm{~m}^{3} \mathrm{~s}^{-1}$ into Equation (4-14) gives $\mathrm{Q}=7.67 \times 10^{-4} \mathrm{~m}^{3} \mathrm{~s}^{-1}$. The corresponding net rate of moisture loss from tank BY-106 is

$$
\dot{\mathrm{m}}=\left(Q+Q_{\mathrm{p}}\right) \rho_{\mathrm{v}}-Q \rho_{\mathrm{v}, \infty}=450 \mathrm{~kg} \mathrm{yr}^{-1}
$$

since $\rho_{\mathrm{v}}=0.0193 \mathrm{~kg} \mathrm{~m}^{-3}$ and $\rho_{\mathrm{v}, \infty}=0.0056 \mathrm{~kg} \mathrm{~m}^{-3}$. Note that the purge flow is dry instrument air. This upper bound evaporation rate from natural convection flow through multiple risers is only $0.041 \%$ of the sludge water content per year of tank BY-106.

Calculations of the rate of water loss by breathing and natural convection were made for each of the ferrocyanide tanks, similar to those described in the foregoing. The results are tabulated in Table 4-5. The purge flow rate is $0.0002 \mathrm{~m}^{3} \mathrm{~s}^{-1}\left(25 \mathrm{ft}^{3} \mathrm{hr}^{-1}\right)$ in the BX, BY, and $\mathrm{C}$ tanks and $0.0004 \mathrm{~m}^{3} \mathrm{~s}^{-1}\left(51 \mathrm{ft}^{3} \mathrm{hr}^{-1}\right)$ in the $\mathrm{T}, \mathrm{TX}$, and TY tanks. The gas temperature and gas volume of each tank is shown in Table 4-4. The relative humidity of the airspace was taken as $74 \%$ for the BY and TX tanks, which are listed (Hanlon 1993) as having saltcake present. For the other tanks it was taken as $88 \%$, which is that measured for air in equilibrium with In Farm simulant sludge (Armstrong et al. 1993). The evaporation rates 
range from 160 to $500 \mathrm{~kg}$ of water per year, or 0.4 to $1.2 \mathrm{~kg} \mathrm{~m}^{-2} \mathrm{yr}^{-1}$. The highest rates are in tanks BY-108, C-112, BY-106, and BY-107. The fraction of the total water present that is evaporated per year ranges from 0.0003 to 0.0033 , with the highest rate in $\mathrm{C}-109$. These rates of water loss are much lower than the rate of decay of the tank heat generation, which is 0.023 per year for ${ }^{137} \mathrm{Cs}$ and ${ }^{90} \mathrm{Sr}$. Thus the tanks are losing their heat source much faster than they are losing water by evaporation.

It is to be noted that higher air exchange by natural convection $\left(9.9 \times 10^{-3} \mathrm{~m}^{3} \mathrm{~s}^{-1}\right)$ has been predicted previously (McLaren 1991, repeated in Grigsby et al. 1992), as part of a thermal analysis of BY-104. A 1/32-in. gap between the top of the risers and the isolation flange was assumed in a calculation to provide an upper bound on heat loss from a tank by convective air flow. A recent, more detailed, investigation (undocumented) of tank isolation records by J. D. McCormack indicates that such gaps do not exist. Therefore, the earlier estimate has been discounted.

\subsubsection{Wind-Induced Exchange Flow Through Multiple Risers}

Another mechanism for vapor removal is air-flow-induced pressure differences caused by winds. The atmospheric pressure at the entrance of one riser may be slightly different from that of a nearby riser from velocity fluctuations in the atmospheric boundary layer. The magnitude of the velocity fluctuations are of the order of the so-called frictional velocity $u_{\text {. }}$. The velocity profile in a turbulent boundary layer is well represented by the logarithmic law

$$
\frac{u}{u_{*}}=\frac{1}{k} \ln \frac{z}{z_{o}}
$$

where $\mathrm{u}$ is the velocity of the air at a distance $\mathrm{z}$ above the surface covered by the boundary layer. This law seems to have found wide acceptance in meteorological work (e.g., Seinfeld 1986). In this application $z_{\mathrm{o}}$ is an empirical ground roughness length and $\kappa$ is an empirical constant equal to 0.4 . The wind speed $u$ is usually evaluated at the height $z=10 \mathrm{~m}$ above the ground. Roughness lengths for various surfaces can be found in Seinfeld (1986). For a level desert, $z_{o}=10^{-3} \mathrm{~m}$, whereas for a tree-covered region, $z_{o}=1.0 \mathrm{~m}$. The average value of the wind velocity at the Hanford Site is $u=3.6 \mathrm{~m} \mathrm{~s}^{-1}(8 \mathrm{mph}$, see McLaren 1993b). Substituting these estimates into Equation (4-16) and solving the result for $u_{*}$ gives a velocity fluctuation of $\mathrm{u}_{*}=0.16 \mathrm{~m} \mathrm{~s}^{-1}$ for a level desert and $\mathrm{u}_{*}=0.65 \mathrm{~m} \mathrm{~s}^{-1}$ for a tree-covered region. 
Table 4-5. Rate of Water Loss from Ferrocyanide Tanks.

\begin{tabular}{|c|c|c|c|c|c|}
\hline \multirow[b]{2}{*}{ Tank } & \multirow{2}{*}{$\begin{array}{c}\text { Gas } \\
{ }^{\circ} \mathrm{C}\end{array}$} & \multirow{2}{*}{$\begin{array}{c}\text { Gas Volume } \\
\mathrm{m}^{\mathrm{b}}\end{array}$} & \multicolumn{3}{|c|}{ Rate of Water Loss } \\
\hline & & & $\mathrm{kg} / \mathrm{yr}$ & $\mathrm{kg} / \mathrm{m}^{2} / \mathrm{yr}$ & $\begin{array}{l}\text { Fraction/yr } \\
\left(\times 10^{-4}\right)\end{array}$ \\
\hline BY-103 & 21 & 2420 & 223 & .55 & 2.6 \\
\hline BY-104 & 26 & 2640 & 429 & 1.05 & 4.7 \\
\hline BY-105 & 26 & 2110 & 403 & .98 & 5.9 \\
\hline BY-106 & 27 & 1460 & 483 & 1.18 & 4.1 \\
\hline BY-107 & 26 & 2920 & 460 & 1.12 & 8.2 \\
\hline BY-108 & 27 & 3080 & 496 & 1.21 & 6.8 \\
\hline BY-110 & 23 & 2870 & 305 & .74 & 3.8 \\
\hline BY-111 & 21 & 2290 & 216 & .53 & 8.0 \\
\hline BY -112 & 22 & 2810 & 264 & .64 & 24.0 \\
\hline C-108 & 23 & 3050 & 361 & .88 & 20.3 \\
\hline C-109 & 24 & 3060 & 453 & 1.10 & 32.8 \\
\hline C-111 & 23 & 3080 & 396 & .97 & 25.7 \\
\hline C-112 & 25 & 2910 & 490 & 1.19 & 20.8 \\
\hline $\mathrm{T}-107$ & 18 & 2610 & 203 & .50 & 4.8 \\
\hline $\mathrm{TX}-118$ & 20 & 2830 & 223 & .54 & 14.0 \\
\hline TY-101 & 18 & 3480 & 218 & .53 & 6.8 \\
\hline TY-103 & 19 & 3320 & 258 & .63 & 4.8 \\
\hline TY-104 & 18 & 3530 & 216 & .53 & 14.0 \\
\hline
\end{tabular}

'Crowe 1993

bKlem 1991 
Consider the three risers shown in Figure 4-1. Assume the pressure above one of the risers from local wind velocity fluctuations is, on average, $P_{1}$, while the average atmospheric pressure above the other two risers is $P_{2}$, and $P_{2}>P_{1}$. The pressure difference is, approximately,

$$
P_{2}-P_{1} \propto \frac{1}{2} \rho_{\infty} u_{*}^{2} .
$$

This pressure difference will drive a volumetric flow $\mathrm{Q}$ through the clustered tanks in accord with the following momentum equation (Equation 4-13 with $Q_{p}=0$ and the hydrostatic driving pressure replaced by $\left.P_{2}-P_{1}\right)$ :

$$
P_{2}-P_{1}=\frac{3}{2} Q R .
$$

Figure 4-1. Illustration of Flow Configuration Through Clustered Tanks.

$\left(Q_{p}\right.$ is dry instrument air purge flow)

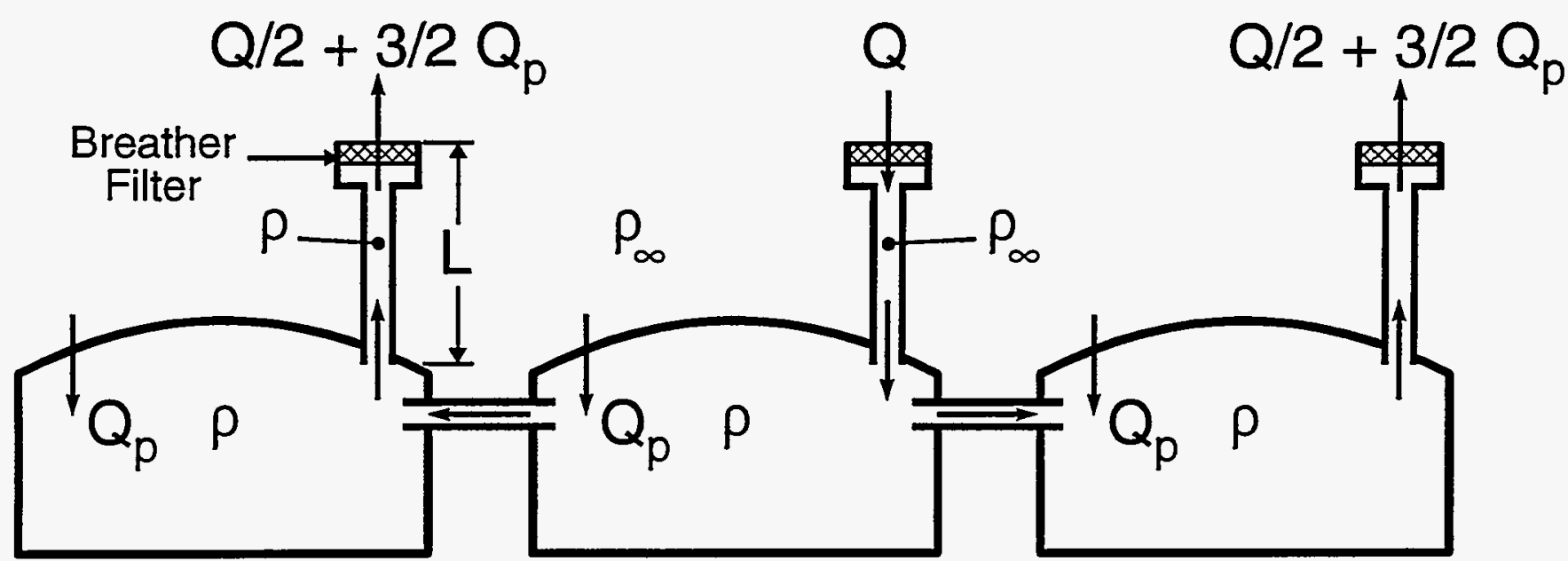


From Equations (4-17) and (4-18),

$$
Q=\frac{\rho_{n} u_{*}^{2}}{3 R}
$$

If the tank farm is identified with a tree-covered region in terms of ground roughness, an estimate is made that $\mathrm{Q}=2.2 \times 10^{3} \mathrm{~m}^{3} \mathrm{yr}^{-1}$, which is almost equal to the tank breathing rate of $2.5 \times 10^{3} \mathrm{~m}^{3} \mathrm{yr}^{-1}$. A more realistic rate of exchange is $5.0 \%$ of the tank breathing rate $\left(\mathrm{Q}=1.33 \times 10^{2} \mathrm{~m}^{3} \mathrm{yr}^{-1}\right)$, corresponding to wind over a level desert. Thus, tank moisture loss from wind-induced exchange flow is negligible.

The rates of water loss are low in all tanks, and continuation of such evaporation rates over many years would not significantly reduce the water content of the ferrocyanide sludge. Therefore, global evaporation of water will not dry out the ferrocyanide sludge and render it chemically reactive. As will be shown in Section 5.0, this water loss would generally be distributed throughout the sludge rather than locally at the surface. 
This page intentionally left blank. 


\subsection{RHEOLOGY OF WATER-SATURATED FERROCYANIDE SLUDGE}

The purpose of this section is to provide convincing evidence that the liquid-holding capacity of sludge is large and quite different from that of a rigid porous medium like packed sand, from which water can readily drain or be driven out by exposure to heat. There is, in fact, a continuum of behavior where water can be expelled from coarse sand with relative ease to the enormous forces that must be applied to expel even small quantities of liquid from the matrix of micron-size sludge particles.

The difference between sand and sludge behavior is mainly the result of the fact that the diameters of the sand particles are two orders of magnitude larger than the diameters of sludge particles, and different microscopic forces are operative. Sludge is a material similar to silty soil, mud, clay, or even toothpaste. These materials are probably best classified as concentrated suspensions of fine particles (or colloids). It is now well known that in such suspensions enormous physical-electrochemical forces act between fluid and particles to hold these materials together. Verway and Overbeek (1948) published the pioneering work on the nature of the electrostatic forces between particles and liquids within concentrated suspensions. Unfortunately, the theory is not predictive in terms of modeling the macroscopic behavior of such suspensions. Accordingly, researchers in the field, particularly those concerned with the settling behavior of moist soils, have introduced into the hydrodynamic equations empirical stress-strain type relationships that presumably represent the effects of the "microscopic forces" that are present within the particle-liquid matrix (e.g., Taylor 1948 and Yong 1992). These stress-strain relationships (or "consolidation curves") must be obtained by detailed laboratory rheological studies of the particular material of interest. Such relationships for ferrocyanide-type sludges have been derived from experimental data and are discussed in some detail in Section 6.0.

This section reviews the available experimental evidence that illustrates the rheology of ferrocyanide sludge, not from the point of view of obtaining a stress-strain relationship, but to show fairly conclusively that the particles are so intimately tied to the liquid in sludge that local dryout is a highly unlikely event. Three different types of experiments are described: drainage of interstitial liquid in a gravity field, flow of sludge from gas or vapor bubble growth, and sludge behavior in the vicinity of a hot surface. The absence of dryout in the vicinity of a heat source is clearly demonstrated in both small- and large-scale experiments. All of the experimental observations are understandable in terms of the rheology of concentrated suspensions.

\subsection{LIQUID DRAINAGE EXPERIMENT AND INTERPRETATION}

Data on the cumulative drainage of interstitial liquid (water and dissolved salts) from a small column of In Farm 2 sludge are being obtained by Crane (1992). The experiment is described in Meacham et al. (1994). In this experiment the sludge column rests on a substrate filter paper that retains the solids and allows the liquid component to flow from the 
bottom of the sludge. The experiment has been conducted for over 600 days and the results obtained so far are shown in Figure 5-1. An interpretation of this curve on the basis of the theory of sludge "consolidation" is presented in Section 6.0. Section 5.0 is limited to a qualitative discussion of sludge consolidation and concomitant sludge drainage.

C. S. Simmons first suggested the possibility that the displaced liquid may be the result of siudge consolidation caused by the settling of the particles in the sludge (Meacham et al. 1994). Indeed, it is now known from recent observations of the column that the loss of interstitial liquid is equal to the reduction in column volume and that the column remains liquid saturated (void free) as it shrinks. Consolidation is the shrinking of the sludge by particle sedimentation or by compression with the application of an external force, and is the result of liquid expulsion from sediments (Michaels and Bolger 1962, Glasrud et al. 1993). This behavior is in contrast to an essentially rigid porous medium, like packed sand, that does not show an appreciable reduction in bulk volume when interstitial water is removed.

The settling behavior of particles in suspension is rather complex, especially when the volume fraction of the particles is high, and the observed settling rate is much less than the Stokes' settling rate for a single particle. In such suspensions the solid particulate phase appears to "condense" slowly to a smaller volume fraction and to expel interstitial liquid while the consolidation process proceeds.

A number of forces cause the suspension to ultimately approach a steady state in which no further settling under gravity occurs. An increase in the concentration of the solid phase in a suspension brings about an increase in the effective viscosity of the whole dispersed system. Attractive as well as repulsive forces that operate between dispersed particles (Ottewill 1977, Overbeek 1977) are responsible for this effective viscosity. These forces are: the short-range Born repulsion force, the long-range van der Waal attractive force, and the long-range electrostatic repulsive force. The first two are of electromagnetic origin and the last one is a result of the interaction of the electrical double layer surrounding charged particles in an electrolytic (aqueous) solution (i.e., an electrostatic force). In aqueous solutions the combination of these forces results in the "flocculation" of the particles into clusters of particles (or "flocs"). The flocs are able to resist breakup under the mild forces experienced in gravitational settling. The diameter of the flocs formed in a suspension of 1.0- $\mu \mathrm{m}$ particles usually exceeds $100 \mu \mathrm{m}$ (Tadros 1980). If the size of the flocs in the In Farm 2 drainage column (Crane 1992) exceed the mesh size of the filter paper, this would explain why only liquid passes through the bottom of the column. The final stabilized particle volume fraction will depend on the relative magnitudes of the interaction forces and, therefore, the floc sizes; it is not a quantity that can be predicted from first principles.

The experimental drainage data obtained by Crane (1992) and presented in Figure 5-1 can be converted to a liquid-mass-fraction-versus-time history. The data indicate that the ferrocyanide sludge settling process starts with $53 \mathrm{wt} \%$ water, slows and approaches a final (asymptotic) water mass fraction of $49 \mathrm{wt} \%$. Thus drainage is now approaching completion and only a small quantity of water was lost from the column. This experiment serves as an 
Figure 5-1. Drainage Weight of Interstitial Liquid versus Time from a 0.2-m Column of In Farm 2 Sludge.

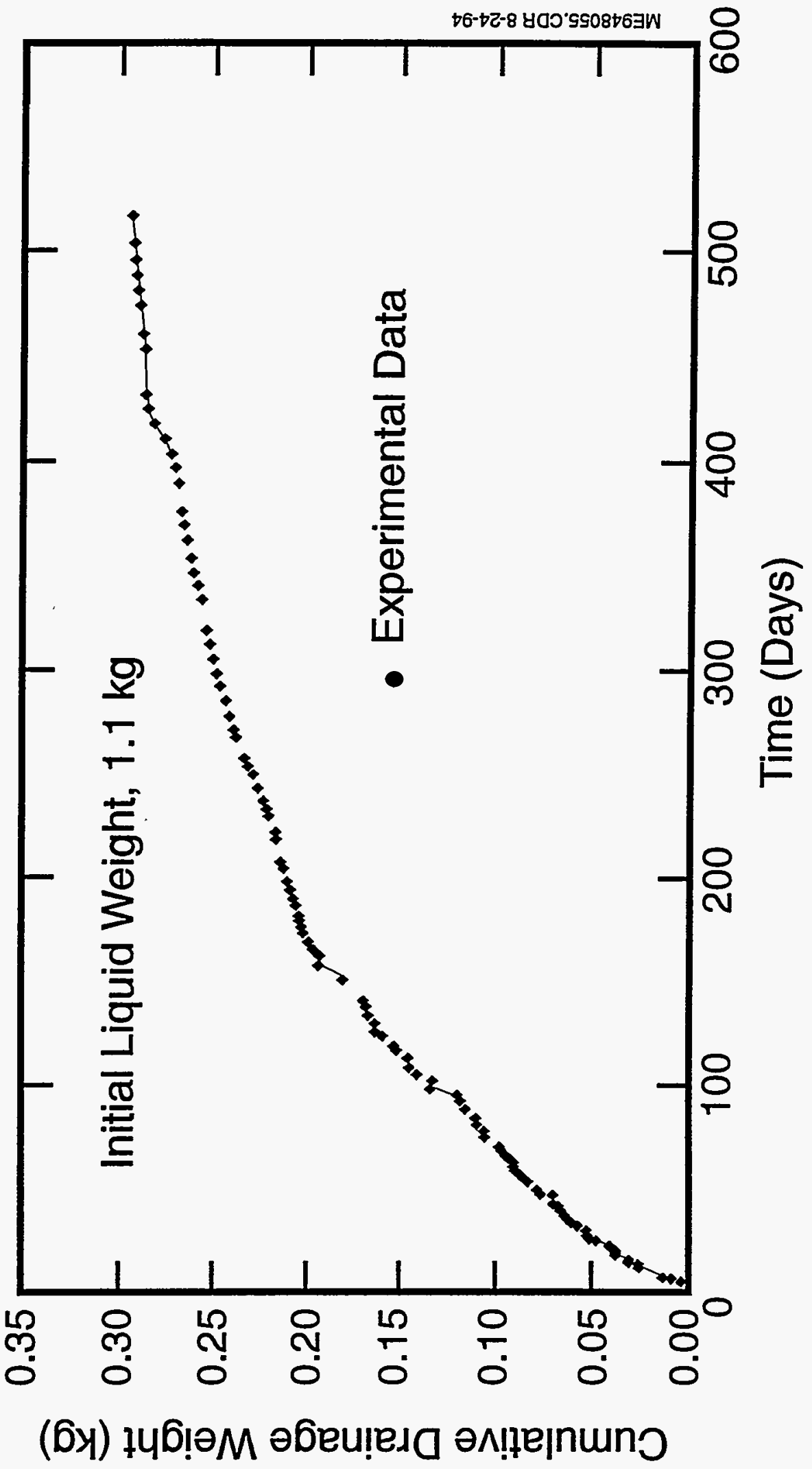


important example of how strongly water is held by the sludge particles. More experimental evidence for the strong attractive forces that hold liquid and particles together within sludge is presented in the subsections that follow.

\subsection{EXPERIMENTS ON SIMULANT WASTE TANK SLUDGE RESPONSE TO VOID GROWTH}

As mentioned previously, and as will be discussed in more detail later on, a major safety issue associated with the ferrocyanide tanks is the possibility of the sludge drying out locally from boiling of the interstitial liquid. It is important to note that the boiling-driven dryout mechanism is only viable if the waste sludge behaves as a porous medium of stationary solid material (such as coarse, saturated sand) and bubble growth results in the expulsion of liquid from the solid phase. The experimental work reviewed in this subsection clearly shows that this is not the case. Instead, the sludge behaves as a concentrated suspension (or colloid); that is, as the bubble grows it displaces both liquid and solid material in the form of a homogeneous particle/liquid flow.

The material presented in this section first appeared in WHC-EP-0713 (Epstein et al. 1993). Because of the importance of this material in terms of understanding waste sludge rheology, it is presented below in essentially unabridged form. This will relieve the reader of having to refer back to the original report for additional information regarding the sludge rheology experiments.

Two different types of experiments were performed at Fauske and Associates, Inc. (FAI) to simulate bubble growth within waste sludge. First, observations were made of the growth of nitrogen-gas-slug bubbles at an orifice submerged in simulant sludge. Second, a combined heating and depressurization technique was used to generate voids within simulant sludge via evaporation of the interstitial liquid. Two types of sludge simulant were used. The In Farm 1 flowsheet simulant sludge, as described in Section 2.1, was used to the extent possible. However, since supplies of this simulant sludge are limited by a lengthy preparation process, a 50/50 wt\% mixture of kaolin and water was also used. ${ }^{\circ}$ From a fluid flow point of view, kaolin is found to represent well the behavior of ferrocyanide simulant sludge material. The validity of using kaolin as a stand-in for ferrocyanide sludge is discussed in Section 5.5.

\subsubsection{Nitrogen Gas Bubble Growth in Waste Tank Simulant Sludge}

A schematic diagram of the apparatus is shown in Figure 5-2 and consists of five main elements connected in series: a nitrogen cylinder, a flow meter, a pressure transducer, a capillary tube-type orifice, and a plexiglass tube (or bubble column). In all the experiments

${ }^{\circ} \mathrm{Kaolin}$ is a hydrous aluminum silicate $\left(\mathrm{Al}_{2} \mathrm{O}_{3} \bullet 2 \mathrm{SiO}_{2} \bullet 2 \mathrm{H}_{2} \mathrm{O}\right)$ that is insoluble in water. 
except one, the kaolin or flowsheet simulant sludge in which a bubble was formed was contained in a vertical plexiglass bubble column of $4.45 \mathrm{~cm} \mathrm{ID}$ and $45.5 \mathrm{~cm}$ length. The final nitrogen bubble growth experiment was conducted with the kaolin particle-water mixture in a much larger bubble column of $12.7 \mathrm{~cm}$ internal diameter. The sludge depths were approximately $21.0 \mathrm{~cm}$ and $50.0 \mathrm{~cm}$ in the small and large bubble columns, respectively. The column is mounted with its axis vertical on top of an aluminum plate. A gasket is placed between the column and the plate in order to form a seal for the sludge in the bubble column. The aluminum plate has a pressure fitting that holds a stainless-steel capillary tube whose tip (orifice) is centrally located near the bottom of the bubble column. The capillary tube has a nominal $0.254 \mathrm{~mm}$ diameter and is $0.1 \mathrm{~m}$ in length.

During an experiment, gas is steadily fed into the bottom of the capillary tube at a known volumetric flow rate and passes out the upper tip of the capillary tube as a bubble. The volume displaced by the upper surface of the sludge at the end of a selected time interval is noted and compared with the volume of gas supplied to the column during the same time interval. If the former volume is significantly greater than the latter volume, then porous-medium type sludge behavior is inferred. On the other hand, if the two volumes are approximately equal to one another, homogeneous (suspension-like) sludge flow is indicated.

The phenomena visually observed in the course of the experiments were the same for the kaolin and In Farm 1 ferrocyanide simulant sludges and for all the nitrogen gas flow rates investigated. The steady introduction of gas into the column resulted in a steady increase in the height of the sludge column. This behavior suggested that a single bubble was forming at the orifice; that is, the bubble did not detach itself from the orifice. It seems reasonable to assume that the bubble expanded out to the walls of the bubble column before the buoyancy force could act to overcome the viscous forces that tend to hold the bubble in place.

An unexpected behavior greatly helped to elucidate the bubble growth process. After the gas bubble expanded out to the wall of the column, the void space formed by the bubble was clearly visible through the plexiglass cylinder. (Apparently, the sludge mixtures do not wet the plexiglass surface very well.) The airspace contained no particulate matter. All of the sludge material was displaced upward by the expanding slug bubble. Further evidence for this homogeneous sludge flow regime was provided by comparing the volume of gas introduced to the column with the volume displaced by the upper surface of the moving column of sludge. The two measured volumes differed by less than $2 \%$, which is of the order of uncertainty of the gas flow metering device.

A photograph of the bubble and the overlying 4.45-cm-diameter column of In Farm 1 ferrocyanide simulant sludge at the end of an experiment is presented in Figure 5-3. A photograph of the slug bubble in the kaolin-water sludge at the end of the experiment with the 12.7-cm-diameter column is shown in Figure 5-4. At the end of each experiment, the gasket seal at the bottom of the bubble column was broken, allowing the bubble to communicate directly with the atmosphere. The overlying sludge material responded by flowing back down the bubble column, demonstrating that the sludge column was supported 
Figure 5-2. Schematic of Bubble Formation Apparatus.

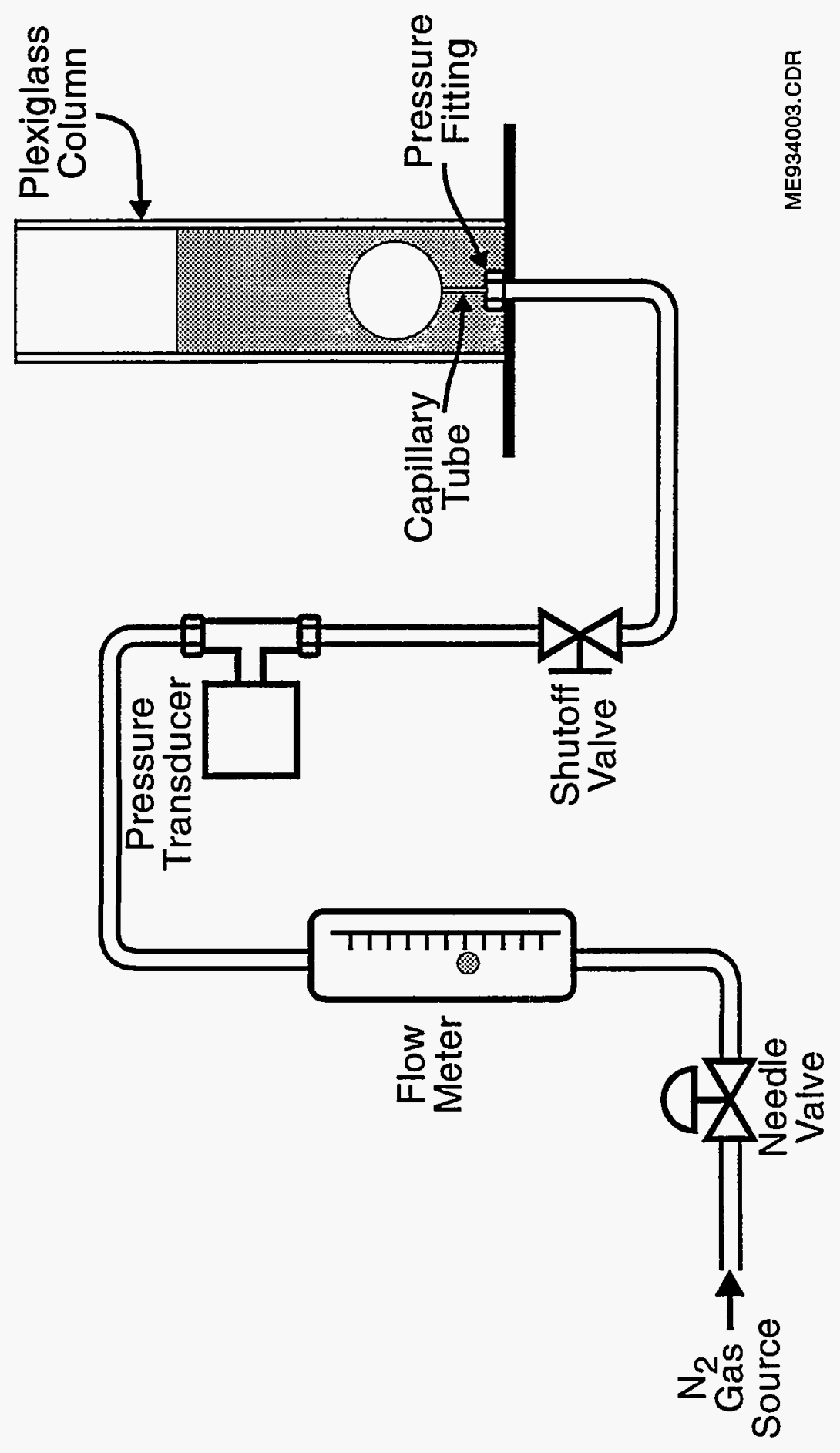


Figure 5-3. Photograph of Gas Bubble and Overlying 4.45-cm-Diameter Column of Ferrocyanide In Farm 1 Flowsheet Simulant Material.

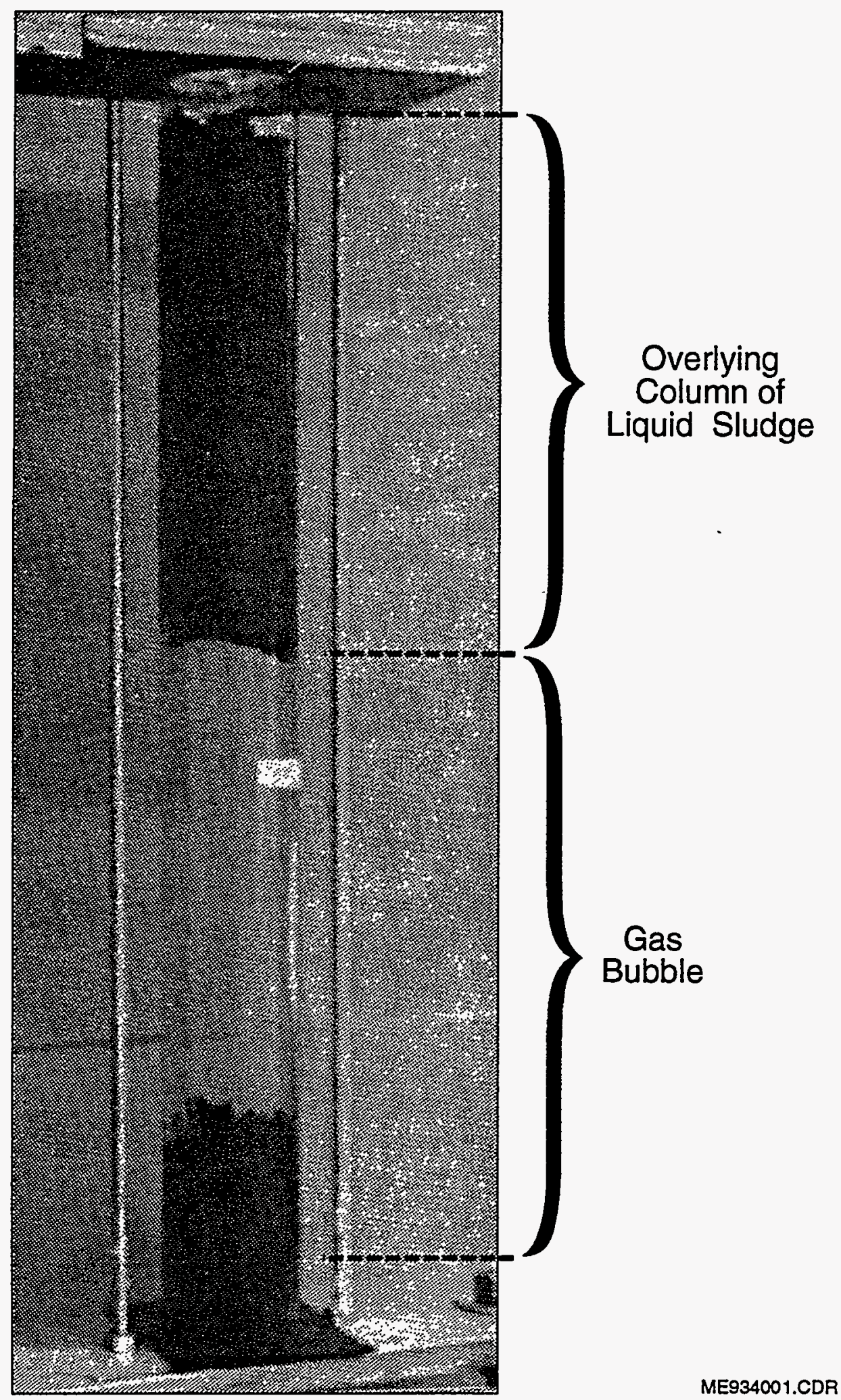


Figure 5-4. Photograph of Gas Bubble Showing the Overlying 50/50 Weight Percent Kaolin Particle-Water in the 12.7-cm-Diameter Column.

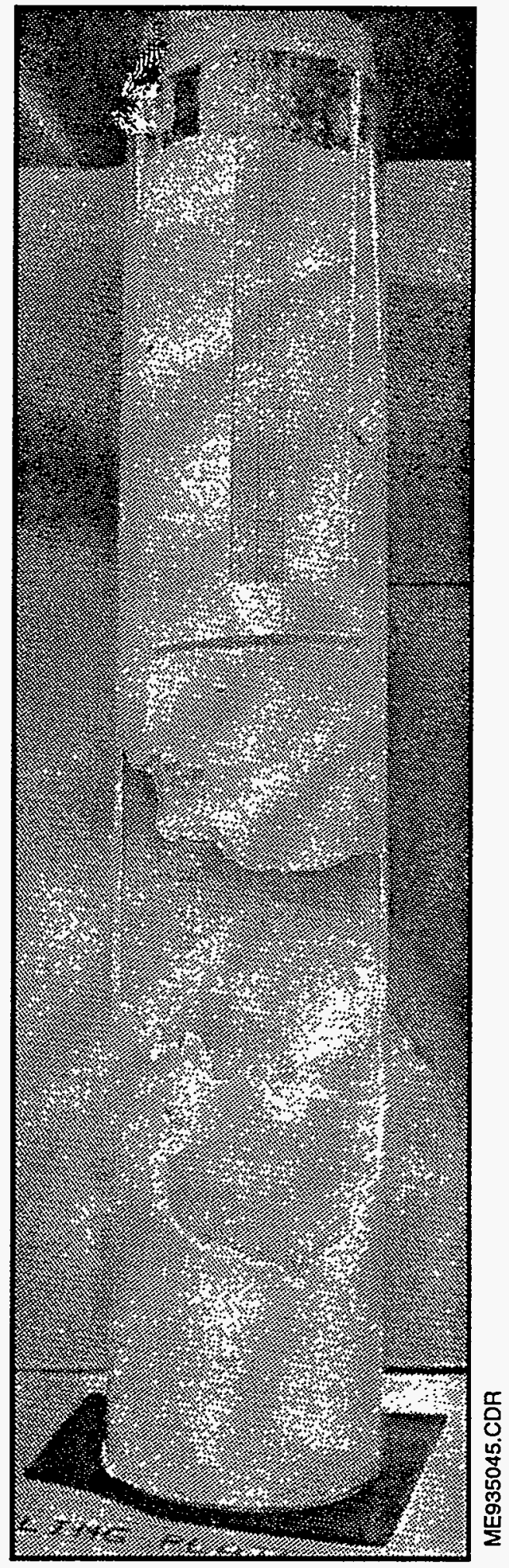


by a stable gas bubble. This behavior is consistent with the concept of a self-regulating hot spot (see Section 6.2.2).

From the above observations, it may be concluded that at small and large scales, sludge bubbles are quite stable for sizes up to at least $12.7 \mathrm{~cm}$ in diameter for the time scale studied and that the sludge particles are intimately tied to the liquid so that homogeneous (suspension-like) sludge flow is the preferred rheology in response to bubble growth.

\subsubsection{Void Growth via Boiling in Simulant Waste Tank Sludge}

The technique employed by FAI (Epstein et al. 1993) to initiate bubble growth by boiling of the sludge liquid at physically realistic rates was that of slow depressurization of hot sludge. Figure 5-5 illustrates the depressurization facility. The sludge in which void growth was achieved was contained in a vertical plexiglass bubble column of $4.45 \mathrm{~cm}$ internal diameter and $45.5 \mathrm{~cm}$ length. The lower portion of the column is wrapped with an 11-cm-long heating coil. The rings of the coil are sufficiently spaced to allow an essentially unobstructed view of the sludge. The heating coil is enclosed within an outer plexiglass column to reduce heat losses to the atmosphere and to help distribute the heat vertically to the regions between the rings of the coil. A pressure transducer is mounted at the top of the test section, which monitors the pressure in the space above the sludge column throughout the depressurization event. Two thermocouples continuously measured the temperature of the sludge along the centerline and near the wall of the column at a height that corresponded approximately to the middle of the heated zone. By comparing the temperature and pressure measurements, the onset of boiling conditions within the heated sludge could be determined.

An experiment was initiated by filling the column with the simulant sludge material to a height of about $23.0 \mathrm{~cm}$. The column was then pressurized with nitrogen gas to about 12.0 psig and the heating coil was turned on. The portion of the sludge that was surrounded by the coil was heated slowly so that the temperature within the sludge was fairly uniform in the radial direction. The temperature difference between the two thermocouples was not allowed to exceed about $1.0^{\circ} \mathrm{C}$. The pressurization prevented boiling during heatup. When the temperature within the heated ("hot spot") zone of the sludge reached the desired value, namely $107{ }^{\circ} \mathrm{C}$ for kaolin and $128^{\circ} \mathrm{C}$ for the flowsheet material, slow depressurization was initiated by opening the needle valve. The controlled nitrogen gas flow from the bubble column was $30 \mathrm{ml} \mathrm{min}^{-1}$ in all the experiments. Recall that this was the rate of void growth in some of the nitrogen bubble-column experiments. From the measured, average sludge temperature decay rate over the period of depressurization, namely $\mathrm{dT} / \mathrm{dt} \approx$ $-7.4 \times 10^{-3} \mathrm{~K} \mathrm{~s}^{-1}$, the authors estimate an equivalent sludge power density $\mathrm{Q} \approx-\rho c_{\mathrm{p}} \mathrm{dT} / \mathrm{dt}=$ $3.4 \times 10^{4} \mathrm{~W} / \mathrm{m}^{-3}$. This is the power density required to initiate boiling in a 0.15 -m-diameter hot spot (see Section 6.2.1 and Equation 6-10).

The homogeneous-flow phenomena visually observed in the course of the depressurization experiments were identical to the homogeneous-flow phenomena observed in the experiments involving nitrogen gas injection to produce bubble growth. The steady, slow 
depressurization resulted in a monotonically increasing sludge-column height with time. A relatively short time after depressurization was initiated, a single vapor bubble was visible through the plexiglass cylinder. The vapor bubble did not contain any particulate matter. All of the sludge material above the vapor nucleation site was displaced upward by the expanding slug bubble. The vapor bubble expansion rate was observed to decrease with time late in the experiment, in contrast with the nitrogen gas bubbles, whose growth rates were constant in time. The difference in behavior may be ascribed to the continuous exposure of cold plexiglass surface above the heating coil upon which vapor was condensed.

Photographs of the bubbles and the overlying columns of kaolin and In Farm 1 ferrocyanide simulant sludge material are presented in Figures 5-6 and 5-7, respectively. Clearly, these experiments provide important additional confirmation of the strong adhesional forces between the liquid and solid components of the sludge that result in homogeneous sludge rheology on a macroscopic scale.

\subsubsection{Bubble Behavior in Water-Saturated Beach Sand}

In order to demonstrate that the phenomena observed with kaolin and ferrocyanide simulants are related to the properties of these materials and not to the method or apparatus, nitrogen gas bubble growth and depressurization experiments were carried out at FAI (Epstein et al. 1993) with water-saturated beach sand. The 4.45-cm-diameter bubble columns used in the nitrogen gas bubble facility and in the depressurization facility were filled with a 20.0-cm-deep layer of fine beach sand. Actually, the bubble columns were first filled with water and then sand was gradually poured into the water column. This technique assured a gas-free, water-saturated column of sand.

As with the previously described gas-bubble growth experiments, a vertical stainless-steel capillary tube, centrally located near the bottom of the column, was used to introduce nitrogen gas into the column. Nitrogen gas flow rates of 30 and $60 \mathrm{ml} \mathrm{min}^{-1}$ in water-saturated beach sand were investigated. Recall that these were the flow rates used in the previous FAI tests with simulant sludges. The phenomena visually observed during the experiments with water-saturated sand were quite different from that observed with kaolin and ferrocyanide In Farm 1 simulant sludges. The single void region (bubble) that was observed to form within the sludge simulant materials did not form in the water-sand mixture. The sand was observed to be stationary. Shortly after the gas was first introduced into the column, small bubbles were observed emerging from the top of the sand column. The bubbling process continued throughout the duration of the test. There were no signs of gas accumulation within the sand column. This behavior, in which the gas is moving relative to stationary sand, is consistent with classical two-phase flow behavior in a porous medium of stationary solid material.

The depressurization experiment was also performed with the water-sand mixture. The single bubble that was observed to form within the sludge simulants did not materialize. The sand was motionless throughout the experiment, yet the temperature and pressure 
Figure 5-5. Schematic of Apparatus for Vapor Bubble Formation in Sludge via Slow Depressurization.

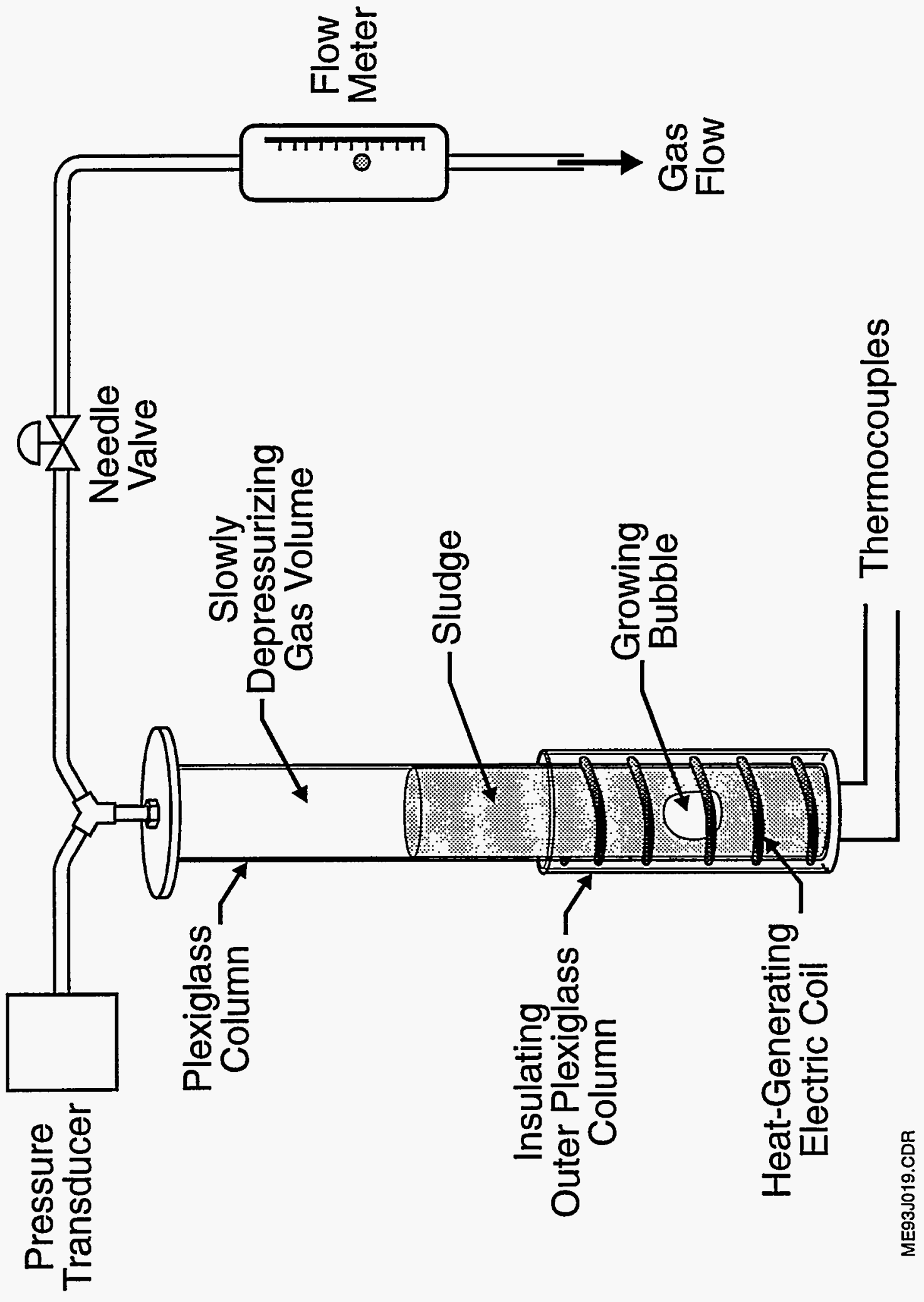


Figure 5-6. Photograph of Vapor Bubble Growing in 50/50 Weight Percent Kaolin Particle-Water Mixture.

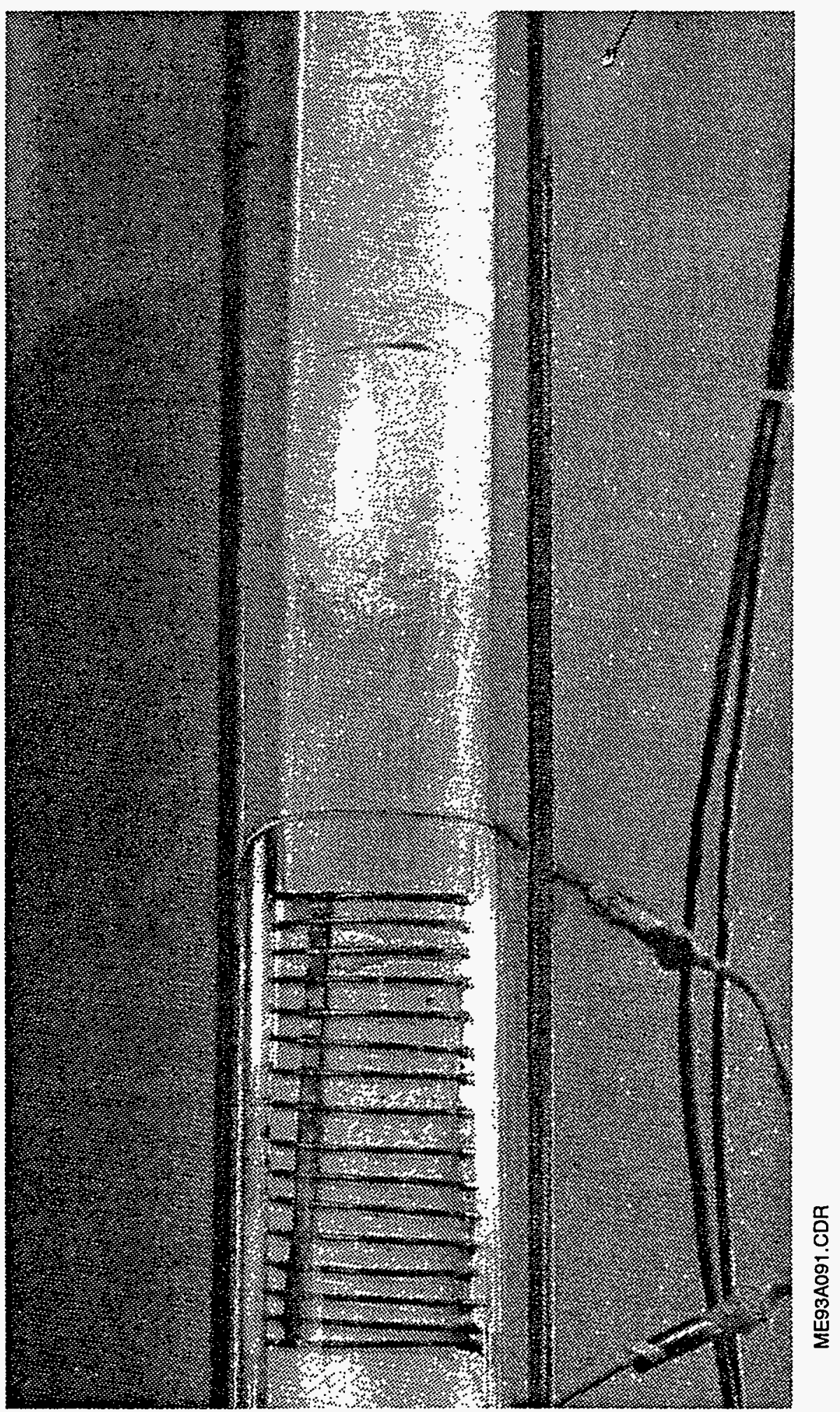


Figure 5-7. Photograph of Vapor Bubble Growing in Ferrocyanide In Farm 1 Flowsheet Simulant Material.

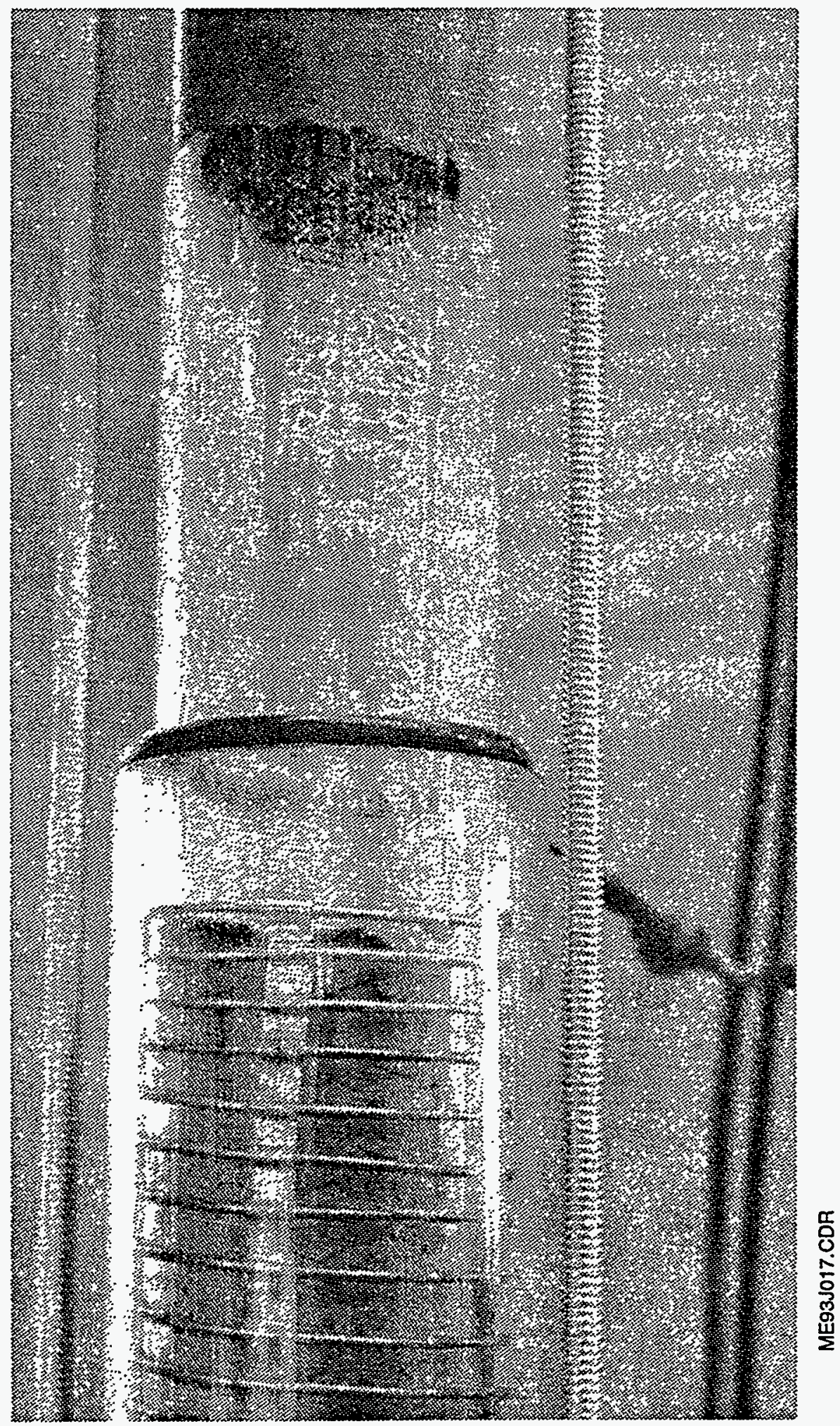


measurements indicated that boiling was occurring within the heated zone of the column. Steam was observed to emerge from the top of the sand column; however, most of the vapor formed within the heated zone of the sand percolated upward (against downflowing water) to the cold surfaces of the plexiglass column and condensed. This is typical of two-phase thermal convection in a porous layer of stationary solid. In a separate experiment, the permeability of the sand was measured by observing the time it takes for a given height of water to drain through a layer of sand of known depth. The results of four experiments indicated a sand permeability of

$$
\kappa=3.54 \times 10^{-11} \pm 0.26 \times 10^{-11} \mathrm{~m}^{2}
$$

and a sand porosity $\epsilon \approx 0.4$. Using the Kozeny relationship between permeability and particle size $d$, namely

$$
x=\frac{d^{2}}{180} \cdot \frac{\epsilon^{3}}{(1-\epsilon)^{2}}
$$

a mean sand-particle diameter $\mathrm{d} \approx 180.0 \mu \mathrm{m}$ was estimated. This diameter is about two orders of magnitude larger than the micron-size precipitate particles that comprise the simulant and actual waste tank sludge material. The coupling (hydrodynamic and colloidal) between the fine precipitate, sludge particles and their host liquid (water) is so strong that a single-medium non-Newtonian rheology is exhibited by the aqueous sludge. Obviously, this is not the case with the relatively coarse sand, which remains stationary and exhibits porous medium ("uncoupled") behavior when submerged in water.

\subsection{SMALL_SCALE EXPERIMENTAL RESULTS ON DRYOUT IN SIMULANT WASTE SLUDGE HEATED LOCALLY}

The experimental work reviewed in the foregoing has shown that waste tank sludge fits the definition of a concentrated suspension or colloid within which the forces between particles and liquid is so strong that the particles and liquid essentially flow together as a single fluid when subjected to an external force. It should be emphasized, however, that the effective viscosity of concentrated suspensions, such as ferrocyanide sludge, is very high. Laboratory results reported by Epstein et al. (1993) indicate that ferrocyanide sludge is best characterized as a Bingham fluid, as some initial yield stress must be exceeded in order to move the sludge.

The observation that the solid particle component of the sludge does not readily separate from the interstitial liquid, and the fact that the sludge resists deformation owing to its high viscosity, raises some interesting questions regarding sludge behavior in the vicinity of a hot rigid surface or a hot free surface where sustained evaporation of the interstitial liquid may take place. How is the sludge moisture transported to the hot surface at a rate that is capable of keeping up with the interstitial liquid evaporation rate? What is the mechanism of vapor 
transport away from the hot surface? Do the particles in the vicinity of the hot surface undergo consolidation (see Section 5.1) as a result of the loss of liquid material via evaporation, thereby resulting in a porous medium rheology ("caking") and local dryout?

In order to address these questions, which impinge directly on the issue of local dryout in waste tanks, small-scale experiments on the thermal response of aqueous ferrocyanide simulant waste to a local heat source were performed at FAI. The data were obtained by immersing cylindrical electrical resistance heaters in kaolin/water mixtures and in U Plant simulant sludge. Two different types of experiments were performed. First, a series of four experiments was conducted in beakers to see whether waste material dries out in a local or global manner when subjected to local heating (Fauske 1993b). A second series of experiments was conducted at FAI in a two-dimensional bench-scale test section in an attempt to determine the morphology of waste dryout in the vicinity of a hot surface, and the results are reported for the first time in this report. The authors note there that in order to ensure that the results obtained in the FAI bench-scale tests could be extrapolated to real waste tanks, large scale kaolin-water heat transfer experiments were performed by Crippen (1994) at Westinghouse Hanford Company. The description and results of Crippen's large scale experiments are presented in Section 5.4. A summary of the characteristics of each experiment is given in Table 5-1. Note that Crippen's test section represents an increase in scale of about 130 times the 3-L vessel employed at FAI (compare first and last entries in Table 5-1).

Table 5-1. Summary of Important Characteristics of Waste-Sludge-Local Heating Tests Presented in Sections 5.3 and 5.4.

\begin{tabular}{|l|l|c|c|l|}
\hline \multicolumn{1}{|c|}{ Vessel Size } & Simulant Sludge & $\begin{array}{c}\text { Heater Area, } \\
\mathrm{m}^{2}\end{array}$ & $\begin{array}{c}\text { Heat Flux, } \\
\text { W/m }\end{array}$ & \multicolumn{1}{|c|}{$\begin{array}{c}\text { Type of } \\
\text { Experiment }\end{array}$} \\
\hline 3-L Beaker & Kaolin/Water & $4.5 \times 10^{-3}$ & $1.5 \times 10^{4}$ & Global Water Loss \\
\hline $\begin{array}{l}\text { 30-cc Beaker } \\
\text { RSST Test Cell) }\end{array}$ & Kaolin/Water & $1.5 \times 10^{-4}$ & $2.7 \times 10^{4}$ & Global Water Loss \\
\hline 40-cc Beaker & $\begin{array}{l}\text { Kaolin/Salt } \\
\text { Water }\end{array}$ & $1.5 \times 10^{-4}$ & $2.7 \times 10^{4}$ & Global Water Loss \\
\hline 40-cc Beaker & Kaolin/Water & $1.5 \times 10^{-4}$ & $2.7 \times 10^{4}$ & Global Water Loss \\
\hline 450-cc Thin Cavity & Kaolin/Water & $1.5 \times 10^{-4}$ & $5.7 \times 10^{4}$ & $\begin{array}{l}\text { Sludge } \\
\text { Morphology }\end{array}$ \\
\hline 450-cc Thin Cavity & Kaolin/Water & $1.5 \times 10^{-4}$ & $6 \times 10^{4}$ & $\begin{array}{l}\text { Evaporation in } \\
\text { Sealed Vessel }\end{array}$ \\
\hline 450-cc Thin Cavity & Kaolin/Water & $1.5 \times 10^{-4}$ & $5.3 \times 10^{3}$ & $\begin{array}{l}\text { Evaporation in } \\
\text { Sealed Vessel }\end{array}$ \\
\hline
\end{tabular}




\begin{tabular}{|l|l|c|c|l|}
\hline \multicolumn{1}{|c|}{ Vessel Size } & Simulant Sludge & $\begin{array}{c}\text { Heater Area, } \\
\mathrm{m}^{2}\end{array}$ & $\begin{array}{c}\text { Heat Flux, } \\
\mathrm{W} / \mathrm{m}^{-2}\end{array}$ & $\begin{array}{c}\text { Type of } \\
\text { Experiment }\end{array}$ \\
\hline 450-cc Thin Cavity & $\begin{array}{l}\text { U Plant } \\
\text { Simulant }\end{array}$ & $1.5 \times 10^{-4}$ & $5.4 \times 10^{4}$ & $\begin{array}{l}\text { Sludge } \\
\text { Morphology }\end{array}$ \\
\hline 450-cc Thin Cavity & Kaolin/Water & $1.5 \times 10^{-4}$ & $4.5 \times 10^{4}$ & $\begin{array}{l}\text { Surface } \\
\text { Evaporation }\end{array}$ \\
\hline 450-cc Thin Cavity & $\begin{array}{l}\text { U Plant } \\
\text { Simulant }\end{array}$ & $1.5 \times 10^{-4}$ & $5.4 \times 10^{4}$ & $\begin{array}{l}\text { Surface } \\
\text { Evaporation }\end{array}$ \\
\hline $\begin{array}{l}\text { 0.4-m } \mathrm{m}^{3} \text { Cylindrical } \\
\text { Tank }\end{array}$ & Kaolin/Water & $9.7 \times 10^{-2}$ & $1.3 \times 10^{3}$ & Calibration \\
\hline $\begin{array}{l}0.4-\mathrm{m}^{3} \text { Cylindrical } \\
\text { Tank }\end{array}$ & Kaolin/Water & $9.7 \times 10^{-2}$ & $4.1 \times 10^{3}$ & Boiling Test \\
\hline $\begin{array}{l}0.4-\mathrm{m}^{3} \text { Cylindrical } \\
\text { Tank }\end{array}$ & Kaolin/Water & $2.4 \times 10^{-2}$ & $2.63 \times 10^{3}$ & $\begin{array}{l}\text { Water Migration } \\
\text { Test }\end{array}$ \\
\hline
\end{tabular}

\subsubsection{Bench Scale Test in 3-Liter Beaker}

The first experiment was run in a 3-L beaker. The beaker was filled with a $2.2-\mathrm{kg}$ kaolin/water mixture containing $50 \mathrm{wt} \%$ water. A single 9.5 -mm-diameter, $28-\mathrm{cm}$-long cylindrical immersion heater was placed vertically in the center of the waste beaker, as shown in Figure 5-8. The area of the outside surface of the heater that covers its heated length is $4.5 \times 10^{-3} \mathrm{~m}^{2}$. A radial array of four thermocouples was used to define the temperature field during the course of the experiment. Thermocouple 1 made contact with the surface of the immersion heater. Thermocouples 2 and 3 were placed on opposite sides of the heater, midway between the heater and the side of the beaker, and Thermocouple 4 was placed $0.64 \mathrm{~cm}$ in from the side of the beaker. The radial positions of the thermocouples are shown in Figure 5-8. Insulating material covered the bottom and side of the beaker; the surface of the kaolin/water mixture was exposed to the atmosphere. The experiment was initiated by turning the heater on to a constant power of approximately $67 \mathrm{~W}$.

The measured temperature-time histories within the 3-L beaker are given in Figure 5-9. The late cooling trend exhibited by Thermocouple 4 is a consequence of the gradual shrinkage (from water loss) of the kaolin/water mixture, which resulted in exposing this peripheral thermocouple to air at six hours into the test. The most important result conveyed by Figure 5-9 is that the temperature of the thermocouple in contact with the surface of the heater, Thermocouple 1, remains essentially constant at or slightly above the boiling point of the water component for about 9 hours. The heat flux emanating from the surface of the heater during this time was $1.5 \times 10^{4} \mathrm{~W} / \mathrm{m}^{-2}$. If the kaolin/water mixture is viewed as a 
porous medium with stationary kaolin particulate, the drying process is predicted to occur once the heat flux exceeds the value given approximately by (e.g., Jones et al. 1984, Hardee and Nilson 1977)

$$
q_{\max }=\frac{h_{f g} k\left(\rho_{f}-\rho_{g}\right) g}{v_{g}}
$$

where $h_{\mathrm{fg}}$ is the latent heat of vaporization of interstitial liquid, $k$ is the permeability of the medium, $g$ is the gravitational constant, $\rho_{\mathrm{f}}-\rho_{\mathrm{g}}$ is the density difference between the interstitial liquid and its vapor phase, and $\nu_{g}$ is the kinematic viscosity of the vapor phase. Substituting the known sludge particle diameter $\mathrm{d} \approx 0.75 \mu \mathrm{m}$ and interstitial liquid volume fraction $(\epsilon \approx 0.7)$ into Equation (5-1) yields $k=10^{-14} \mathrm{~m}^{2}$ for the permeability of "porous medium sludge". Using this value together with the parameters $\rho_{\mathrm{f}}-\rho_{\mathrm{g}}=10^{3} \mathrm{~kg} \mathrm{~m}^{-3}, \mathrm{~h}_{\mathrm{fg}}=$ $2.2 \times 10^{6} \mathrm{~J} \mathrm{~kg}^{-1}$, and $\nu_{g}=2 \times 10^{-5} \mathrm{~m}^{2} \mathrm{~s}^{-1}$ in Equation (5-2) gives $\mathrm{q}_{\max }=10 \mathrm{~W} / \mathrm{m}^{-2}$. Thus drying should have been observed immediately after the heater was turned on if the sludge behaved as a porous medium of stationary solid. It is worth noting that a steam concentration gradient in the vicinity of the heater can give rise to a capillary-driven flow of liquid toward the heater and counterflow of steam away from the heater. Using the porous medium model of capillary flow developed at FAI, this can result in a $q_{\max }$ as large as $10^{3}$ $\mathrm{W} / \mathrm{m}^{-2}$. While this value is much larger than that predicted with Equation (5-2), it is still small compared with heat flux produced by the heater. It is reasonable to conclude that the observed sludge behavior does not conform to the porous medium (stationary solid) model.

It is interesting to calculate the mass of water converted to steam during the 9-hour period prior to dryout in the vicinity of the immersion heater. Denoting $Q$ as the heater power (in watts), and $t$ as time to dryout, gives

$$
m=\frac{t Q}{h_{f g}}
$$

as the mass of water evaporated. Substituting the values $Q=67 \mathrm{~W}$ and $t=9.0$ hour $\left(3.24 \times 10^{4} \mathrm{~s}\right)$ into Equation $(5-13)$ gives $\mathrm{m}=0.99 \mathrm{~kg}$. Thus the waste simulant did not dry out until about $94 \%$ of the original $1.05 \mathrm{~kg}$ of water was lost by evaporation. This approximate result implies that a large fraction of the water within the waste beaker was actively involved in cooling the heater.

Clearly, the transport of heat from the heater to the kaolin/water mixture is convective in nature. However, visual observations of the surface of the simulant waste revealed no motion. Also, it was difficult to detect the presence of steam at the surface. Apparently, if convection occurred in the beaker, liquid and vapor migration must have taken place beneath the surface and out of view. This issue will be returned to later (Section 6.0), and an 
Figure 5-8. Schematic of 3-Liter Beaker Test Indicating Locations of Cylindrical Immersion Heater and Thermocouples.

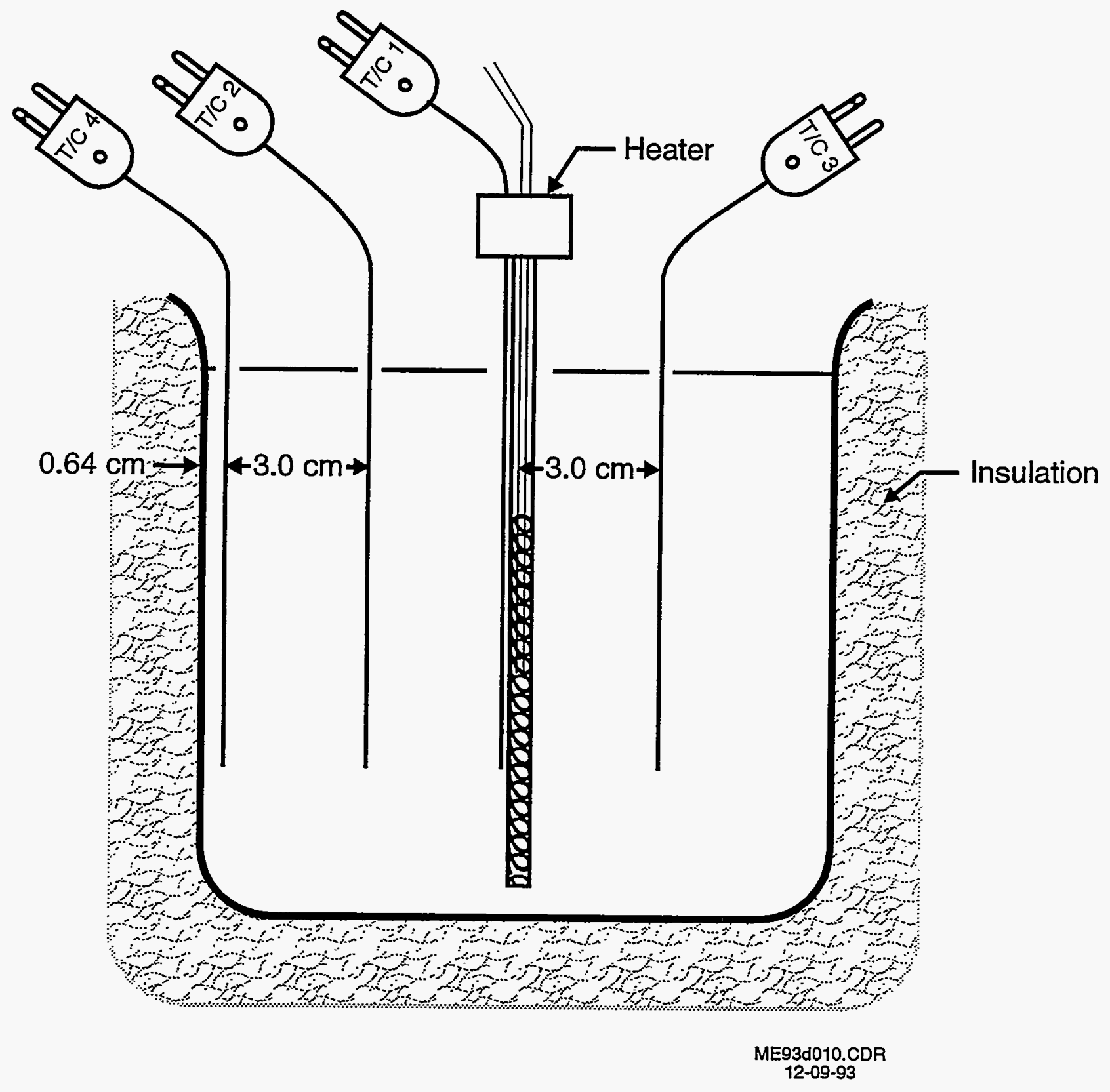


Figure 5-9. Thermal. Response of 50/50 Kaolin/Water Mixture by Mass to 67-Watt Cylindrical Immersion Heater.

(Total mass of mixture, $2.2 \mathrm{~kg}$ )

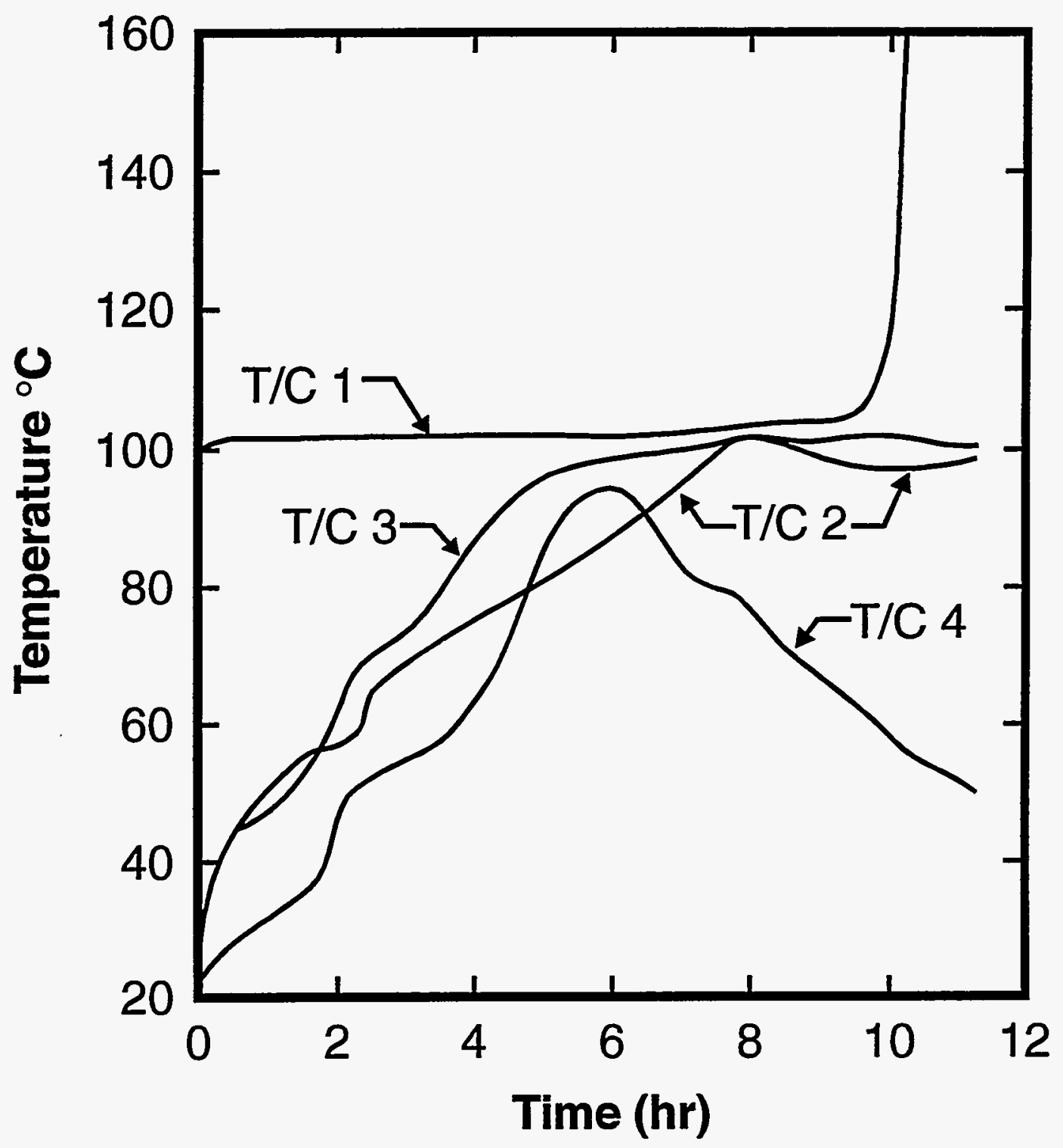


explanation, adopted from moist soil behavior theory, will be provided for the surprisingly high cooling capacity of the waste material.

\subsubsection{Small Scale Test in Reactive System Screening Tool Spherical Test Cell}

In order to conserve simulant waste material and obtain an accurate measure of the amount of water that must be removed from the waste before dryout (overheating) occurs, several small-scale experiments were carried out. The first of these small-scale tests made use of the reactive system screening tool (RSST) ${ }^{d}$ spherical glass test cell, which is equipped with both an external wrap-around heater and an internal, cylindrical immersion heater. As in the 3.0-L beaker test, a 50/50 kaolin/water mixture by mass was used. The initial mass of the mixture was $17.48 \mathrm{~g}$. Two thermocouples were placed in the cell; one was attached directly to the immersion heater while the other was placed about $1 \mathrm{~cm}$ from the heater. The external heater was used to bring the sample up to about $100^{\circ} \mathrm{C}$. Both thermocouples were recording the same temperature during the external heating period.

After a few minutes at $100{ }^{\circ} \mathrm{C}$, the external heater was turned off and the internal immersion heater was turned on. The temperature of the sample briefly fell to about $90{ }^{\circ} \mathrm{C}$ when the heaters were switched; however, the temperature quickly returned to $100{ }^{\circ} \mathrm{C}$. During the subsequent period of purely immersion heating, the thermocouple within the material read $100{ }^{\circ} \mathrm{C}$ while the heater thermocouple read about $103{ }^{\circ} \mathrm{C}$. The temperature of the surface of the heater remained at this temperature for about 150 minutes and then began to rise rapidly, indicating that local dryout had been achieved. A mass balance indicated that 7.09 grams of the sample were lost. If all of this mass loss is attributed to water evaporation, then it can be concluded that $80 \%$ of the initial water component of the simulant waste must be removed before local waste overheating can begin.

Note that the RSST heater delivers about $4 \mathrm{~W}$ of power through a cylindrical surface of area $1.5 \times 10^{-4} \mathrm{~m}^{2}$ ( $3 \mathrm{~mm}$ diameter and $1.5 \mathrm{~cm}$ long). Thus, the heat flux off the heater's surface was $2.7 \times 10^{4} \mathrm{~W} / \mathrm{m}^{-2}$, which is well above the dryout heat flux predicted using a porous medium model which assumes a rigid kaolin microparticle structure in water (see Equation 5-2).

A post-test examination of the material left in the test cell revealed many void spaces and cracks. The material appeared uniformly dry and crumbled easily. Note that the observation of uniform dryness is compatible with the observation that a large fraction of the initial water inventory must be removed from the mixture before local overheating can occur.

'The reader should consult Creed and Fauske (1990) for more information regarding the RSST calorimeter system. 


\subsubsection{Small-Scale Test in 40-cc Beaker with Nitrate Salt}

In the second small-scale test, the simulant waste material used was a kaolin/aqueous sodium-nitrate salt-solution mixture. The mixture contained 13.93 grams of kaolin, 6.97 grams of sodium nitrate salt $\left(\mathrm{NaNO}_{3}\right)$, and 10.05 grams of water. Also, the RSST test cell was replaced by a 40-cc beaker and $4 \mathrm{~W}$ of power were supplied by the cylindrical RSST immersion heater described previously. The heater was placed vertically in the center of the simulant waste material. Two thermocouples were employed: one on the surface of the heater and one located about $1.5 \mathrm{~cm}$ from the heater. The temperature-versus-time curves generated by the thermocouple readings are shown in Figure 5-10. The temperature of the heater's surface rises relatively rapidly to about $140{ }^{\circ} \mathrm{C}$ and then gradually rises throughout the test. Similarly, the in-material thermocouple rises rapidly to about $110^{\circ} \mathrm{C}$ and then continues to rise at a rather gradual rate. The gradually rising temperatures were probably a result of the changing boiling point of the aqueous $\mathrm{NaNO}_{3}$ solution as the solution became more concentrated. The instantaneous boiling point of the salt solution probably lies between the flat portions of the two curves in Figure 5-10. Seventy-five percent of the water was lost in this test.

\subsubsection{Small-Scale Test in 40-cc Beaker}

The third small-scale test was essentially the same as the second (previously described) small-scale test except that salt $\left(\mathrm{NaNO}_{3}\right)$ was not used in the mixture. The simulant waste contained $50 \%$ water by mass, and its total mass (kaolin + water) was 30.01 grams. The temperature-time histories, as recorded by the thermocouple attached to the heater and the thermocouple positioned about $1.0 \mathrm{~cm}$ from the heater, are presented in Figure 5-11. Note that the dryout (overheat) condition was met at about 220 minutes after the heater was turned on. The water mass lost during the test was 10.25 grams, which indicates that overheating did not occur until $68 \%$ of the total water inventory was removed by evaporation.

\subsubsection{Tests Performed in a Thin Rectangular Cavity}

The implication of the above-reviewed dryout studies with respect to real waste material is simple and far-reaching: the rate of transport of heat from a postulated hot region of waste to the surrounding cooler waste material is rapid enough to prevent the region from being heated beyond the boiling point of the interstitial liquid. It remains to explain the observed high cooling capacity of the simulant kaolin/water waste material.

The second stage of the FAI laboratory program on waste dryout in the vicinity of a hot surface involved simulating the bulk waste with a two-dimensional slice of it in the form of 
Figure 5-10. Thermal Response of Kaolin/Aqueous Sodium Nitrate Salt Solution to a 4-Watt Cylindrical Immersion Heater. (Kaolin mass, 13.93 grams; $\mathrm{NaNO}_{3}$ mass, 6.97 grams; water mass, 10.05 grams)

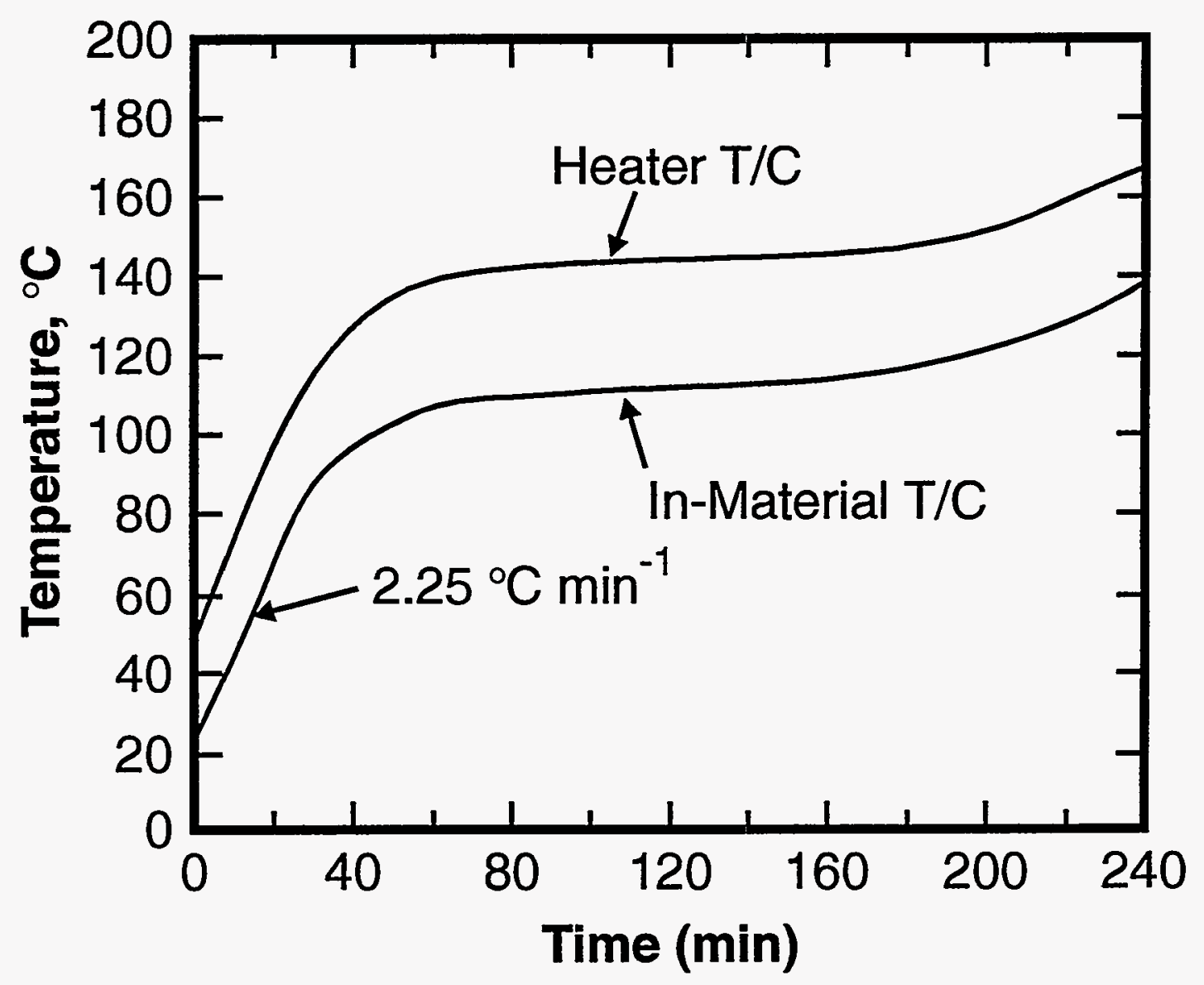

ME93d014.CDR

$12-10-93$ 
Figure 5-11. Thermal Response of 50/50 Kaolin/Water Mixture to 4-Watt Cylindrical Immersion Heater.

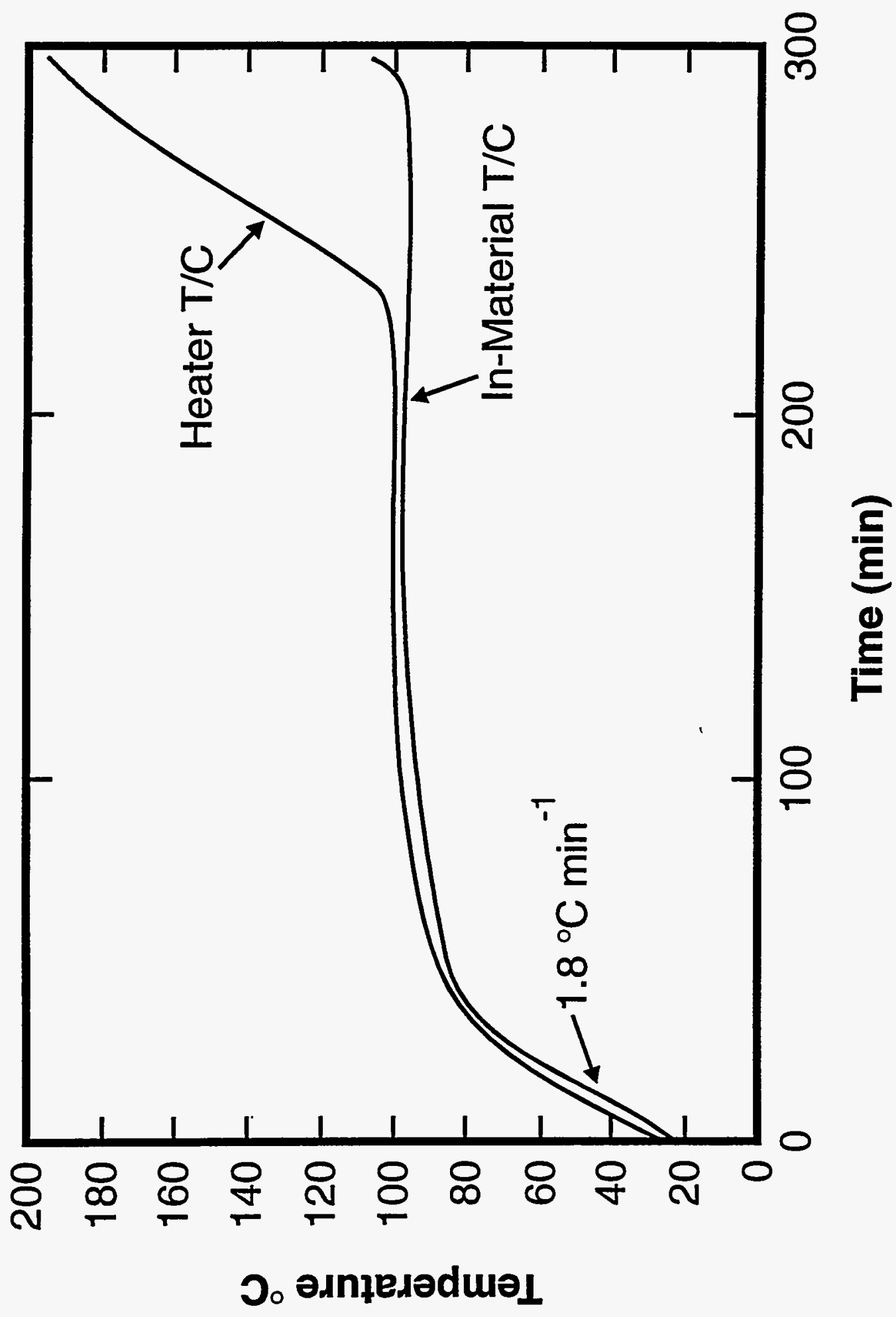


a thin rectangular cavity. The test section is shown in Figure 5-12. The slice is bounded by two closely spaced, rectangular, parallel plexiglass plates. The height and width of the cavity are 10.2 and $17.8 \mathrm{~cm}$, respectively. The narrow lateral dimension is $2.5 \mathrm{~cm}$.

A cylindrical (RSST) heater is positioned horizontally in the center of the cavity; its heating element is $1.5 \mathrm{~cm}$ long and $3 \mathrm{~mm}$ in diameter and it traverses about $60 \%$ of the narrow dimension of the test cell. The simulant waste material was at first water-saturated, fine kaolin particulate. Since one lateral dimension of the test vessel is small, it was expected that the response of kaolin suspension to local heating would be observable. Indeed, this turned out to be the case.

An initial experiment was conducted without temperature measurements in order to minimize the possible influence of the thermocouple stems on the behavior of the suspension.

A photograph of the waste material in the vicinity of the heater for a heater power of $8.6 \mathrm{~W}$ (surface heat flux $5.7 \times 10^{4} \mathrm{~W} / \mathrm{m}^{-2}$ ) is shown in Figure 5-13. As heat was supplied to the kaolin/water mixture, dissolved gas was released from the water component in the form of gas bubbles. The simulant waste material was again observed to behave as a pure liquid in that the interiors of the bubbles contained no particulate matter. Recall that this observation is in agreement with the earlier FAI studies (Epstein et al. 1993) of slug bubble growth in simulant waste (see Section 5.2). The two-dimensional cavity is superior to the bubble column apparatus in this regard because it enables one to observe the homogeneous response of simulant waste to the appearance and growth of small bubbles in the size range $0.5-10 \mathrm{~mm}$ (see Figure 5-13).

Some time after the heater was turned on, cracks appeared in the sludge mixture; the cracks can be seen in Figure 5-13. The authors speculate that the cracks resulted from the gradual shrinking (consolidation) of the sludge as its water content decreased by evaporation. Regardless of the mechanism, the fact that the cracks are particle free attests once again to the strong forces holding the particles and liquid together. Interestingly enough, bubble formation and cracking may render a seemingly impermeable waste suspension highly permeable.

It was difficult to visualize the flow of liquid and vapor through the side walls of the two-dimensional test cavity. However, liquid and vapor were observed to emerge from cracks that propagated to the surface, indicating perhaps that water and steam occupy the cracks. The authors suggest that liquid evaporated at the surface of the heater is rapidly transported to the cooler regions of the waste through an elaborate matrix of bubbles and connecting cracks where condensation occurs. Regions close to the heater that become partially depleted of liquid because of evaporation are perhaps replenished by a wetting process in which the condensate liquid within the cracks penetrates the particulate regions between the cracks or flows within the cracks and returns to the evaporation interface. Clear experimental evidence for the flow of water and steam within cracks is presented below.

After the morphology experiment was conducted in the thin rectangular cavity, two relatively long-term local heating experiments were carried out in the same test section. Temperature measurements were obtained at the lower boundary of the heater's surface and at a vertical 
distance of about $2 \mathrm{~cm}$ below the heater (see Figure 5-12). The outside surfaces of the walls and bottom of the test section were insulated. A thin water layer was added above the initially $50 \mathrm{wt} \% \mathrm{kaolin} /$ water waste simulant, and a metal plate covered the top of the cavity to minimize global evaporation losses of interstitial liquid. In the first experiment, the heater power was set at $9.0 \mathrm{~W}$ (surface heat flux $6 \times 10^{4} \mathrm{~W} / \mathrm{m}^{-2}$ ). As in the morphology test, bubble formation and crack propagation were observed. About ten minutes into the test the thermocouple at the surface of the heater reached $100^{\circ} \mathrm{C}$. This reading remained constant for a period of about three days, at which time the experiment was terminated.

The second experiment began by filling the test section with fresh kaolin/water sludge and setting the heater to a much lower power of $0.8 \mathrm{~W}$ (surface heat flux $5.3 \times 10^{3} \mathrm{~W} / \mathrm{m}^{-2}$ ). The experiment was operated at this power level for seven days. The temperature at the surface of the heater increased from room temperature to about $35^{\circ} \mathrm{C}$ in a few hours and then no further increase was observed. A few thin cracks were observed and the waste appeared faintly striated in the region above the heater. The absence of local dryout in the vicinity of the heater in these long-term experiments clearly shows that a rather effective water return mechanism is operative within the sludge, at least on the scale of the two-dimensional test section.

Another experiment was carried out in the two-dimensional test section with ferrocyanide $\mathrm{U}$ Plant simulant material and a heater power of $8.1 \mathrm{~W}$ (surface heat flux $5.4 \times 10^{4} \mathrm{~W} / \mathrm{m}^{-2}$ ). The temperature at the surface of the heater passed through $100{ }^{\circ} \mathrm{C}$ in about 10 minutes and then slowly oscillated between $105^{\circ} \mathrm{C}$ and $130{ }^{\circ} \mathrm{C}$ during the remainder of the experiment. The experiment was terminated after approximately five hours of operation. The thermal . oscillations at the heater were probably caused by the continuously changing sludge boiling point from spatial and time variations in the sludge's dissolved salt content.

Two major cracks, together with numerous small "hairline cracks", were observed through the front wall of the test section. For the first time vapor bubbles and vapor slugs were noted to migrate through the cracks and away from the heater. Apparently, the dark bluish-gray color of the U Plant simulant provided the appropriate contrast for viewing the steam voids within the cracks, whereas the milky-white appearance of the liquid within cracks formed in kaolin paste is not ideal for this purpose. A photograph of one of the large cracks is shown in Figure 5-14. The authors conclude that countercurrent flow of steam and water within the cracks is at least partially responsible for the high cooling capacity of the sludge material. Later, however, it will be seen that most of the liquid probably returns to the surface of the heater by migrating through the particle-rich region between cracks.

A final set of two experiments was conducted in the two-dimensional test section to examine the thermal response of waste material to a heat source placed just beneath the free surface of the waste medium. Note that these experiments attempt to address the issue of local dryout from evaporation of interstitial liquid from a relatively warm segment of surface sludge (see 
Figure 5-12. Schematic of "Two-Dimensional Test Section" for Observing Simulant Waste Material Response to a Local Heat Source.

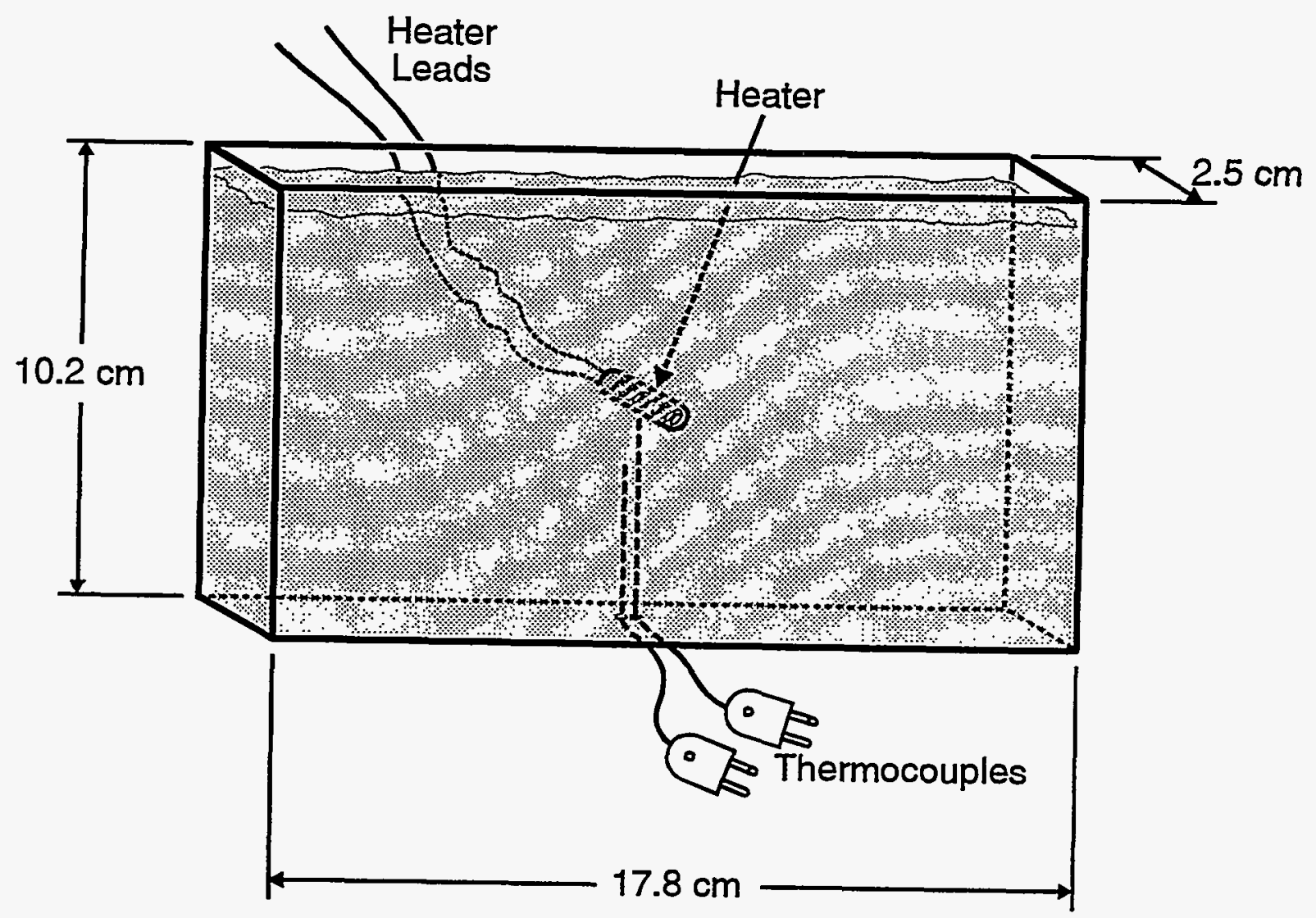

ME943021.CDR 3-14-94 
Figure 5-13. Photograph of Simulant Waste (Kaolin) Morphology in Vicinity of 8.6-Watt Cylindrical Heater.

(White spot etched in plexiglass wall is $13 \mathrm{~mm}$ in diameter, indicates location of water cross section, and serves as a benchmark for determining bubble and crack dimensions.)

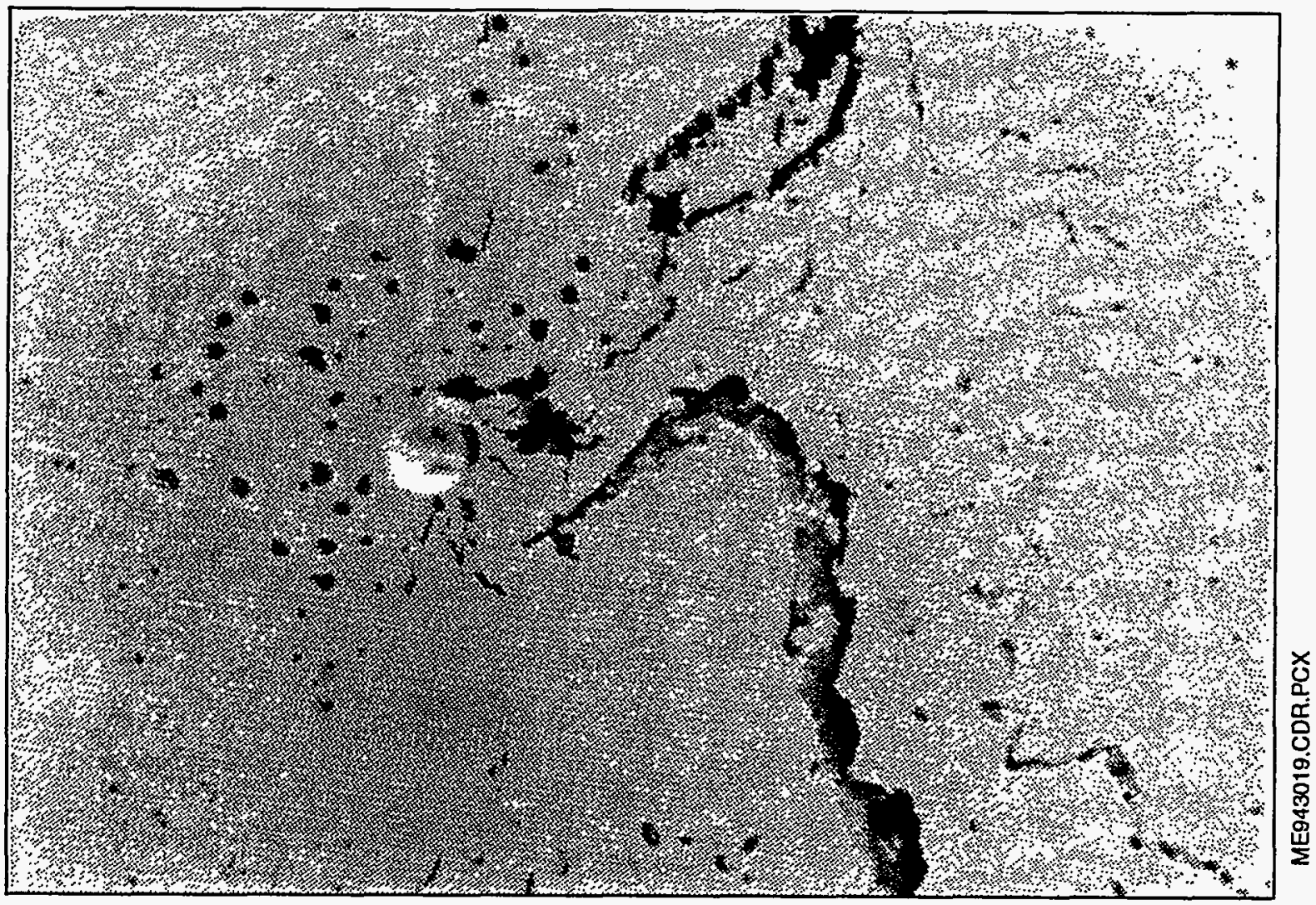


Figure 5-14. Photograph of U Plant Simulant in Vicinity of 8.1-Watt Cylindrical Heater. (White spot etched in plexiglass wall is $13 \mathrm{~mm}$ in diameter, indicates location of water cross section, and serves as a benchmark for determining bubble and crack dimensions. Width of large crack is approximately $0.5 \mathrm{~mm}$ )

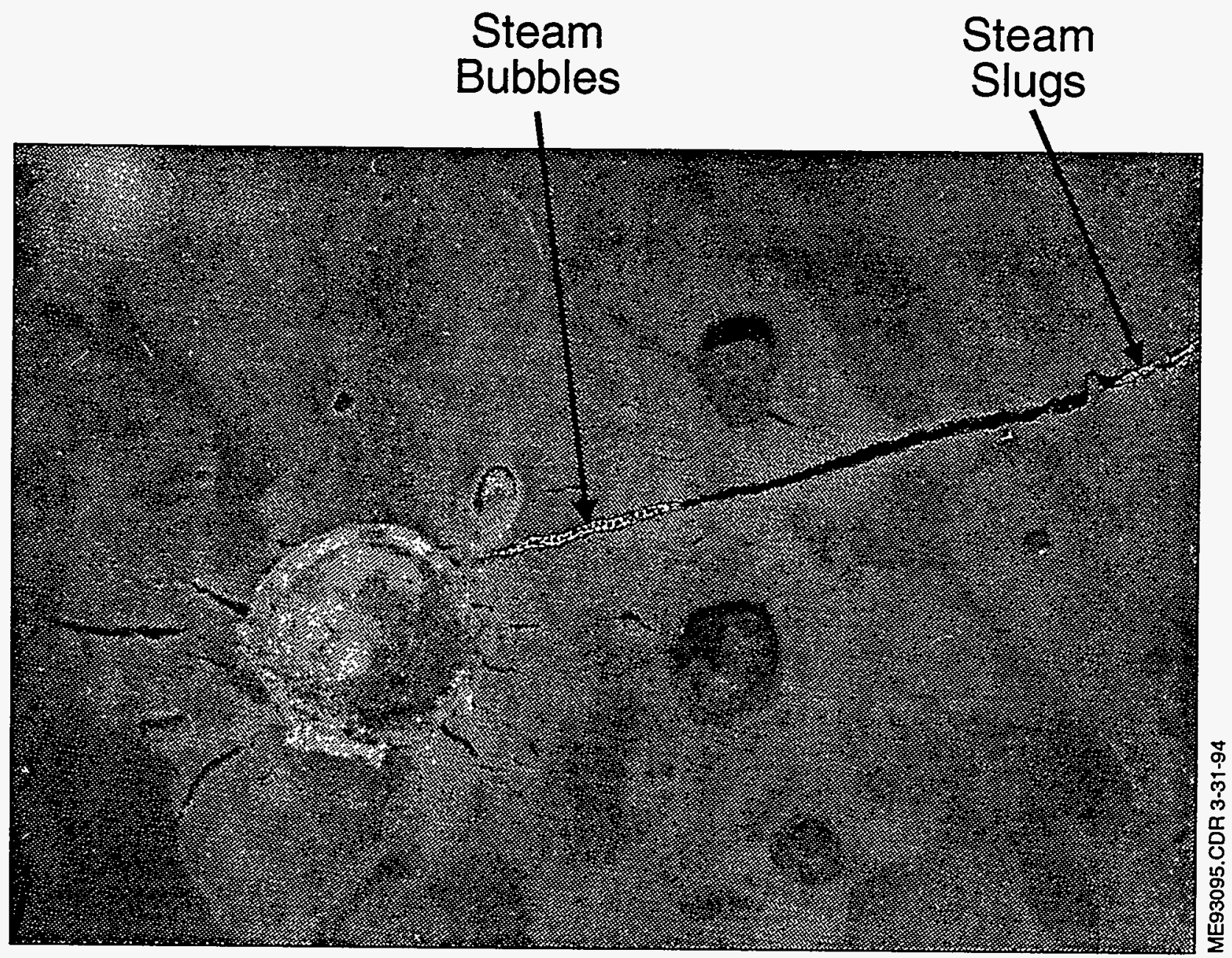


Section 1.0). The simulant sludge material occupied the lower half of the test section shown in Figure 5-12 so that the top of the centrally located, fixed-position heater was buried about $0.95 \mathrm{~cm}$ below the surface of the sludge. The top of the rectangular cavity was left open to the atmosphere; therefore, evaporated liquid material was free to leave the test section without returning to the sludge. In the first "overheated surface test," the horizontal RSST heater delivered about $6.8 \mathrm{~W}$ (surface heat flux $4.5 \times 10^{4} \mathrm{~W} / \mathrm{m}^{-2}$ ) to kaolin/water sludge. Four hours passed before the temperature at the surface of the heater reached the boiling point of the interstitial water. Obviously, convective heat transfer off the surface of the sludge just above the heater prevented a rapid rate of temperature rise. Recall that in previous tests in the rectangular cavity with similar heater output, the heater thermocouple reached the boiling point of the liquid component in about 10 minutes. During the remaining $4-1 / 2$ hours of the test the heater thermocouple remained at $100^{\circ} \mathrm{C}$. The gradual shrinkage (consolidation) of the kaolin/water sludge from water loss caused the sludge to separate from the $2.5 \times 10.2 \mathrm{~cm}$ side walls of the test section. There was also a small reduction $(\sim 2 \mathrm{~mm})$ in the height of the sludge.

A mass balance indicated that $34 \%$ of the water was removed from the waste by evaporation; however, a post-test examination of the kaolin sludge revealed that the material was still uniformly wet. Even the sludge material in the region just above the heater was moist. One can only conclude from these observations that water initially below and far removed from the heater was somehow transported to the heater's surface. Apparently gravity-driven countercurrent flow of steam and water through cracks is not the only mechanism responsible for preventing local dryout in the vicinity of the heater. An alternative mode of liquid transport to the heated zone involves sludge consolidation (shrinkage), and this is the subject matter of Section 6.1.

In the second "overheated surface test," the RSST heater was submerged just below the surface of U Plant simulant sludge material and the heater power was set at $5.5 \mathrm{~W}$ (surface heat flux $3.7 \times 10^{4} \mathrm{~W} / \mathrm{m}^{-2}$ ). The experimental results were similar to those conveyed in the foregoing for kaolin/water sludge in that the temperature of the heater thermocouple slowly increased over a period of eight hours until the boiling point $\left(\approx 120^{\circ} \mathrm{C}\right)$ for the $\mathrm{U}$ Plant simulant sludge was achieved. During the remainder of the test, the heater thermocouple recorded temperatures between 119 and $121{ }^{\circ} \mathrm{C}$. The test was terminated after 15 hours of operation. Again, water loss resulted in the gradual shrinkage of the sludge layer. Salt deposits were observed to form on the surface of the sludge in the vicinity of the heater and, as time progressed, at surface locations remote from the heater. The normal glassy, bluish-gray color of the sludge turned to gray in the surface region above the heater. An examination of this surface region at the end of the test indicated that the sludge material was still wet just beneath the surface. Approximately $22 \%$ of the water was lost to evaporation. 


\subsection{LARGE-SCALE EXPERIMENTAL RESULTS ON DRYOUT IN SIMULANT WASTE SLUDGE HEATED LOCALLY}

The purpose of the series of tests reported in this section was to extend the small-scale experiments discussed in the foregoing on such a scale as to be more full sized and give confidence that the results could form a firm basis upon which to estimate scenarios in actual tanks.

Heaters for this experiment consisted of sheathed resistance units $3 \mathrm{~mm}$ in diameter, and a heated length of $244 \mathrm{~cm}$ for a total heated area of $243 \mathrm{~cm}^{2}$. The heaters were coiled in a horizontal plane with about $3 \mathrm{~cm}$ between successive coils to a total diameter of $30 \mathrm{~cm}$. The non-heated end of the coil was bent at a right angle so that the electrical connections would be above the simulant material. Four heaters were used with $13-\mathrm{cm}$ vertical spacing between heaters, the bottom one being $6 \mathrm{~cm}$ above the tank bottom and the top being $15 \mathrm{~cm}$ below the simulant surface. Standard Type K sheathed (1.5-mm-diameter) thermocouples were used. Calibration with ice water and boiling water showed them to be no more than 1 degree in error at 0 and $100{ }^{\circ} \mathrm{C}$ as read at the data recorder.

Three thermocouples were arranged along the vertical centerline of the heater array and three others at the mid-plane of the tank at various radii. Figure 5-15 illustrates the arrangement and gives critical dimensions of both heaters and thermocouples. A cage was made of $1 / 2$-in. stock sheet acrylic plastic to retain the heaters and thermocouples in their selected geometry while the simulant was being placed around them. The cage also facilitated mechanical anchoring of the hardware. Because it was open in design and had no part more than $1 / 2$ in. $x 1 / 2$ in., it minimized any thermal variations in the simulant. Figure 5-16 is a photograph of the cage, heaters, and thermocouples as assembled and just before placement of the clay simulant mixture.

The simulant and heaters were contained in a galvanized steel stock-watering trough $90 \mathrm{~cm}$ in diameter and $60 \mathrm{~cm}$ deep. After the heater cage was placed in the center, the tank was filled with $703 \mathrm{~kg}$ of a $45 \%$ water and $55 \%$ kaolin mixture by weight. The mixture can best be described as have the consistency of peanut butter; because of this consistency, a concrete vibrator was required to help flow the mixture into the tank. A plastic cover was placed over the material and taped to the sides so that evaporation water could not escape from the top surface.

After the tank was filled, the cage was about $3 \mathrm{~cm}$ off center. However, the relative placement of the thermocouples and the heaters was unchanged and the radial thermocouples were still on a 46-cm-long radius, so the effect of the off-center cage was ignored. 
Figure 5-15. Large-Scale Test Section Indicating

Locations of Coiled Immersion Heaters and Thermocouples.
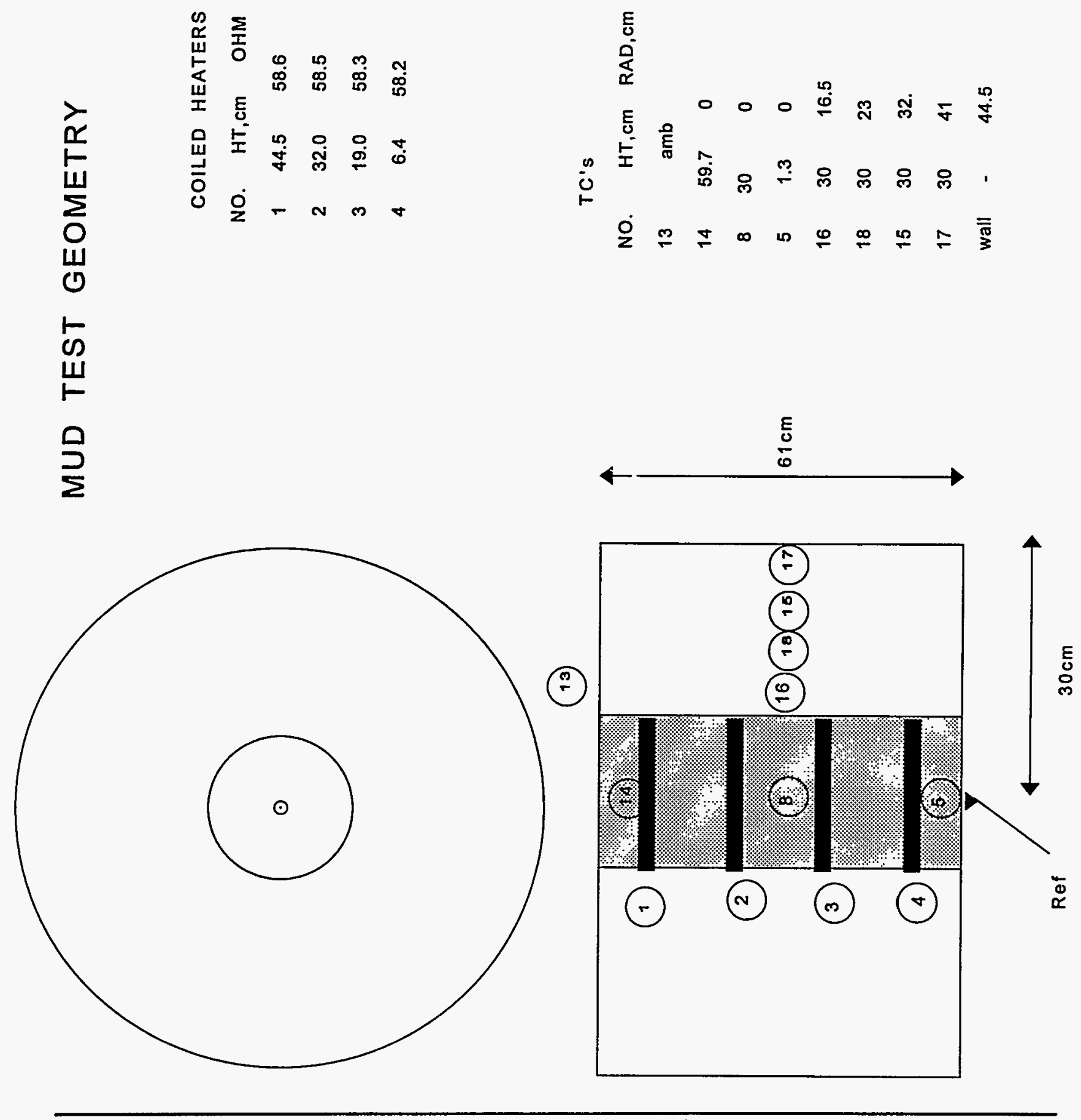
Figure 5-16. Photograph of Heater and Thermocouple Arrangements in Large-Scale Kaolin Tank.

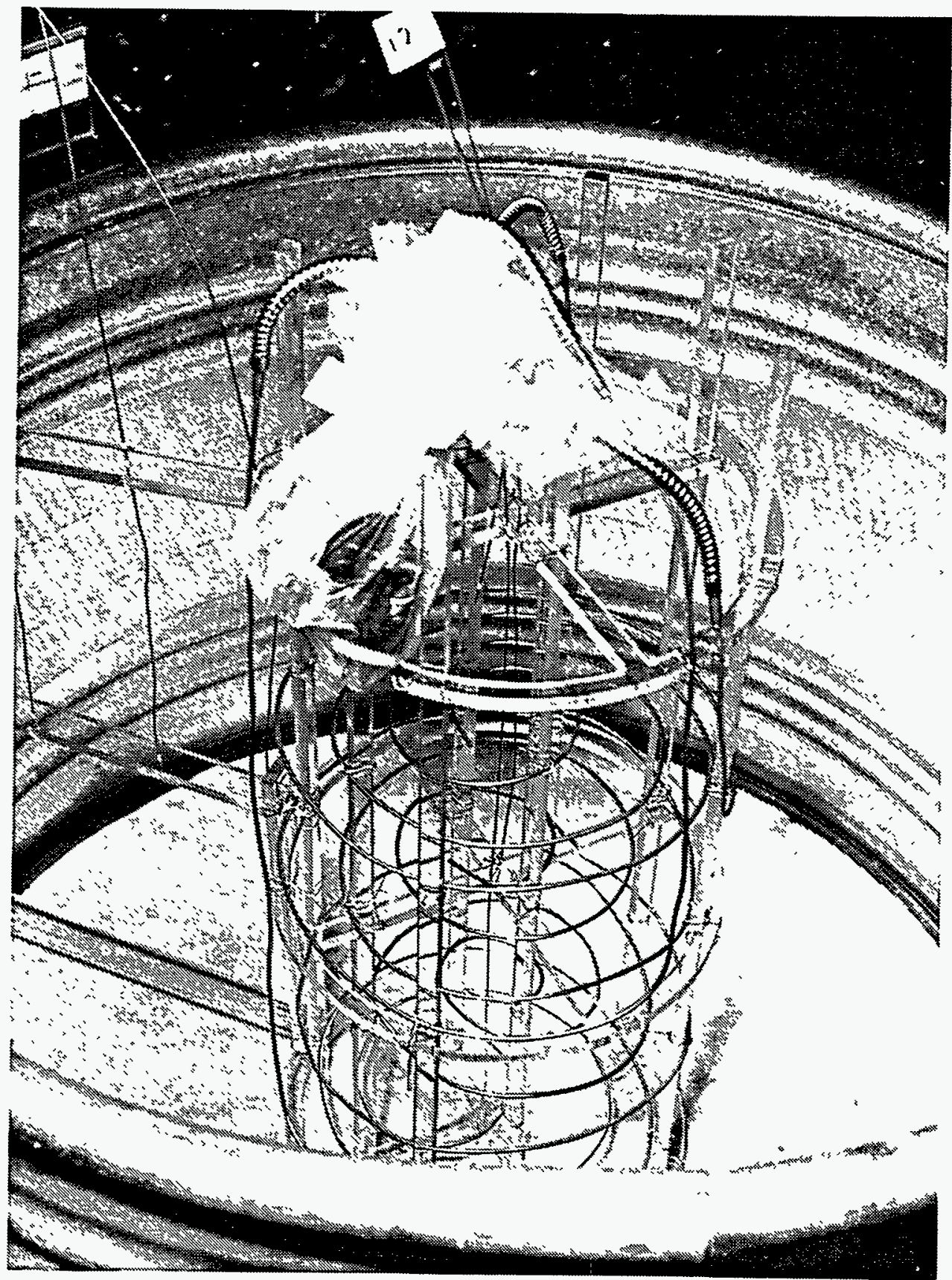




\subsubsection{Calibration Run}

The first large-scale tank experiment was conducted by starting the four heaters at about 30 to $33 \mathrm{~W}$ each for a total $127 \mathrm{~W}$ for the array. This energy input was maintained at a constant value by the use of variable transformers for a number of days. Figures 5-17 and 5-18 show the results. The surface heat flux from the heaters was about $1.3 \times 10^{3} \mathrm{~W} / \mathrm{m}^{-2}$ and the power density for the $30 \times 61-\mathrm{cm}$ cylindrical region of coiled heaters was $2.85 \mathrm{~W} / \mathrm{L}$. These values are both noticeably lower than used in the small-scale experiments reported in Section 5.3, but are higher than the actual waste tank averages by a factor of 300 to 3,000.

A computer model of this experiment was constructed using a cylindrical relaxation grid of 1.3-cm cells in both vertical and radial directions and a time step increment of $1 / 100$ hour. The computer program was run to show the temperature history of the tank at any of several locations. All of the pertinent constants such as heat capacity, thermal conductivity, density, and transfer coefficients were varied to achieve the best match to the measured thermal contour lines. A best fit was obtained with reasonable thermophysical sludge property values and heat-transfer coefficients, indicating that conduction dominates the heat transfer within the sludge.

A check of actual water content was made at the start of the test. At the mid-plane of the array near the heaters, the water content was $44 \%$ at about $54{ }^{\circ} \mathrm{C}$, and near the outer wall, $43.6 \%$ at about $35^{\circ} \mathrm{C}$. The water content of a portion of the original test simulant material kept in a storage can was $44.4 \%$ at $23^{\circ} \mathrm{C}$. It appears that some water loss occurred during mixing, but no significant variation occurred within the heated volume.

\subsubsection{Boiling Experiment}

After steady state conditions were reached in the calibration experiment the power level was raised to $380 \mathrm{~W}$ to determine the system's behavior while boiling was occurring in the heated volume. Within a day, it was obvious that boiling was taking place. Faint but distinct bumping noises could be heard, similar to those made by a full boiling pan of water on a stove. The central thermocouple rapidly rose to about $101^{\circ} \mathrm{C}$ and continued at that value. Within a few days, vent holes could be seen in the simulant. The pulsing movement and high relative temperature of the plastic over these holes indicated that considerable amounts of steam were being vented from the sludge. As the temperature history showed (see Figures 5-19 and 5-20), the vent paths occasionally changed on an irregular basis.

A check of the actual water content was made at the start of the test. At the mid-plane of the array near the heaters, the water content was $41.54 \%$ at about $101{ }^{\circ} \mathrm{C}$, and $43.2 \%$ at about $46^{\circ} \mathrm{C}$ near the outer wall. It appears that very limited moisture variation occurred within the heated volume. 
Figure 5-17. Measured Temperature-Time Histories at Various Vertical Locations Along Centerline of Large-Scale Tank During Calibration Run.

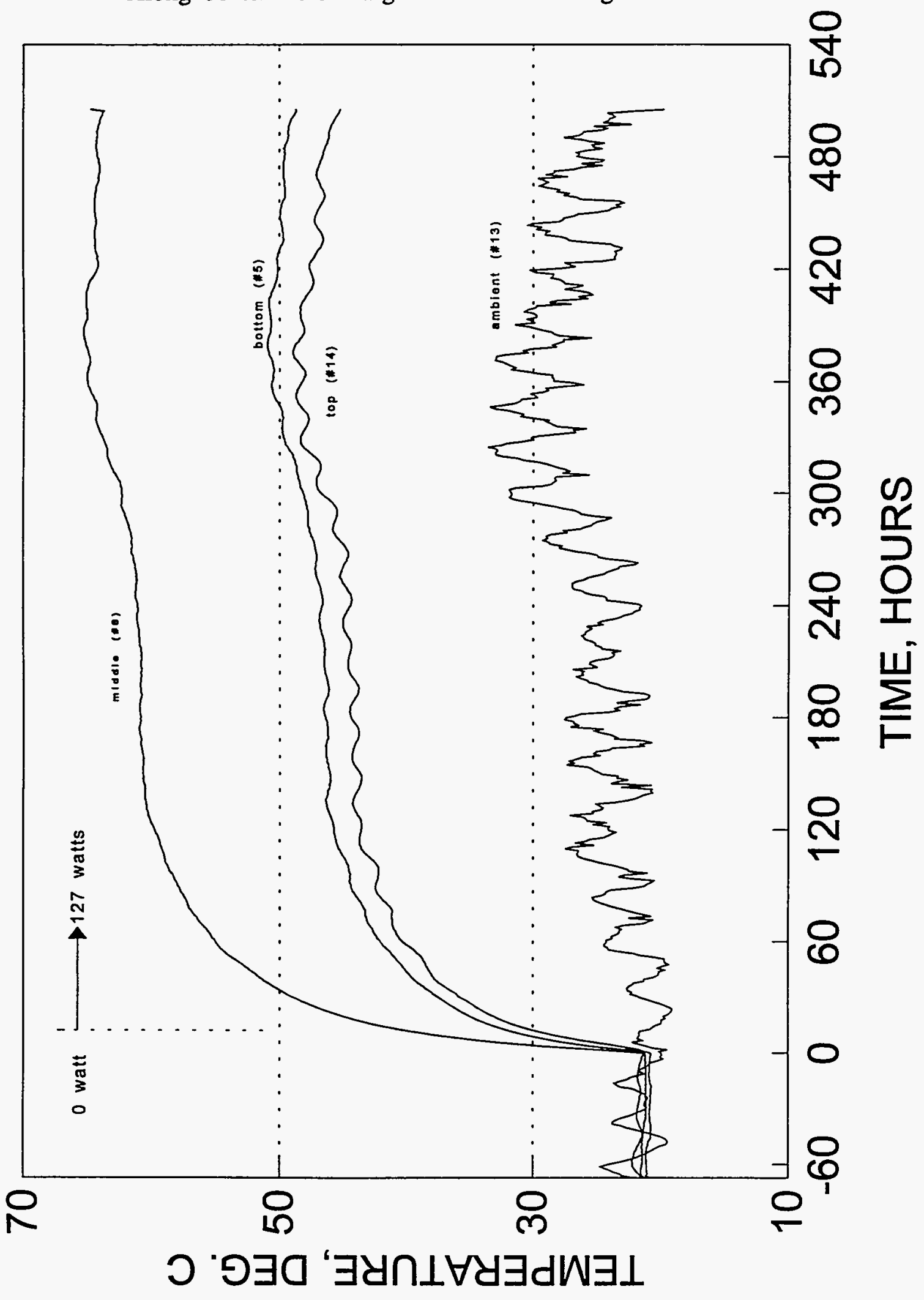


Figure 5-18. Measured Temperature-Time Histories at Various Radial Locations in Large-Scale Tank During Calibration Run.

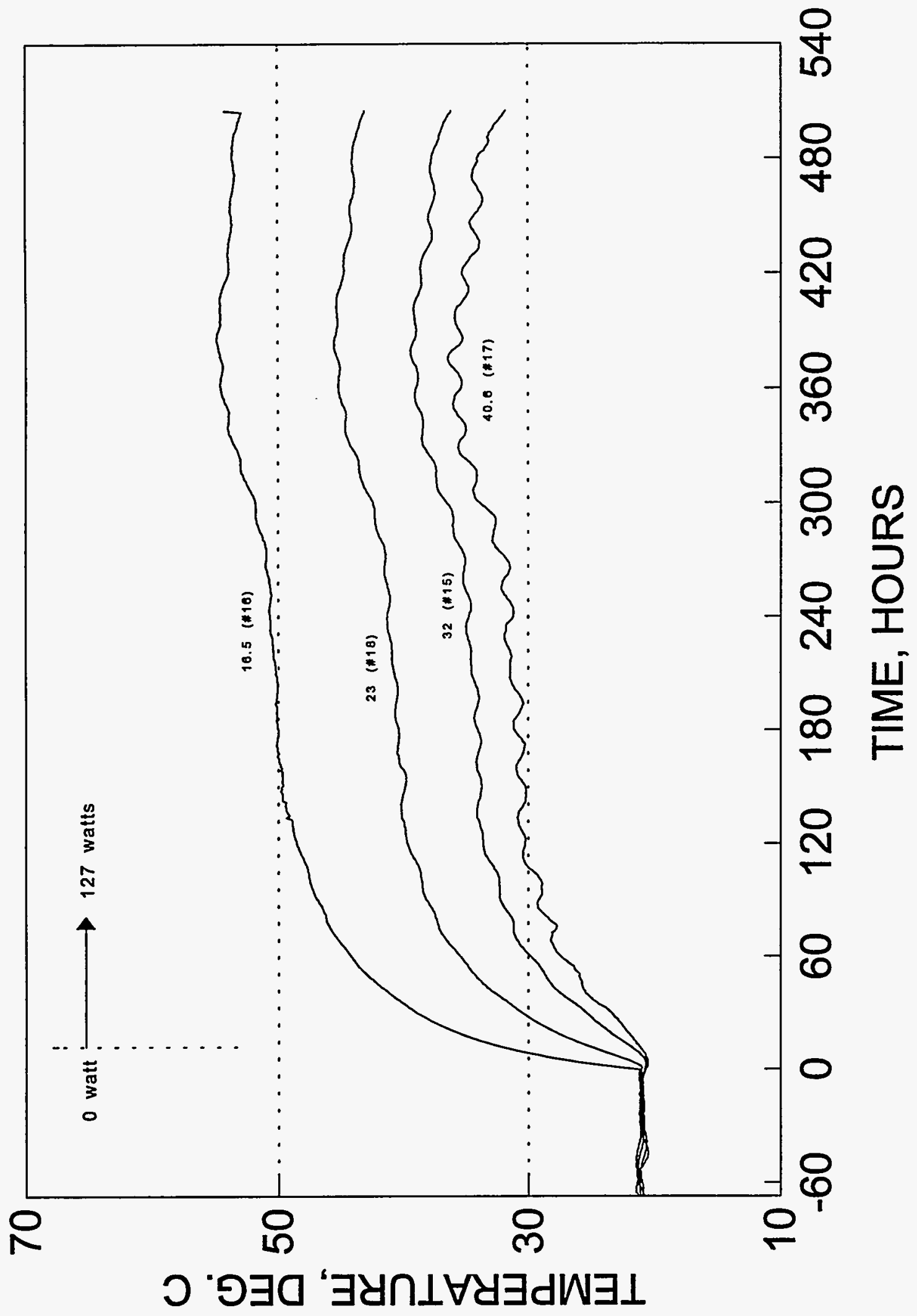


Figure 5-19. Measured Temperature-Time Histories at Various Locations Along Centerline of Large-Scale Tank During Boiling Experiment.

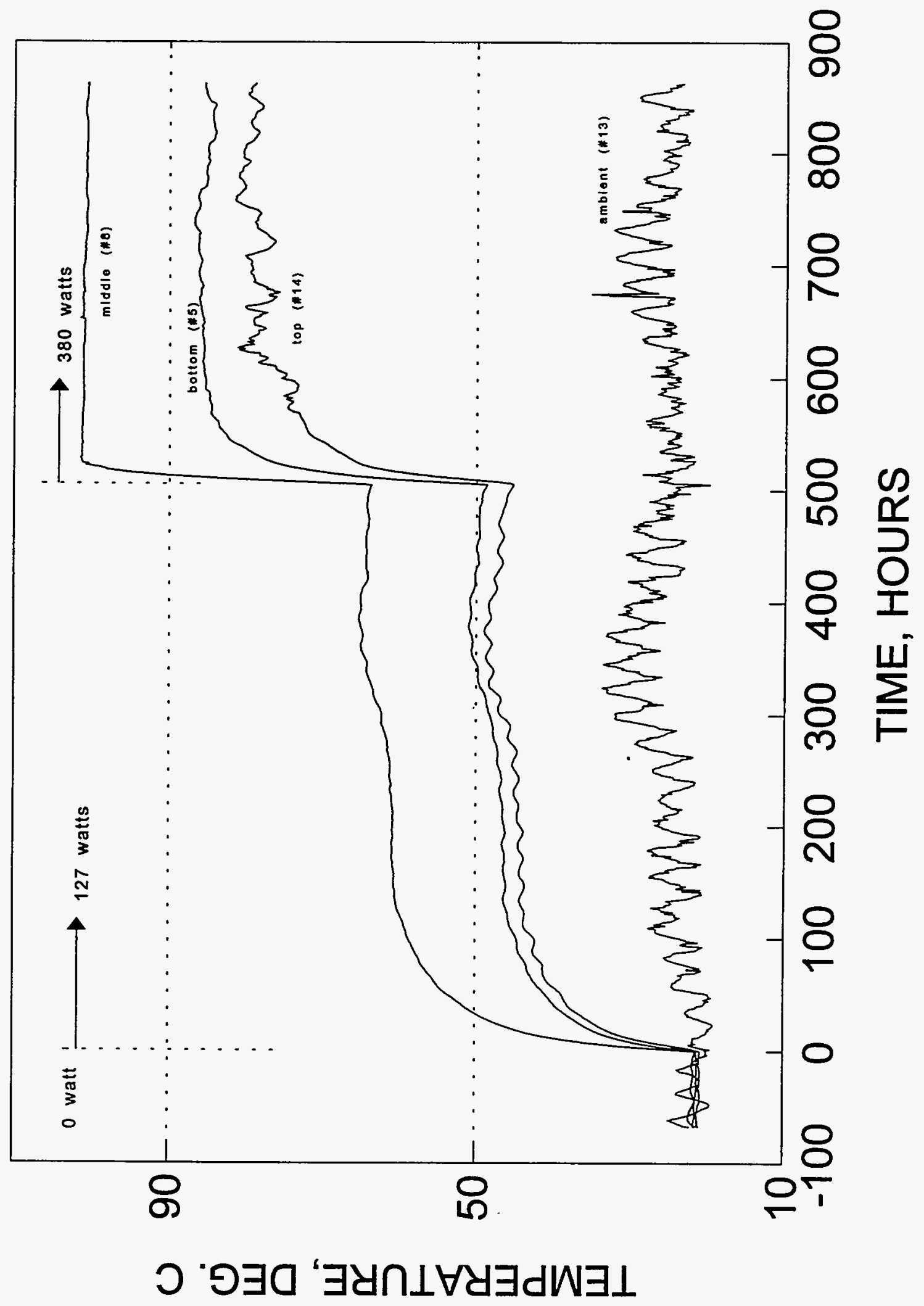


Figure 5-20. Measured Temperature-Time Histories at Various Radial Locations in the Large-Scale Tank During Boiling Experiment.

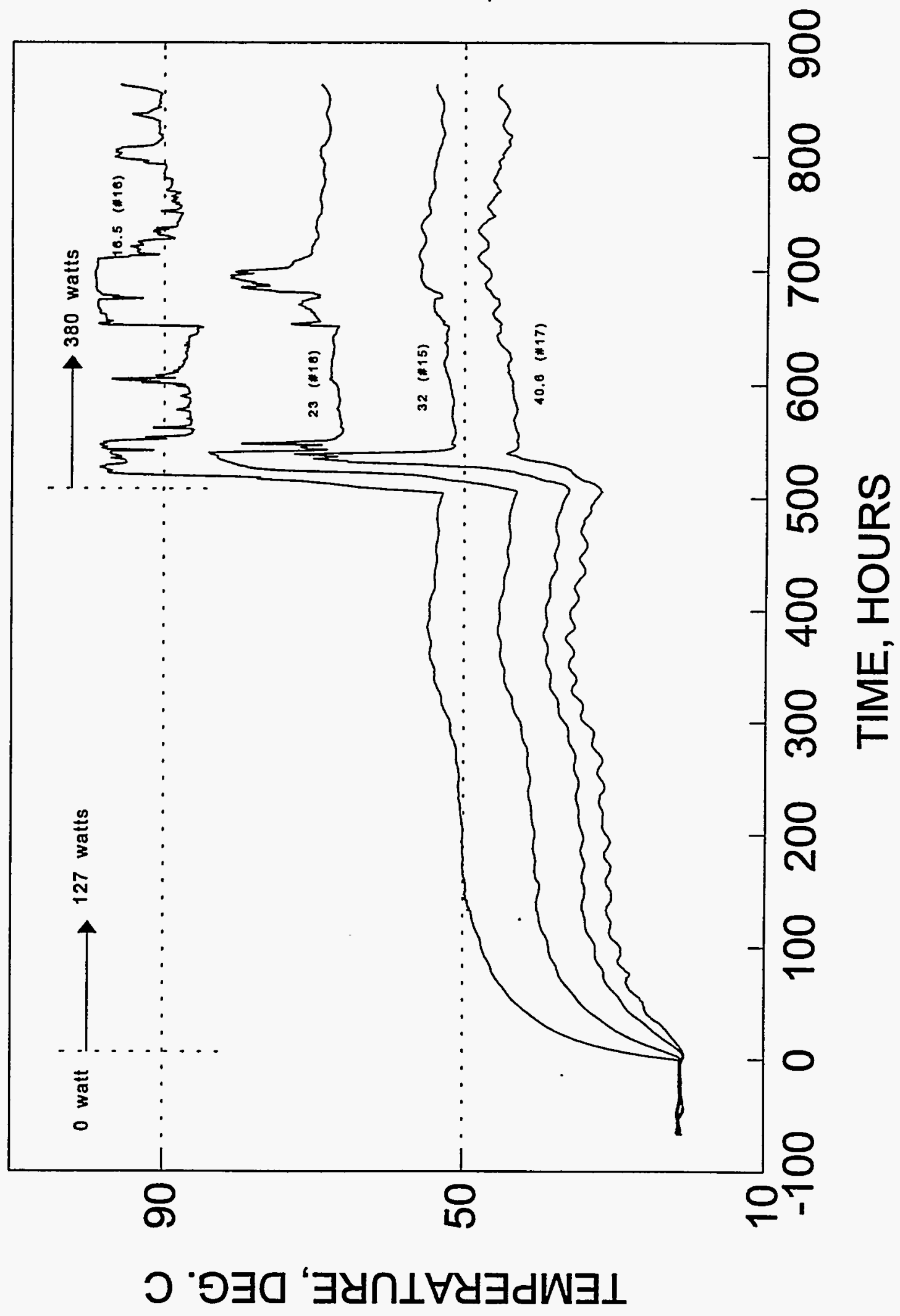




\subsubsection{Water Migration Experiment}

As mentioned previously in this report, one of the postulated mechanisms of local dryout is based on the appearance of a warm spot near the surface of the sludge. If some accumulation of radionuclides were to occur at or near the surface, then water could evaporate over that area, recondense on the tank ceiling or on the cooler portions of the surface and be returned to some other area of the tank. The net result could be a drying out of some volume without ever reaching boiling or phase change within the warm area and without net removal of water from the tank. This scenario was tested in the small-scale laboratory program (see Section 5.3.5) and has been tested in the large-scale tank by re-configuring the simulant kaolin sludge. After a modest cooling period, the top several inches of simulant were removed, leaving $8 \mathrm{~cm}$ of material over the top of the top (\#1) heater. The other three heaters remained in place but were not operated. Thermocouples were moved so that one was at the center of the horizontal plane of the active heater and another was $2.5 \mathrm{~cm}$ above it. Plastic sheeting was used to make a tent with low spots at the outer edge so that condensate would return to the edge and not the center heated area. The heater was operated at $63 \mathrm{~W}$ (top surface heat flux $860 \mathrm{~W} / \mathrm{m}^{2}$ ) for over 1,000 hours. On a weekly basis, samples of the kaolin clay were taken just under the surface over the heater and near the edge of the tank. A third sample was usually taken at the edge near the bottom of the tank; presumably this sample was at the same temperature as the one above it and differed only by the $61 \mathrm{~cm}$ of hydraulic head. These samples were oven dried to determine moisture content as a function of time and position. Table 5-2 gives the results as weight percent water.

Table 5-2. Sample Results in Water Migration Experiment: Weight Percent Water.

\begin{tabular}{|l|c|c|c|c|c|c|c|c|}
\hline \multirow{2}{*}{ Location } & \multicolumn{7}{|c|}{ Elapsed time, hours } \\
\cline { 2 - 10 } & zero & 164 & 404 & 500 & 739 & 837 & 1051 & 1197 \\
\hline $\begin{array}{l}\text { Center } \\
\text { Surface }\end{array}$ & 40.9 & 39.4 & 39.2 & 38.0 & 38.5 & 39.2 & 40.1 & 39.0 \\
\hline Edge Surface & 41.8 & 41.1 & 40.7 & 41.3 & 41.3 & 41.7 & 40.7 & $\begin{array}{l}42.7 \\
43.6\end{array}$ \\
\hline Edge Bottom & - & 42.3 & 43.7 & 42.4 & 42.3 & 41.6 & 43.1 & 41.1 \\
\hline
\end{tabular}

At $63 \mathrm{~W}$, all the water in a volume extending from $7.6 \mathrm{~cm}$ directly above and $7.6 \mathrm{~cm}$ directly below the heater could be boiled off every 106 hours. This implies that the water inventory is turning over rapidly but showing little or no net change. 
Figures 5-21 and 5-22 show a portion of the temperature history of the test. Inspection showed that the heated volume of clay was well below boiling and that the ullage volume of captured air was warm enough to promote reasonable vapor transfer. Visual inspection of the surface showed drip marks in the clay at the outer perimeter but no significant puddling of water, despite some unevenness in the surface. There were a few cracks in the outer areas (but no obvious ones over the heater) $0.63 \mathrm{~cm}(1 / 4$ in.) deep by $0.16 \mathrm{~cm}(1 / 16 \mathrm{in}$.) wide totaling 51 to $76 \mathrm{~cm}$ ( 20 to $30 \mathrm{in}$.) in length.

Table 5-2 shows the moisture analysis over the course of the test. Within the accuracy of the determination (estimated at $\pm 0.5 \%$ ), it is difficult to see any trend. A linear regression analysis was performed on the data and showed the slope of the water content vs. time to be essentially zero with a low correlation coefficient $\left(r^{2}<0.3\right)$. The differences between warm and cool surfaces never exceed $2 \%$, which is similar to the top-to-bottom difference at the edge of the test tank. Whatever the water return mechanism is, it is certainly sufficient to match the power density over the heated volume, which is 600 to 6,000 times the average of a real waste tank. Crippen's (1994) tests clearly show that it is difficult to achieve dryout on a large scale and that water from $0.5 \mathrm{~m}$ away is available in a surprisingly short time to cool a hot spot.

Application to the waste tanks of the experiments described in Sections 5.3 and 5.4 is discussed in Section 6-4.

\subsection{RHEOLOGICAL PROPERTIES OF FERROCYANIDE WASTE TANK SIMULANTS COMPARED WITH PROPERTIES OF WASTE TANK SAMPLES}

The experimental studies presented in the foregoing provide important information on the high moisture retention capacity of simulant sludge materials. However, before concluding that actual waste tank sludge is just as resistant to local dryout as the simulant sludges, it is prudent to compare the relevant physical properties of the simulant sludges used in the present study with those of waste tank samples to ensure that their rheologies are the same.

The ferrocyanide simulant sludges were prepared using the same materials and procedures as were used in the treatment of tank waste in order to produce a product as similar as possible to the ferrocyanide waste added to the tanks in the 1950s. However, variation from tank properties may result from uncertainties as to composition of the originally treated tank waste, settling of the tank sludge by gravity over a longer time and at a larger scale, mixing of other types of waste added on top of the ferrocyanide layer, and aging reactions. The simulants contained nitrite in place of part of the nitrate to model that formed in the tanks by radiolysis. The waste simulants contained no uranium or fission products. 
Figure 5-21. Measured Temperature-Time Histories at Various Vertical Locations Along Centerline of Large-Scale Tank During Water Migration Test.

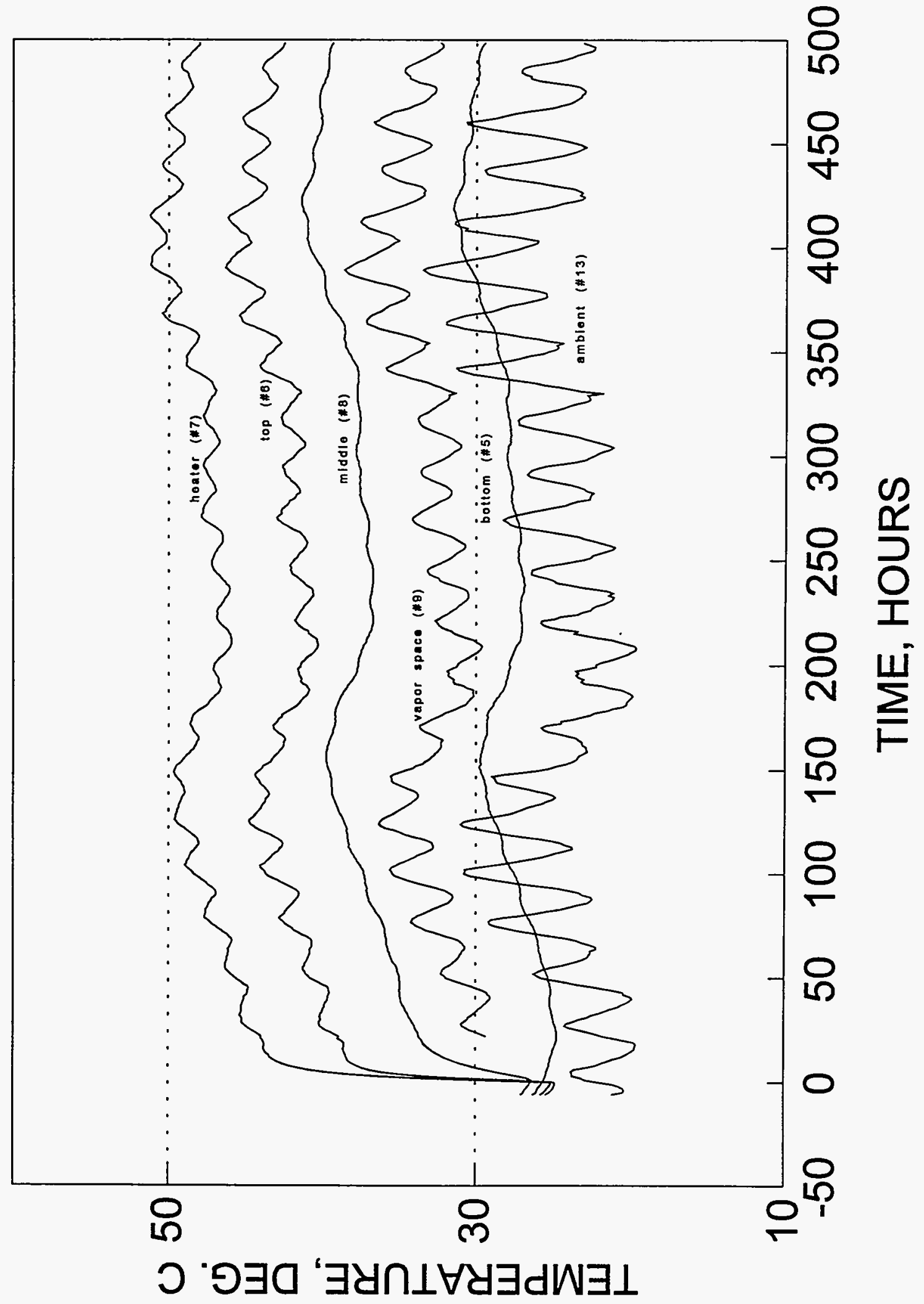


Figure 5-22. Measured Temperature-Time Histories at Various Radial Locations in Large-Scale Tank During Water Migration Test.

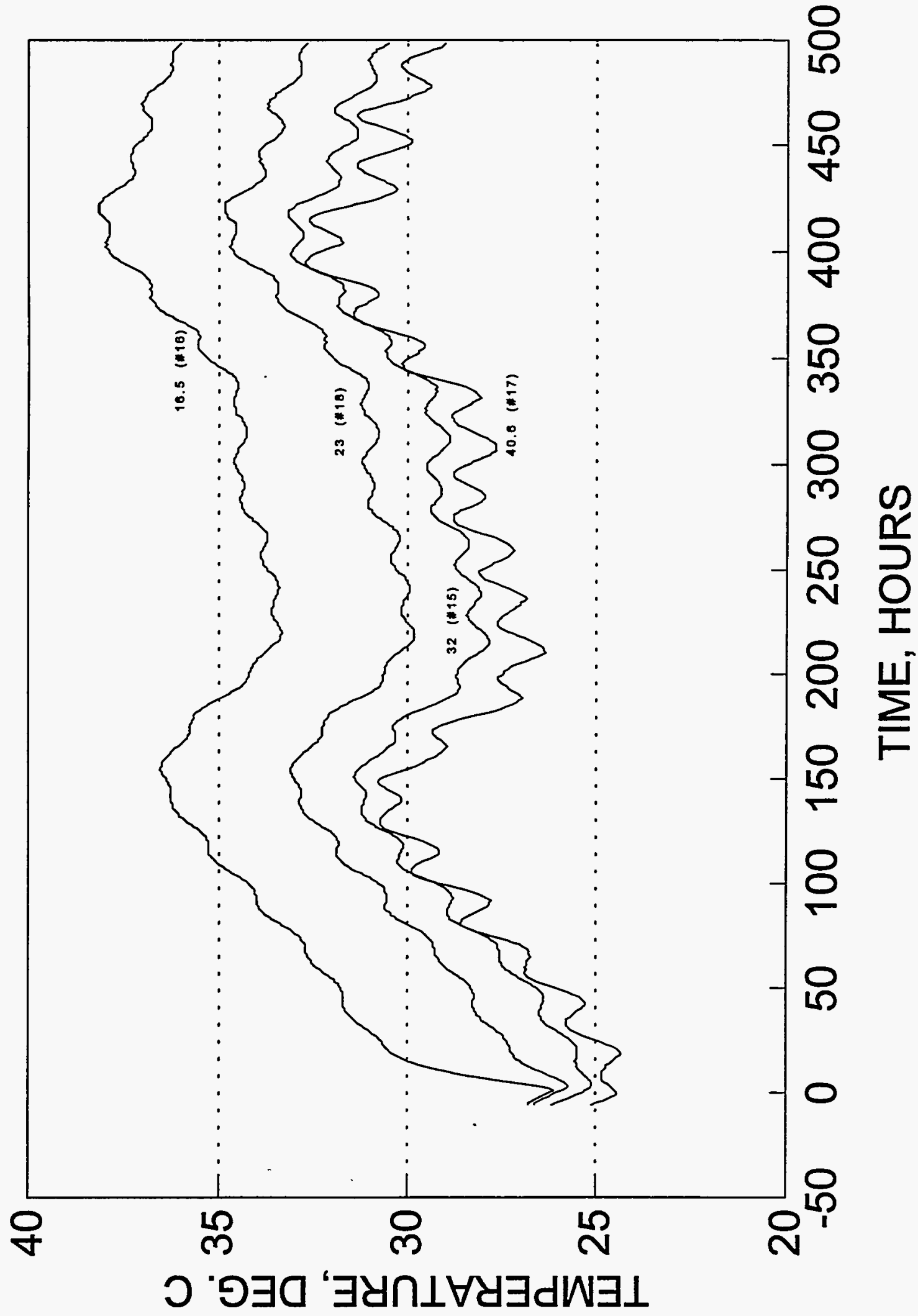


Particle size is one of the more important parameters in determining rheological properties. The particle size distributions have been measured for the simulant sludges and for tank samples using the same methods of measurement. The median particle sizes are given in Table 5-3. Tank samples are, as yet, available only for C-109 and C-112, which were filled with In Farm sludge, and T-107, which was filled with U Plant sludge. The number median diameters are very small, less than $1.0 \mu \mathrm{m}$, and are comparable for the simulant sludge and tank samples. There is greater variation in the volume median diameters; this may be caused by agglomeration during measurements, which was hard to control.

Table 5-3 also includes data for the kaolin clay used in the FAI tests and in the larger-scale tests at the Hanford Site. The kaolin had number median diameters about 1.6 times those of the tank samples. The particle sizes given in Table 5-3 are believed not to be true primary particle sizes, but to represent some degree of agglomeration. The degree of agglomeration will depend on the dispersant liquid used. This is a water-glycerol mixture for the tank samples, mother liquor for the In Farm and U Plant simulant sludges, and water for the kaolin.

The water content of a sludge will also effect its rheology. The measured water contents of the simulant sludge and of tank samples are given in Tables 2-1 and 2-2, respectively. The samples from C-109 average $36 \%$ water, those from C-112 average $52 \%$ water, and the In Farm simulant sludge is $50 \%$ water.

The general characteristics of the C-109 tank samples have been described (Simpson et al. 1993b) as follows. "The samples had a firm consistency. They were thick cohesive sludges that held their shape after extrusion (removal from sampling device). The core materials all appeared to be saturated with liquid." The description of the C-112 samples (Simpson et al. 1993a) reads, "The samples also ranged in consistency from thin and slurry to very thick, chunky sludge. They appeared to be saturated with liquid. The samples slumped somewhat, but held their shape relatively well (high viscosity, non-Newtonian fluids)."

A shear strength of 17,300 dynes $/ \mathrm{cm}^{2}$ was measured for a sample of C-109 sludge; 16,000 dynes $/ \mathrm{cm}^{2}$ for $\mathrm{C}-112$. The shear strength of U Plant 1 sludge was $>10,000$ dynes $/ \mathrm{cm}^{2}$.

The chemical composition of the sludge liquid may affect rheology through its electrolytic properties. The composition of the drainable liquid from samples from C-109 and C-112 is compared in Table 5-4 to that of In Farm simulant sludge, because these tanks received sludge from the In Farm process. Concentration is shown for the dominant anions; in all cases, sodium was the only cation in significant concentration. The tank samples are lower in nitrate than the simulant sludge; this may be caused by destruction of nitrate in the tanks by radiolysis and slow oxidation of ferrocyanide. Nitrite and sulfate concentrations are similar; phosphate is low in the simulant sludge. 
Table 5-3. Particle Sizes of Tank and Simulant Sludges.

\begin{tabular}{|l|c|c|l|}
\hline \multirow{2}{*}{ Sludge } & \multicolumn{2}{|c|}{ Median Particle Diameter, $\mu \mathrm{m}$} & \multirow{2}{*}{ Reference } \\
\cline { 2 - 3 } & By Number & By Volume & \\
\hline C-109, Core 47 & 0.85 & 39 & Simpson et al. 1993b \\
Core 48 & 0.77 & 3 & Simpson et al. 1993b \\
Core 49 & 0.90 & 24 & Simpson et al. 1993b \\
\hline C-112, Core 34 & 0.76 & 6.0 & Simpson et al. 1993a \\
Core 34 dup. & 0.83 & 6.3 & Simpson et al. 1993a \\
Core 36 & 0.84 & 33 & Simpson et al. 1993a \\
\hline T-107, Core 50 & 0.85 & 33 & Sasaki and Valenzuela \\
& 0.76 & 14 & Jeppson and Wong 1993 \\
\hline In Farm 1 Simulant & 0.76 & 15 & Jeppson and Wong 1993 \\
\hline In Farm 2 Simulant & 0.80 & 4.1 & Jeppson and Wong 1993 \\
\hline U Plant 2 Simulant & 1.40 & 24 & Bechtold 1994 \\
\hline Kaolin (FAI Tests) & 1.33 & 6.8 & Bechtold 1994 \\
\hline Kaolin (WHC Tests) & & & \\
\hline
\end{tabular}

Table 5-4. Composition of Liquids in Tank and Simulant Sludges (Normality).

\begin{tabular}{|c|c|c|c|c|c|}
\hline & \multicolumn{2}{|c|}{ Simulant Sludges } & \multicolumn{3}{c|}{ Tank Samples } \\
\cline { 2 - 6 } & In Farm 1 & In Farm 2 & $\begin{array}{c}\text { C-109 } \\
\text { Composite }\end{array}$ & $\begin{array}{c}\text { C-112 } \\
\text { Core 34 }\end{array}$ & $\begin{array}{c}\text { C-112 } \\
\text { Core 35 }\end{array}$ \\
\hline $\mathrm{NO}_{3}$ & 4.5 & 3.8 & 1.3 & 1.4 & 1.3 \\
\hline $\mathrm{NO}_{2}$ & 1.5 & 1.3 & 1.8 & 1.4 & 1.4 \\
\hline $\mathrm{PO}_{4}$ & 0.1 & 0.1 & 0.5 & 0.4 & 0.6 \\
\hline SO & 0.2 & 0.2 & 0.3 & 0.3 & 0.3 \\
\hline TOTAL & 6.3 & 5.4 & 3.9 & 3.5 & 3.6 \\
\hline pH & 8.7 & 9.4 & 12.1 & 10.3 & 10.5 \\
\hline Density, g/mL & 1.3 & 1.3 & 1.2 & 1.2 & 1.4 \\
\hline Reference & $\mathrm{a}$ & $\mathrm{a}$ & $\mathrm{b}$ & $\mathrm{c}$ & $\mathrm{c}$ \\
\hline
\end{tabular}

Jeppson and Wong 1993

'Simpson et al. 1993b

'Simpson et al. 1993a 
Table 5-4 also compares the density and $\mathrm{pH}$ of the sludge liquid. The density is comparable, but the $\mathrm{pH}$ is higher (10 to 12$)$ in the tank samples than in the simulant (9). This may be caused by the addition of high-pH cladding waste on top of the ferrocyanide. Since the only tank samples are core composites, it is not known how much this high $\mathrm{pH}$ penetrated into the ferrocyanide.

The simulant sludges model the ferrocyanide sludge as it originally settled in the waste tanks. Because the sludge has been stored for more than 30 years, subjected to radiation and often to elevated temperatures, aging reactions may have occurred to change its chemical composition. The principal aging reaction identified is destruction of the ferrocyanide by radiolysis and hydrolysis. Laboratory studies of simulant sludges have shown that such reactions do occur (Lilga et al. 1993). The tank samples from C-109 and C-112 showed ferrocyanide concentrations (as calculated from energy release) that were only a small fraction of that of the In Farm sludge originally added (Simpson et al. 1993a, 1993b). However, dryout of sludge with the low ferrocyanide concentrations found in the C-109 and C-112 samples would be of no concern, because it is too dilute to sustain a propagating reaction even if completely dry (Postma et al. 1994). The only concern with ferrocyanide reactions is for unsampled tanks or regions of tanks in which it is unknown whether aging reactions proceeded as far as in the samples taken to date. In this respect, then, the unaged simulant sludges are good simulants for the tank waste of greatest concern. 


\subsection{WATER RETENTION CAPABILITY OF SLUDGE AND THE UNLIKELTHOOD OF LOCAL DRYOUT}

As mentioned in Section 1.0, three mechanisms that may result in local dryout followed, perhaps, by the overheating of the precipitate, have been postulated: 1) sludge drying by boiling of interstitial liquid in a "hot spot" of concentrated heat generating radionuclides; 2) drainage of interstitial liquid; and 3) dryout of a warm (surface) region by local evaporation. Recall that Mechanism 2 is usually considered a global dryout mechanism but is more conveniently discussed in this section on local dryout. While the experiments reviewed in Section 5.0 clearly illustrate the difficulty of achieving local dryout via draining or by evaporation or boiling in small- and large-scale sludges, it is useful to discuss what is known on a more fundamental level about the water retention capabilities of ferrocyanide sludge. Accordingly, in the next subsection (Section 6.1), the concept of sludge effective stress and the related sludge "consolidation curve" is introduced. Once the consolidation curve is understood the experimental results described in Section 5.0 can be quantitatively explained, at least from a macroscopic point of view, and mechanisms 1 through 3 can readily be dismissed as credible modes of waste dryout.

\subsection{CONSOLIDATION PRINCIPLES}

As mentioned previously, sludge may be viewed as a concentrated (aqueous) suspension of fine precipitate particles produced from a dilute chemical suspension by gravitational settling. Once the settling process is essentially over, such suspensions do not form a rigid porous medium like packed sand but, instead, the particles are brought to rest and form a non-rigid configuration in that the particles may not touch each other or they may be in point contact but still be free to rotate relative to one another. The packed state is prevented because when the particles are small and within close proximity of one another, the particle field is influenced strongly by electrostatic forces. In an aqueous concentrated suspension there are two main opposing forces that act on the particles: an electrostatic repulsion force and the van der Waals attractive force. More details regarding the roles played by these forces in stabilizing the suspension against gravity can be found in the classic work of Verwey and Overbeek (1948) or in the review articles of Tadros (1980) and Russel (1980).

The fact that there are repulsive forces that hold suspension particles apart means that work must be done or forces must be applied in order to reduce the bulk volume of the stabilized suspension below that volume reduction already accomplished by gravity. This reduction in suspension volume is referred to as consolidation and, of course, is accompanied by liquid expulsion from the suspension, assuming that the space between particles is liquid filled (saturated). . The shrinking of a concentrated suspension under the influence of gravity (self-weight of the suspension) is also a consolidation process.

The physics of the consolidation of concentrated suspensions is discussed commonly in most soil mechanics texts (e.g., Taylor 1948, Yong et al. 1992). Consider the experimental 
apparatus shown in Figure 6-1, known as a consolidation cell. A concentrated and saturated suspension of fine particulate and known bulk volume and liquid content is placed in a column and is supported from below by an outflow porous disk through which liquid may flow but not the particulate. The upper surface of the suspension is in contact with a piston. A pressure transducer penetrates the side of the column and is used to measure the liquid (pore) pressure, $\mathrm{p}$, within the suspension. When a downward force is applied to the piston in Figure 6-1, the suspension is compressed by the applied load (stress or pressure, P) and the interstitial liquid begins to flow through the porous disk. Because the volume change within the suspension is initially zero due the inability of water to move rapidly, the pore water pressure is initially equal to the applied load; i.e., $p=P$. The increased difference between the pore water pressure and the atmospheric pressure outside the cell causes liquid to be expelled through the porous disk. The liquid flows out until the liquid pressure inside the suspension becomes equal to the atmospheric pressure outside. During this period of liquid expulsion and decreasing pore pressure, the load is being increasingly borne by the repulsive forces between particles. Ultimately, the repulsive forces between particles will counter the imposed pressure $P$, liquid will stop flowing out, and an equilibrium bulk volume of the suspension is arrived at. The volume of the suspension decreases by an amount equal to the volume of the liquid expelled under the compression of the applied load. This process is called consolidation.

The instantaneous difference between the applied pressure $P$ and the pore-liquid pressure $p$ is the effective stress $\sigma$ :

$$
\boldsymbol{\sigma}=\mathbf{P}-\mathbf{p} .
$$

The effective stress is the component of the applied pressure $P$ that acts to force particles together; it is often referred to in the literature on concentrated suspensions as the "particle pressure". Effective stress $\sigma$ at a location can increase if either the applied pressure increases or the pore-liquid pressure decreases. An increase in $\sigma$ causes consolidation wherever it occurs, provided the suspension is not already compressed to its maximum density. At its maximum density it will form a solid material, no longer able to shrink, but still retaining a certain quantity of chemically bound or hydrited water.

The applied load (pressure) above the suspension may be increased incrementally. At each state of increased pressure, the interstitial liquid is expelled until the suspension returns to hydrostatic equilibrium with the applied pressure. Again, in the apparatus shown in Figure 6-1, pore-liquid pressure equals atmospheric pressure when equilibrium is reached. A curve can now be constructed that gives the relationship between the liquid content and the effective stress measured at each equilibrium state. This curve is known as the consolidation curve. It should be noted that consolidation curves are also obtained in the laboratory by placing the sample suspension in a centrifuge and measuring the effective stress and liquid expelled at incrementally increased g's. 
Figure 6-1. Schematic of Consolidation Cell for Measurement of Effective Stress $\sigma=\mathrm{P}-\mathrm{p}$.

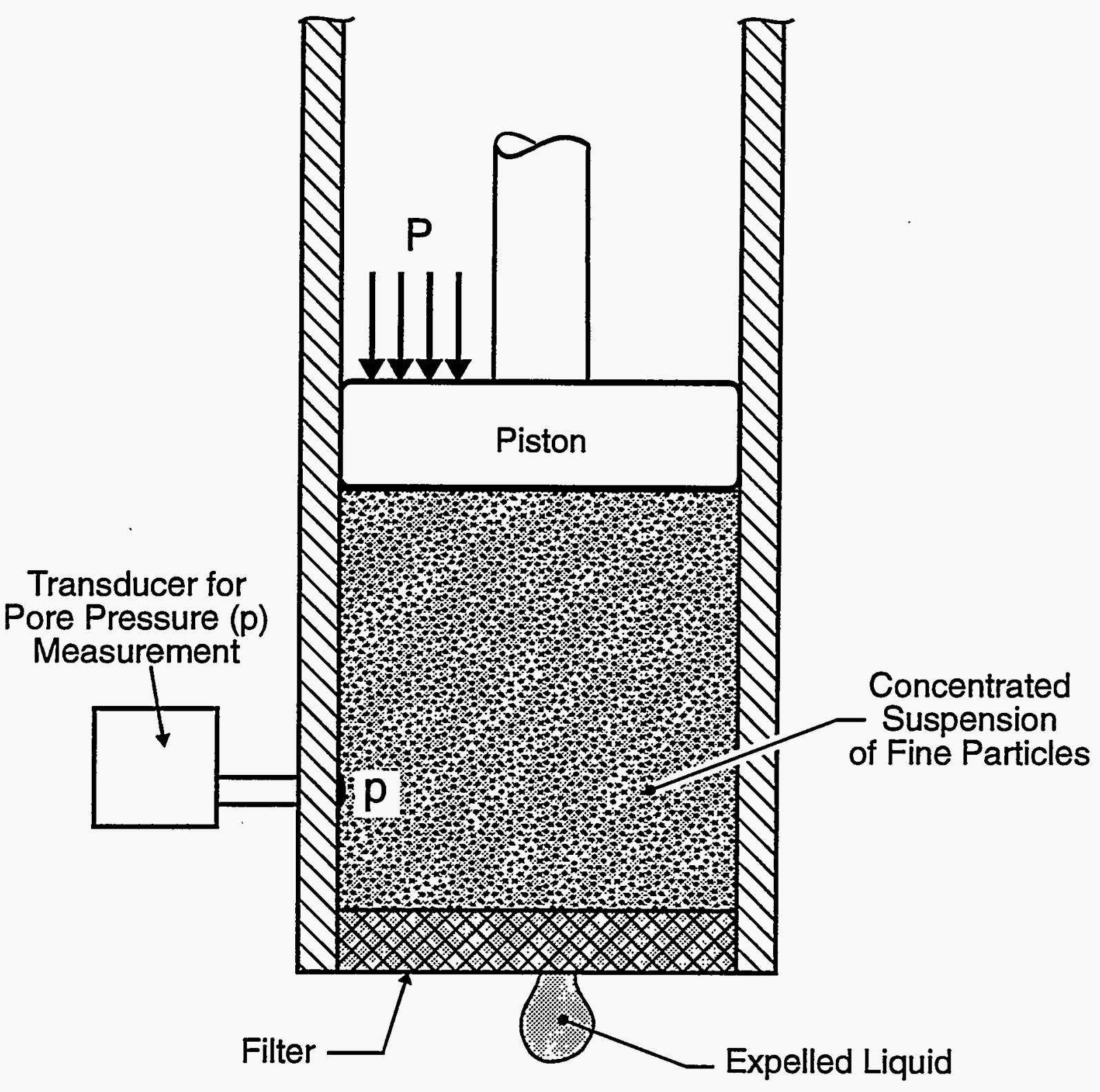

ME948051.CDR 8-24-94 
Figure 6-2 shows the consolidation curve calculated for In Farm 2 simulant from centrifuge measurements at $1,10,20,50,100,2000$ g's. Analytical curves (linear relationships) are fitted through the measured points to estimate values between actual measurements and to facilitate interpolation for modeling purposes. Note that the liquid content is expressed in terms of a void ratio parameter in Figure 6-2. The void ratio " $e$ " is defined as the volume of the interstitial liquid divided by the volume of the particles. Specifically, if $\mathrm{V}_{\mathrm{o}}$ is the initial volume of the interstitial liquid and $\mathrm{V}$ is the sludge bulk volume after consolidation, while $\mathrm{m}_{\ell, \mathrm{ex}}$ is the mass of the liquid expelled from the sludge sample, then

$$
e=\frac{v_{0}-m_{l \text { ex }} / \rho_{l}}{v-v_{0}}
$$

where $\rho_{\ell}$ is the density of the liquid. The stress $\sigma$ is expressed in Figure 6-2 in terms of water head, which is the height of a column of water that would exert the effective stress at the bottom.

Figure 6-2. Analytical Consolidation Curve for In Farm 2 Simulant Based on Centrifuge Measurements.

(Sludge initial density is $1.39 \mathrm{~g} / \mathrm{ml}$, and supernatant specific gravity is 1.27 . Water fractions are $52 \mathrm{wt} \%$ in sludge and $73.6 \mathrm{wt} \%$ in supernatant. Sludge density reaches $1.51 \mathrm{~g} / \mathrm{ml}$ at the minimum void ratio (at 2,000 g's), and samples shrink to about $50 \%$ of starting length.)

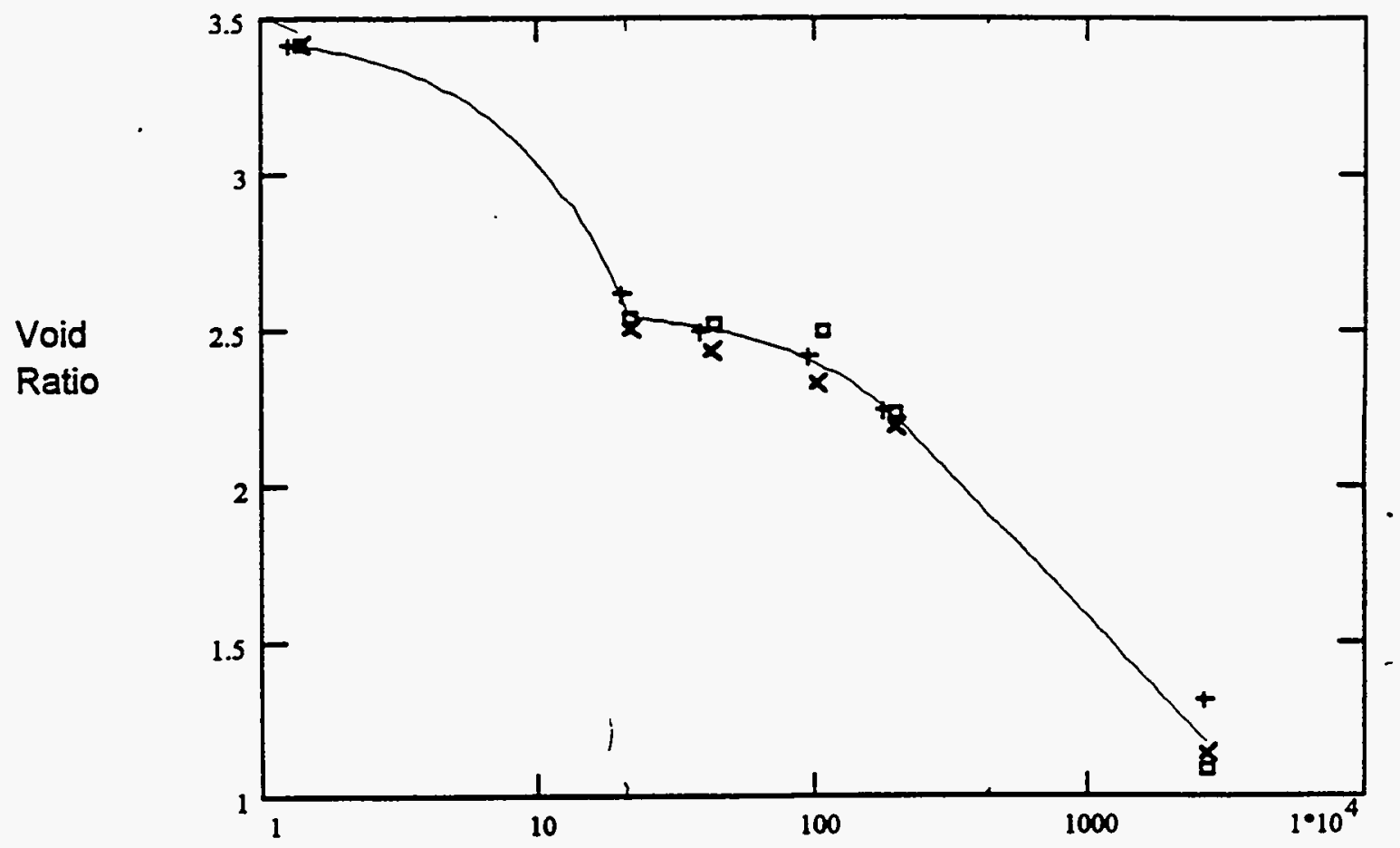

Effective Stress head (cm of water) 
The wt\% water content in an In Farm 2 sample corresponding to a particular void ratio is given in Figure 6-3. Over a void ratio of 3.4 to nearly 1, In Farm simulant changed water content from 52 to $34 \mathrm{wt} \%$.

Figure 6-4 shows the consolidation curve obtained for U Plant 1 simulant. Results are presented directly in terms of wt\% water instead of void ratio, by using a conversion. These curves will later be related to the water content under postulated dryout conditions in waste tank sludge. By using the curves in Figures 6-2 and 6-4, the wt\% water content can be looked up once the effective stress is known or predicted.

\subsection{THE HOT SPOT}

The first of the three local dryout mechanisms considered is the boiling hot spot. This mechanism would require that the heat-generating material become highly concentrated in a hot spot, sufficient to raise the temperature of some local region above the boiling point of the sludge liquid, and that this event actually results in dryout of a significant volume of sludge. If these conditions could be met, such a hot spot would be highly significant to ferrocyanide tank safety. A hot spot capable of heating some volume above the boiling point $\left(120^{\circ} \mathrm{C}\right.$ ) might also heat the center of the dry volume to the ignition temperature (about $\left.250{ }^{\circ} \mathrm{C}\right)$. Furthermore, the dry region would be at an elevated temperature $\left(120\right.$ to $\left.250^{\circ} \mathrm{C}\right)$ and propagation might occur with lower fuel concentrations than were measured in tests with initial temperatures of 25 to $60^{\circ} \mathrm{C}$. Chemical reactivity could also be increased by removal of bound water at these elevated temperatures. Thus, such a hot spot might act as a common-mode initiator of dry fuel, ignition temperature, and reactivity at lower ferrocyanide concentrations. Therefore, the reasons for classing such an event as not credible are discussed in considerable detail below. A defense-in-depth is used; any one of the following three considerations would render dryout of sludge temperatures above boiling to be impossible.

1) Analysis based primarily on conduction heat transfer shows that the concentration of heat generators required, or the fraction of the total tank heat load that must be placed in the hot spot, to heat even a single point to $120^{\circ} \mathrm{C}$ are too large to be credible (see Section 6.2.1). This argument is independent of sludge rheology and of data from simulants.

2) Experiments have shown that the rheology of the sludge is such that steam formation would push aside the sludge and form a bubble of pure steam without expelling the liquid from the solid sludge constituents. Furthermore, the expansion from steam formation would move the heat-generating sludge into a more coolable geometry, and would thus tend to be self-limiting (see Section 6.2.2). 
Figure 6-3. Conversion Curve for Translating Void Ratios into Weight Percent Water Content of In Farm 2 Simulant Sludge.

(Covers range of centrifugation test)

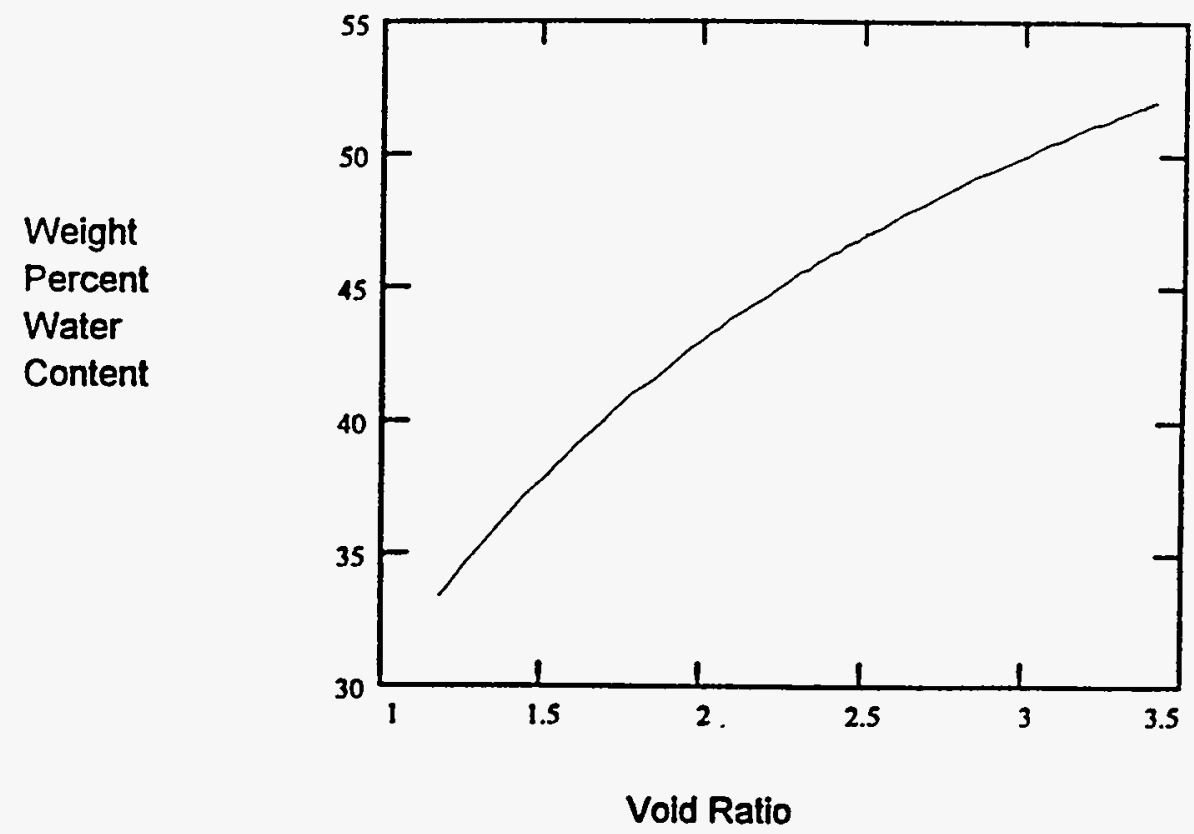

Figure 6-4. Consolidation Curve for U Plant 1 Simulant Sludge

Based on Tempe Cell Water Retention Measurements.

(Based on initial $69 \mathrm{wt} \%$ water in sludge and $74 \mathrm{wt} \%$ water in supernatant)

Weight \%

Water

Content

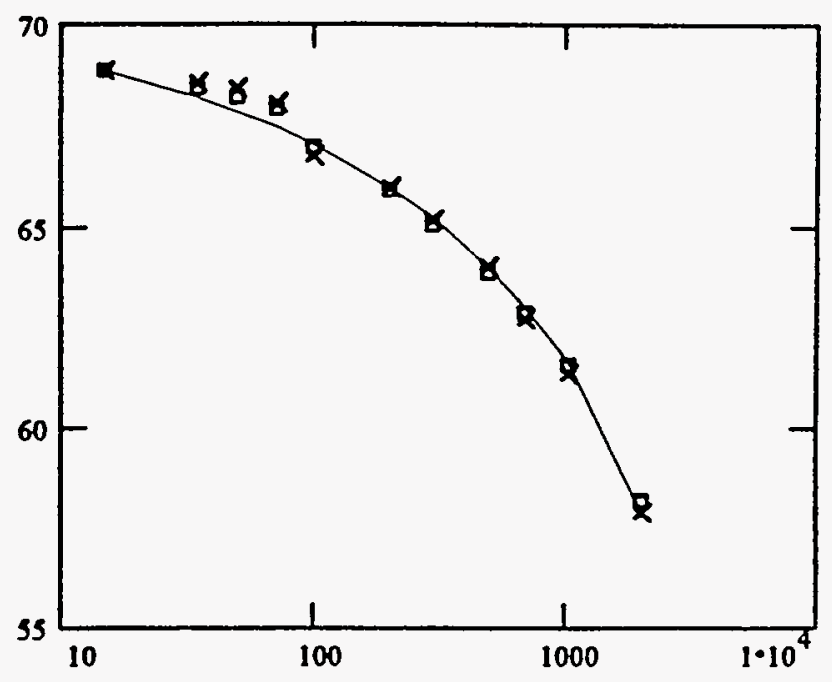

Effective Stress Head (cm water) 
3) Rheology experiments have shown that when ferrocyanide sludge is heated locally to boiling at high heat flux, a network of cracks develops that provides cooling by convection of liquid and steam and limits local temperatures to the boiling point.

There is no local dryout (see Section 6.4.2).

\subsubsection{Concentration of Heat Required for Incipient Boiling}

The difficulty of forming a hot spot can be appreciated by considering the heat-generating material-concentration enhancements required to raise the temperature at the center of the hot spot to the boiling point of the interstitial liquid $\left(\sim 120^{\circ} \mathrm{C}\right)$. For purposes of mathematical tractability, a spherical hot spot form is assumed of radius $\mathrm{R}_{\mathrm{HS}}$ and power density $\mathrm{Q}$. Later, it shall be seen that the analysis presented here is also valid for non-spherical hot spot regions. The differential equation of heat conduction for the temperature distribution $T(r)$ in the hot spot is

$$
\frac{k}{r^{2}} \frac{d}{d r}\left(r^{2} \frac{d T}{d r}\right)=-Q ; 0<r<R_{H S}
$$

where $\mathrm{k}$ is the thermal conductivity of the ferrocyanide suspension and $\mathrm{r}$ is the radial distance measured from the center of the hot spot. Outside the hot spot, in the semi-infinite spherical region $\mathrm{R}_{\mathrm{HS}}<\mathrm{r}<\infty$, the power density is very small compared with $\mathrm{Q}$ and it can be neglected. Thus the differential equation for conduction outside the hot spot is

$$
\frac{\mathrm{k}}{\mathrm{r}^{2}} \frac{\mathrm{d}}{\mathrm{dr}}\left(\mathrm{r}^{2} \frac{\mathrm{dT}}{\mathrm{dr}}\right)=0, \quad \mathrm{R}_{\mathrm{HS}}<\mathrm{r}<\infty .
$$

Integration of these two equations gives

$$
\begin{aligned}
& \mathrm{T}=-\frac{\mathrm{Qr}^{2}}{6 \mathrm{k}}-\frac{\mathrm{c}_{1}}{\mathrm{r}}+\mathrm{c}_{2}, 0<\mathrm{r}<\mathrm{R}_{\mathrm{HS}} \\
& \mathrm{T}=-\frac{\mathrm{c}_{3}}{\mathrm{r}}+\mathrm{c}_{4}, \quad \mathrm{R}_{\mathrm{HS}}<\mathrm{r}<\infty .
\end{aligned}
$$

in which the $c_{i}$ 's are integration constants. They are evaluated by means of the boundary conditions 


$$
\begin{aligned}
& T(0)=T_{b p} ; k \frac{d T}{d r}(0)=0 \\
& T\left(R_{H S}^{-}\right)=T\left(R_{H S}^{+}\right) ; k \frac{d T}{d r}\left(R_{H S}^{-}\right)=k \frac{d T}{d r}\left(R_{H S}^{+}\right) \\
& T(\infty)=T_{\infty}
\end{aligned}
$$

where the signs + and - refer to conditions just outside and just inside the hot spot, respectively; $T_{b p}$ is the boiling point of the liquid component of the sludge, and $T_{\infty}$ is the temperature of the sludge far from the hot spot. Evaluation of the constants of integration leads to the following relationship between the power density and the radius of the hot spot at the incipient boiling condition:

$$
\mathrm{Q}=\frac{2 \mathrm{k}\left(\mathrm{T}_{\mathrm{bp}}-\mathrm{T}_{\mathrm{w}}\right)}{\mathrm{R}_{\mathrm{HS}}^{2}} .
$$

Denoting the average waste tank sludge power density by the symbol $Q_{\text {avg }}$, it follows that a hot spot of radius $R_{\mathrm{HS}}$ must attract a concentration of heat-generating material from the surrounding sludge that exceeds the average tank concentration of heat-generating material by the ratio

$$
\frac{\mathrm{Q}}{\mathrm{Q}_{\mathrm{avg}}}=\frac{2 \mathrm{k}\left(\mathrm{T}_{\mathrm{bp}}-\mathrm{T}_{\boldsymbol{\alpha}}\right)}{\mathrm{R}_{\mathrm{HS}}^{2} \mathrm{Q}_{\mathrm{avg}}}
$$

Taking the sludge thermal conductivity $\mathrm{k}=1.0 \mathrm{~W} / \mathrm{m}^{-1} \mathrm{~K}^{-1}$ (Section 4.1 ) and $\mathrm{Q}_{\text {avg }} \approx$ $8.0 \mathrm{~W} / \mathrm{m}^{-3}$ (maximum from Table 4-2), it is found from Equation (6-11) that a 4.0-cm radius hot spot surrounded by sludge at $\mathrm{T}_{\infty}=30^{\circ} \mathrm{C}$ requires a concentration ratio $\mathrm{Q} / \mathrm{Q}_{\mathrm{avg}}=$ 14,000 before the interstitial liquid will achieve its boiling point $T_{b p}=120^{\circ} \mathrm{C}$ at the center of the hot spot. Of course, a larger hot spot would require less heat-generating material to be brought to incipient boiling, but even a hot spot as large as $0.5 \mathrm{~m}$ requires a concentration ratio of about 90 before boiling could be started.

The conclusion reached above that extreme concentration of heat generation would be required to even reach the boiling point of the sludge liquid is confirmed by calculations in more complex geometries. Dickinson et al. (1993) calculated the heat generation within a cylindrical hot spot of various sizes, shapes and locations required to reach incipient boiling. The worst case was found to be a hot spot near the bottom of tank BY-104 having an 
equidimensional shape. The concentration of decay heat required for the peak temperature of such a hot spot to reach boiling is shown in Figure 6-5 as a function of hot spot diameter. The required concentration is expressed both as a concentration factor, the ratio of heat generation per unit volume in the hot spot to that in the tank as a whole, and as the fraction of the total tank heat load that must be concentrated into the hot spot. For example, a hot spot of $0.4 \mathrm{~m}$ radius would require a concentration factor of 236 , compared to a factor of 360 calculated by Equation (6-9) for the same conditions. A hot spot smaller than $1.25 \mathrm{~m}$ would require concentrating the radionuclides by a factor of over 100 , while a larger hot spot would require more than $10 \%$ of the total tank heat load. These calculations were made for a thermal conductivity of the sludge of $0.47 \mathrm{~W} / \mathrm{m}{ }^{\circ} \mathrm{C}$. More recent analysis of available data gives an estimate of sludge conductivity of $1.0 \mathrm{~W} / \mathrm{m}{ }^{\circ} \mathrm{C}$ (Section 4.1 ); thus, these calculations are conservative. The calculations assumed a boiling point of $120^{\circ} \mathrm{C}$, which is also conservative in that it takes no credit for increase in the boiling point at the higher pressures at the bottom of the tank. The average heating rate in BY-104 was taken as

\section{$1.5 \mathrm{~W} / \mathrm{m}^{3}$.}

Figure 6-5. Requirements for Dryout $\left(120^{\circ} \mathrm{C}\right)$.

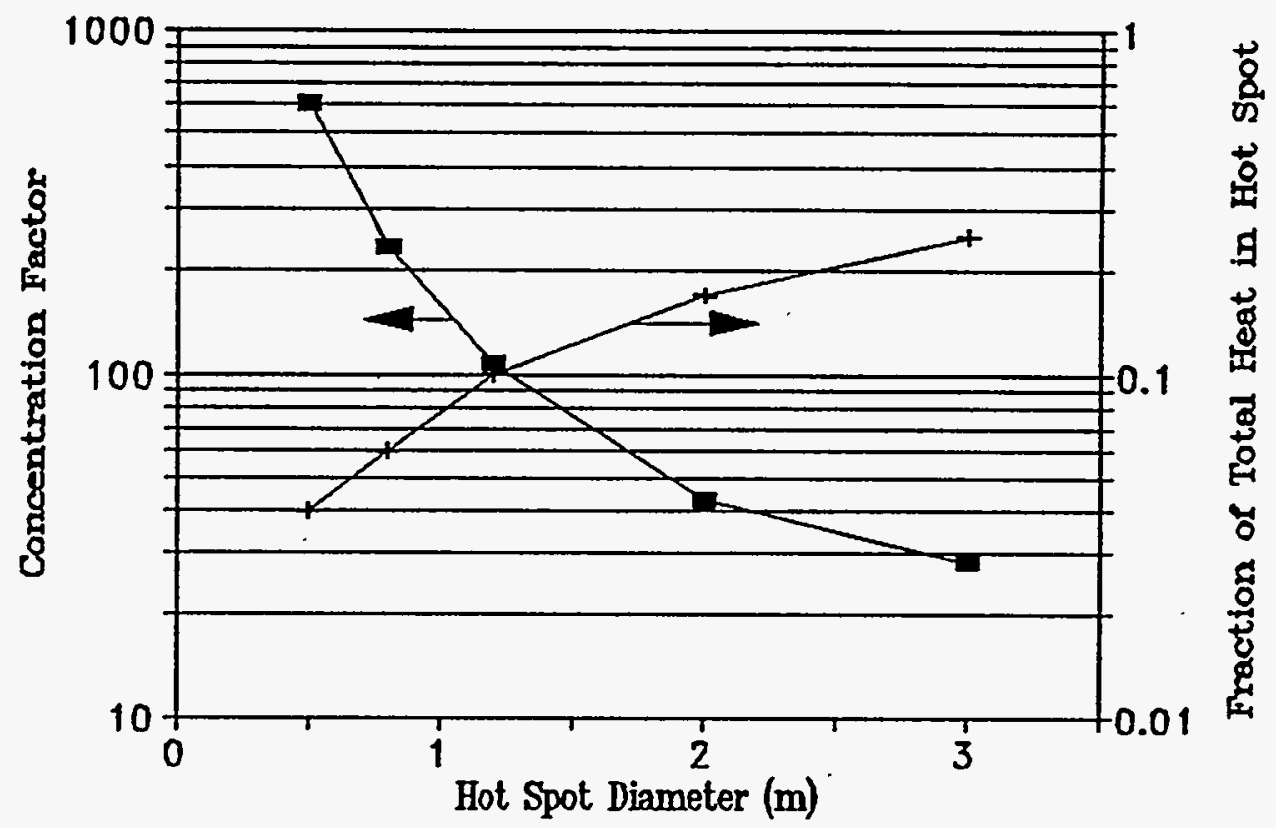

$$
\rightarrow-\text { Concentration } \rightarrow \text { Fraction of Heat }
$$




\subsubsection{Hot Spot Rheology}

Even if the boiling point is reached within a hot spot, dryout will not occur. As demonstrated experimentally (see Section 5.2), the ferrocyanide sludge is a suspension of fine particles and responds to bubble growth in a homogeneous manner rather than by displacement of water from the pores of a stationary medium of solids. Thus, the interior of a growing steam bubble within a hot spot contains only vapor. The particles are pushed aside along with the liquid, as illustrated in Figure 6-6. The original spherical hot spot is ultimately converted to a thin, thermally stable annular region at the termination of the bubble growth process.

An explanation of the homogeneous sludge rheology observed in the bubble growth experiments and illustrated schematically in Figure 6-6 probably requires estimating the effective stress $\sigma$ on the sludge side of the vapor bubble/sludge interface. From extrapolating the consolidation curves (Figures 6-2 and 6-4) down to, say, $20 \mathrm{wt} \%$ water content, it is known that the effective stress at this location must exceed at least $10.0 \mathrm{~atm}\left(10^{4} \mathrm{~cm}\right.$ water) before the breakdown of the saturated sludge state occurs and bubble growth into a packed bed of precipitate particles becomes possible. A simple force balance suggests that $\sigma=\mathrm{P}_{\mathrm{b}}-\mathrm{P}_{\infty}$, where $\mathrm{P}_{\mathrm{b}}$ is the bubble pressure (applied pressure) and $\mathrm{P}_{\infty}$ is the ambient pressure (pore-liquid pressure), from which it is inferred that bubble pressures of about $10 \mathrm{~atm}$ or, equivalently, liquid superheats of $80^{\circ} \mathrm{C}$ are required for the separation of particles and liquid at the bubble interface. This criterion is consistent with the laboratory experiments, but is probably much too simplistic, and its application to bubble growth with large driving pressures should be regarded with caution. Other phenomena may play an important role when the surface stresses are large; for example, sludge cracking may result in stress relief. The experimental observations indicate that the forces holding the liquid and particles together are stronger than the effective forces exerted by the bubble vapor (gas) trying to penetrate.

It is useful to consider the quantitative consequences of a homogeneous two-phase sludge response to boiling within a hot spot. At the end of its growth period the hot spot bubble is surrounded by a spherical shell of concentrated heat-generating material bounded by inner radius $R_{\text {in }}$ and outer radius $R_{\text {out }}$ (see Figure 6-6). All the sludge material in the original hot spot (minus the small quantity of evaporated interstitial liquid) is now contained in the spherical shell. Thus, the hot spot power density in the shell is also $Q$, and the approximate condition is

$$
\mathbf{R}_{\mathrm{out}}^{3}-\mathrm{R}_{\mathrm{in}}^{3}=\mathrm{R}_{\mathrm{HS}}^{3} \text {. }
$$


Figure 6-6. Sludge Suspension Response to Bubble Growth. (Note that for the sake of clarity, the particulate material initially present outside the hot spot boundary is not shown)

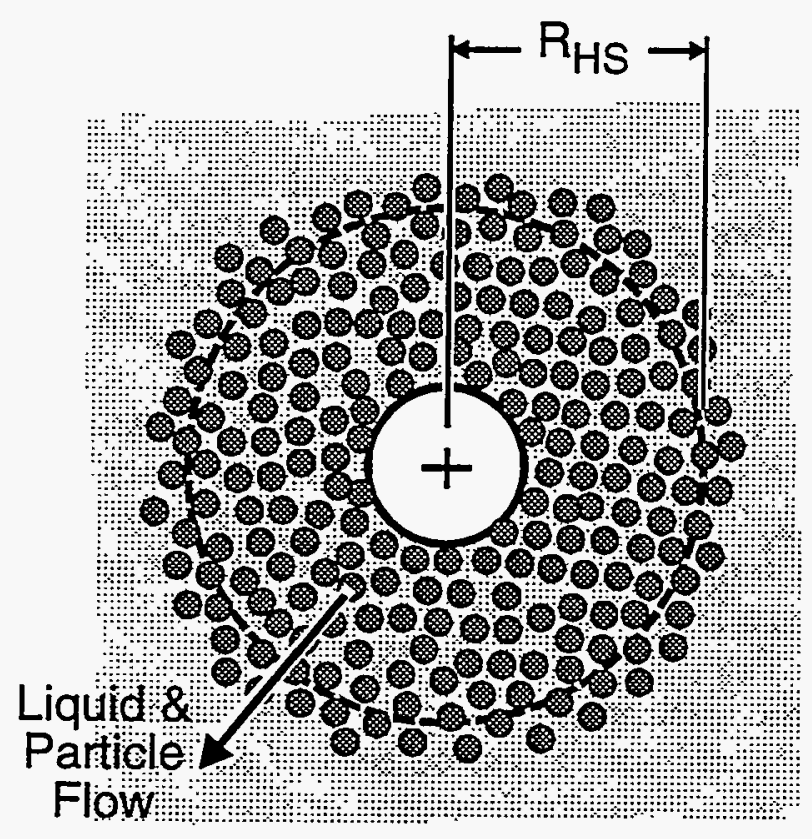

(i) Bubble Growth Displacing Hot Spot

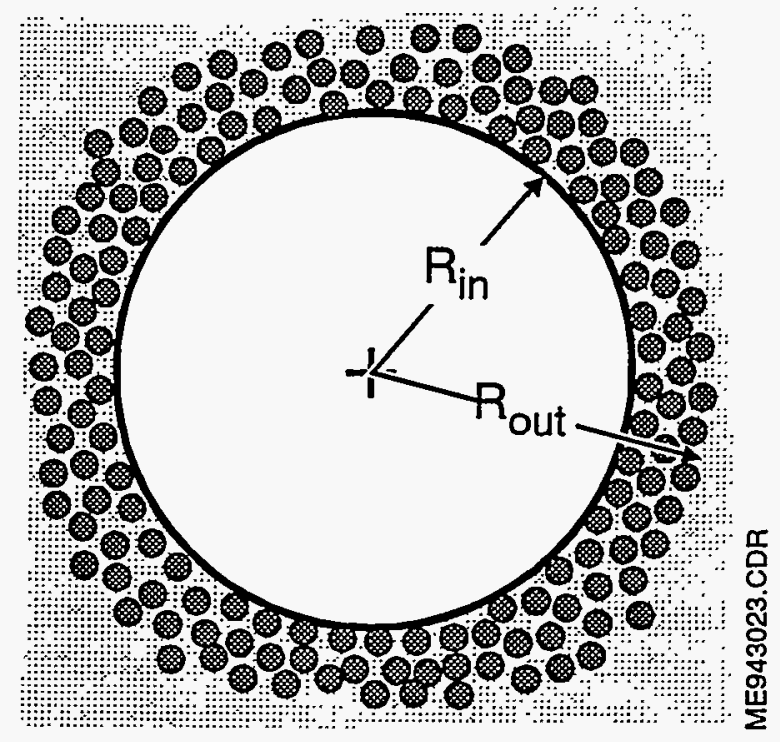

(ii) Final Stable Configuration

Now the solution for the temperature profile $T(r)$ in the heat-generating spherical shell and the liquid region outside the shell is given by the solution of Equation (6-3) in the interval $R_{\text {in }}<r<R_{\text {out }}$, and the solution of Equation (6-4) in the interval $R_{\text {out }}<r<\infty$. The appropriate boundary conditions are given by Equations (6-7) to (6-9) with $\mathrm{r}=0$ replaced by $r=R_{\text {in }}$ in Equation (6-7) and $R_{H S}$ replaced by $R_{\text {out }}$ in Equation (6-8). The solution of this system yields

$$
\frac{k\left(T_{b p}-T_{\infty}\right)}{Q}=\frac{1}{2}\left(R_{o u t}^{2}-R_{i n}^{2}\right) .
$$

Equations (6-12) and (6-13) may be rewritten as

$$
\left(x^{3}+1\right)^{2 / 3}-x^{2}=\frac{2 k\left(T_{b p}-T_{\infty}\right)}{Q R_{H S}^{2}}
$$


where

$$
x=\frac{R_{\text {in }}}{R_{\mathrm{HS}}} ; \quad \mathbf{R}_{\text {out }}=\left(\mathbf{R}_{\mathrm{HS}}^{3}+\mathrm{R}_{\mathrm{m}}^{3}\right)^{1 / 3}
$$

For example, suppose a hot spot of radius $R_{\mathrm{ris}}=4.0 \mathrm{~cm}$ appears in the tank and is surrounded by sludge at $\mathrm{T}_{\infty}=30^{\circ} \mathrm{C}$, with a boiling point of $\mathrm{T}_{\mathrm{bp}}=120^{\circ} \mathrm{C}$. The power density required to raise the temperature at the center of the hot spot to $T_{b p}$ is then $Q=$ $1.12 \times 10^{5} \mathrm{~W} / \mathrm{m}^{-3}$. Thus, if $\mathrm{Q}$ exceeds this value, the hot spot is thermally unstable and boiling will ultimately begin at its center. Suppose $Q=1.7 \times 10^{5} \mathrm{~W} / \mathrm{m}^{-3}$ is chosen. According to Equations (6-14) and (6-15) the final, stable hot spot configuration consists of a 3.3-cm radius bubble surrounded by a rather thin shell of relatively high power density sludge and radial thickness $R_{\text {ot }}-R_{\text {in }}=1.3 \mathrm{~cm}$. The shell is now thin enough so that all the heat generated in it is conducted outward to the surrounding sludge. The bubble surface no longer receives a portion of the heat generated and its growth ceases.

Perhaps the strongest evidence for discounting the existence of hot spots is that ferrocyanide sludge decay heat loads have been dissipated passively during four decades of storage history, during which time sludge temperatures have gradually decreased or remained constant.

\subsection{DRAINAGE OF INTERSTITIAL LIQUID}

\subsubsection{Interpretation of Test Data}

If drainage of interstitial (pore) liquid is to occur in a waste tank because of a leak or because of pumping, it can only occur as a consequence of the consolidation of the waste suspension. Indeed, the draining process in the $20-\mathrm{cm}$ long column of simulant sludge studied by Crane (1992) and mentioned previously is a consolidation process. It is of interest to determine whether the water expelled from the sludge by drainage will eventually result in sludge dryout. For the sake of simplicity it is assumed that the tank contents are spatially homogeneous. It is also assumed that during the drainage (consolidation) process the particle component remains fixed in space and that a meaningful sludge permeability $\kappa$ may be defined so that liquid flows from higher to lower pore-pressures within the sludge in accordance with Darcy's law.

Let $\mathrm{p}_{\mathrm{T}}$ and $\mathrm{p}_{\mathrm{B}}$ denote the pore-liquid pressures at the top of the sludge (just beneath the upper surface) and at the bottom of the sludge, respectively. From a momentum balance applied to the pore liquid over the height $L$ of the sludge, 


$$
p_{T}-p_{B}+p_{\ell} g L=\frac{\mu_{\ell} v L}{k}
$$

where $\mu_{\ell}$ and $\rho_{\ell}$ are the viscosity and density of the pore liquid, and $\mathrm{v}$ is the downward superficial velocity of the pore liquid. The last term in the above equation is the Darcy-law pressure drop resulting from the flow of liquid past the sludge particles. Because the water is freely expelled at the bottom of the sludge from, say, tank leakage, the effective stress $\sigma=0$, and therefore the pore water pressure is equal to the ambient pressure at this location, which will be identified here with the atmospheric pressure $P_{\infty}$. The effective stress in the sludge just below its upper surface is the atmospheric pressure minus the pore pressure, or

$$
\sigma(e)=P_{-}-P_{T}
$$

where $e$ is the void ratio and the relationship $\sigma(e)$ is known and represented by the consolidation curve. Recall that in the present problem $\mathrm{e}$ is taken to be spatially uniform. Thus with $\mathrm{P}_{\mathrm{B}}=\mathrm{P}_{\infty}$ and $\mathrm{P}_{\mathrm{T}}=\mathrm{P}_{\infty}-\sigma(\mathrm{e})$, Equation (6-16) becomes

$$
v=\frac{k}{\mu_{l} L}\left[\rho_{\ell} g L-\sigma(e)\right]
$$

Now the time rate of change of the volume $V_{\ell}$ of the liquid component of the sludge is equal to the instantaneous draining rate of liquid; that is,

$$
\frac{d V_{l}}{d t}=-A v
$$

where $\mathrm{A}$ is the cross-sectional area through which the draining of pore liquid occurs and $\mathrm{t}$ is time. Introducing the definition of the void ratio gives

$$
\mathrm{V}_{\mathrm{l}}=\frac{\mathrm{AL}_{\mathrm{o}}}{1+\mathrm{e}_{\mathrm{o}}} \cdot \mathrm{e}
$$

where the subscript $o$ refers to values of $L$ and $e$ at time $t=0$. Combining Equations (6-18) to $(6-20)$ yields

$$
\frac{d e}{d t}=-\frac{k\left(1+e_{0}\right)}{\mu_{\ell} L L_{0}}\left[\rho_{\ell} g L-\sigma(e)\right] .
$$


The volume consolidation of initially concentrated suspensions is usually rather small, so that $\mathrm{L}$ is not very much smaller than $\mathrm{L}_{\mathrm{o}}$. It shall also be assumed that $\sigma(\mathrm{e})$ varies over a small enough segment of the consolidation curve that the functional relationship $\sigma(e)$ is a linear one and given by

$$
\sigma=\sigma_{f}-\frac{1}{\beta}\left(e-e_{f}\right)
$$

where $\beta$ is a constant coefficient of compressibility (in $\mathrm{Pa}^{-1}$ ) for the linear segment of the consolidation curve. Note that the authors chose to linearize the effective stress with respect to the final or equilibrium state $\left(\sigma_{\mathrm{f}}, \mathrm{e}_{\mathrm{f}}\right)$ of the draining sludge column. Substituting Equation (6-22) into Equation (6-21) gives

$$
\frac{\mathrm{de}}{\mathrm{dt}}=-\frac{\kappa\left(1+\mathrm{e}_{\mathrm{o}}\right)}{\mu_{\ell} \mathrm{L}_{\mathrm{o}}^{2}}\left[\rho_{\ell} \mathrm{gL}_{\mathrm{o}}-\sigma_{\mathrm{f}}+\frac{1}{\beta}\left(\mathrm{e}-\mathrm{e}_{\mathrm{f}}\right)\right]
$$

However, subject to the approximation $\mathrm{L} \approx \mathrm{L}_{\mathrm{o}}$, at the end of the drainage process

$$
\sigma_{\mathrm{f}} \propto \rho_{\mathrm{l}} \mathrm{gL}_{\mathrm{o}} .
$$

Thus Equation (6-23) simplifies to

$$
\frac{\mathrm{de}}{\mathrm{dt}}=-\frac{\kappa\left(1+\mathrm{e}_{\mathrm{o}}\right)}{\mu_{l} \mathrm{~L}_{\mathrm{o}}^{2} \beta}\left(\mathrm{e}-\mathrm{e}_{\mathrm{f}}\right) \text {. }
$$

Finally, by integrating this expression from the initial condition $\mathrm{e}=\mathrm{e}_{\mathrm{o}}$ at $\mathrm{t}=0$, the following sought expression for the time history of the sludge liquid concentration is obtained:

$$
\frac{e-e_{f}}{e_{o}-e_{f}}=\exp \left[-\frac{k\left(1+e_{0}\right)}{\mu_{l} L_{o}^{2} \beta} t\right]
$$

In any particular sludge draining application, the final, equilibrium liquid concentration (void ratio) can be estimated from Equation (6-24) and the consolidation curve. Referring to Crane's (1992) small In Farm 2 drainage column gives $\mathrm{L}_{\mathrm{o}}=0.2 \mathrm{~m}$ and, from Equation $(6-24), \sigma=1.96 \times 10^{3} \mathrm{~Pa}=19.6 \mathrm{~cm}$ of water. From Figure 6-2, a final void ratio of $\mathrm{e}_{\mathrm{f}} \approx 2.6$ is predicted. With the information obtained from the experiment on the 
cumulative drainage weight versus time (see Figure 5-1) and the fact that the In Farm 2 sample remains saturated as it consolidates, the volumetric liquid content e on the average in the column can be calculated, and this is shown in Figure 6-7. The void ratio in this figure appears to approach asymptotically a lower limit of $\mathrm{e}_{\mathrm{f}}=2.7$, in excellent agreement with the value obtained from the consolidation curve and Equation (6-24).

Of additional interest is the comparison of Equation (6-26) with the shape of the drainage curve given in Figure 5-1 or, equivalently, Figure 6-7. The appropriate physical parameter values are $\mu_{\ell}=2.8 \times 10^{-3} \mathrm{~kg} \mathrm{~m}^{-1} \mathrm{~s}^{-1}$ (Wong 1992 and Jeppson and Wong 1993), $\mathrm{L}_{\mathrm{o}}=$ $0.2 \mathrm{~m}, \mathrm{e}_{\mathrm{o}}=3.4$ and $\beta=4.5 \times 10^{-4} \mathrm{~Pa}^{-1}$ for the linearized void ratio versus effective stress range of 0 to $1.96 \times 10^{3} \mathrm{~Pa}(20 \mathrm{~cm})$. If the exponential form given by Equation (6-26) fits the drainage curve in Figure 5-1 reasonably well, an inverse estimation procedure is provided for inferring $k$. Equation (6-26) with $\kappa=9 \times 10^{-16} \mathrm{~m}^{2}$ is represented by the solid curve in Figure 6-7. The exponential function implied by consolidation theory is seen to be consistent with the drainage data obtained from the small-scale In Farm 2 sludge column. The time scale of consolidation (drainage) may be taken as the time the exponential term in Equation (6-26) reaches a value of about 0.1 or when the argument is about 2 . Thus

$$
t=\frac{2 \mu_{\ell} L_{o}^{2} \beta}{k\left(1+e_{o}\right)}
$$

\subsubsection{Application to Waste Tanks}

Given the excellent agreement between Equations (6-24) and (6-26) and the observed behavior of a $20-\mathrm{cm}$ deep column of sludge, these equations may now be applied to determine the drainage behavior of a typical-size tank containing In Farm 2 type sludge and leaking at the bottom. To retain a one-dimensional problem, the authors assume the extreme case of a leak covering the entire bottom surface. An initial sludge height of $\mathrm{L}_{\mathrm{o}}=4.3 \mathrm{~m}$ is assumed, and the sludge is assumed to contain $52 \mathrm{wt} \%$ water initially or, equivalently, $e_{o}=3.4$ (see Figure 6-3). The average effective stress at the end of the drainage process is, from Equation (6-24), $\sigma_{f}=4.2 \times 10^{4} \mathrm{~Pa}=430 \mathrm{~cm}$. From Figure 6-2 the void ratio at this time is $e_{f}=1.89$ and from Figure 6-3 the final water content is $42 \mathrm{wt} \%$. The time for the tank-water expulsion process can be estimated from Equation (6-27) providing that one is willing to accept the following two assumptions: 1) the value $k=9 \times 10^{-16} \mathrm{~m}^{2}$ inferred from the small In Farm 2 drainage test is applicable to the waste tank; and 2) a linearized void fraction versus stress ratio relationship is applicable during the entire consolidation process. The second assumption results in the coefficient of compressibility estimate $\beta=-\mathrm{de} / \mathrm{d} \sigma \approx 3.6 \times 10^{-5} \mathrm{~Pa}^{-1}$. Substituting these estimates, together with $\mu_{\ell}=2.8 \times 10^{-3} \mathrm{~kg} \mathrm{~m}^{-1} \mathrm{~s}^{-1}, \mathrm{~L}_{\mathrm{o}}=4.3 \mathrm{~m}$, and $\mathrm{e}_{\mathrm{o}}=3.4$, into Equation (6-27) gives $\mathrm{t}=30$ yrs. 
Figure 6-7. Comparison of Suspension Settling and Liquid Conduction Models for the Drainage from the Small In Farm 2 Sludge Column.

(Squares are a subsampled set of the measurements. Model curve is solid line.)

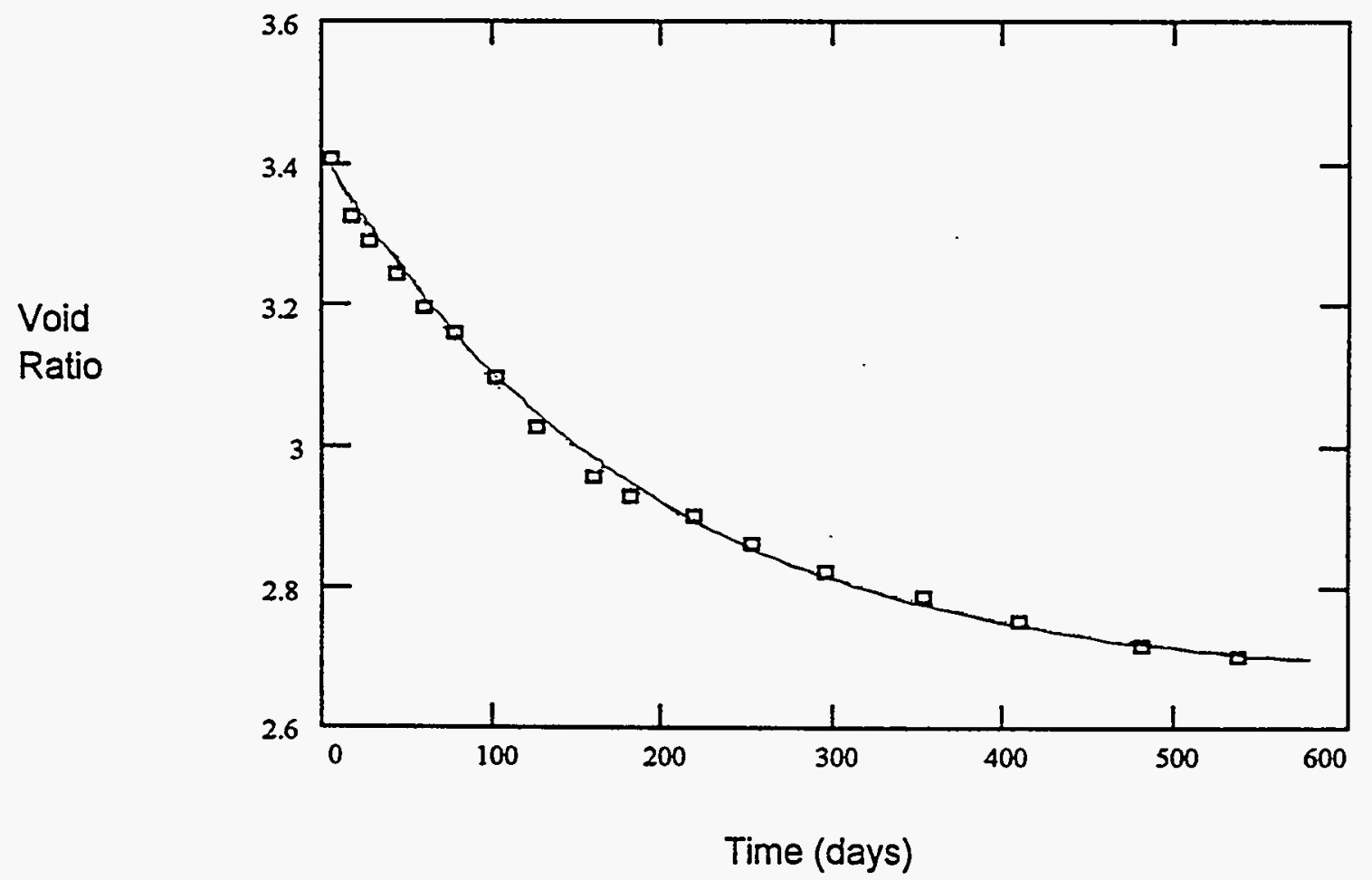

Thus, the maximum conceivable leak in a ferrocyanide tank containing material represented by the In Farm 2 simulant would undergo a reduction of water content from 52 to 42 wt\% at equilibrium, and this would occur on a 30 -year time scale.

Similar calculations have been made for a range of sludge heights from 0.6 to $4.4 \mathrm{~m}$. The equilibrium water content ranged from 47 to 42 wt\% for In Farm 2 simulant (initially $52 \mathrm{wt} \%$ ) and 66 to $64 \mathrm{wt} \%$ for U Plant 1 simulant (initially $67.7 \mathrm{wt} \%$ ). The variation of the equilibrium water content with vertical position was small, being $0.5 \mathrm{wt} \%$ at most for the conditions investigated. The lowest water contents were at the bottom, because the hydrostatic pressure acting to expel water is highest here.

Regardless of the accuracy of our estimate of the time scale of the sludge draining process, it can be said with considerable confidence from the consolidation curve and Equation (6-24) that the sludge will retain a significant quantity of water at the final equilibrium state, thereby resisting dryout by drainage.

The above prediction that the ferrocyanide sludge does not drain as a porous medium of stationary solid (non-consolidating medium) and cannot become dried out by drainage is consistent with experience with those tanks which have been pumped to remove excess water. Liquid was allowed to drain into a vertical, cylindrical saltwell, which extended to the bottom of the tank and was surrounded by a porous screen. The liquid was pumped from 
the bottom of the well until the pumping rate fell below $0.05 \mathrm{gpm}$. The resulting interstitial liquid level is measured by traversing a neutron probe, which detects water content, through a Liquid Observation Well (LOW).

The saltcake layer at the top of the tank was found to drain easily; the ferrocyanide sludge layer did not drain. Data are shown in Table 6-1 for the three tanks with a deep ferrocyanide layer that were pumped and contain LOWs. For all three tanks, the liquid level is well above the bottom of the tank and near the estimated level of the top of the ferrocyanide sludge. In view of the uncertainty in estimating the present height of the ferrocyanide layer (which may have undergone compaction with time), it is probable that the interstitial liquid level has dropped no further than the top of the ferrocyanide sludge.

Table 6-1. Comparison of Sludge Height and Interstitial Liquid Level."

\begin{tabular}{|l|c|c|c|}
\hline \multicolumn{1}{|c|}{ Tank } & BY-104 & BY-107 & BY-110 \\
\hline Total Height of Solids, m & 3.9 & 2.7 & 3.9 \\
\hline $\begin{array}{l}\text { Height of FeCN } \\
\text { (Anderson 1990) }\end{array}$ & $2.4 \cdot$ & 1.8 & 2.1 \\
\hline $\begin{array}{l}\text { Height of FeCN Sludge, m } \\
\text { (Borsheim and Simpson 1991) }\end{array}$ & 2.6 & 1.6 & 2.3 \\
\hline Interstitial Liquid Level, m & 2.1 & 1.6 & 1.9 \\
\hline
\end{tabular}

'Data from Grigsby et al. 1992

${ }^{b} \mathrm{FeCN}$ is an abbreviation for ferrocyanide

\subsection{LOCAL EVAPORATION AND BOILING}

\subsubsection{Surface Evaporation}

Evaporation of water from warmer regions of waste surface (e.g., above a hot spot) and condensation on cooler portions of the surface is another postulated mechanism of locally removing the water content from ferrocyanide sludge. However, the experimental work reported in Section 5.3.5 and 5.4.3 shows that waste material suspensions cannot dry out in this manner, as the liquid return flow is capable of keeping the evaporation surface wet.

Evaporation is a process which results in the removal of liquid from the sludge and concomitant sludge shrinkage just beneath the evaporating surface. Because the sludge is under internal stress produced by atmospheric pressure and sludge self-weight, local shrinkage results in a reduced local pore water pressure, so more of the applied load is borne by the "particle pressure." This results in a gradient in the pore water pressure, which causes the surrounding liquid to flow into the zone of evaporation and shrinkage. Sludge 
permeability determines whether the incoming flow rate is sufficient to remove the heat converted into latent heat of vaporization.

Suppose that as a result of some local accumulation of heat-generating particulate beneath the surface, evaporation takes place from the surface over an area of radius $R$ (see Figure 6-8). The vaporization process is assumed to result in a superficial liquid velocity $v$ that is perpendicular to the surface and uniform over the surface area subject to evaporation $\left(\pi R^{2}\right)$. The liquid velocity $v$ can be related to the sludge decay "evaporation power" $Q_{e v}$ that converts liquid to vapor via the energy balance

$$
Q_{e v}=\pi R^{2} h_{f g} \rho_{l} v
$$

where $h_{f g}$ and $\rho_{\ell}$ are, respectively, the latent heat of evaporation and density of the interstitial liquid. In writing Equation (6-28), the authors have ignored the fact that the dissolved salt does not contribute to the evaporation mass flow of water. This omission will not alter the conclusions of the analysis in any significant way.

Figure 6-8. Physical Model of Water Migration to Surface Region Hot Spot.

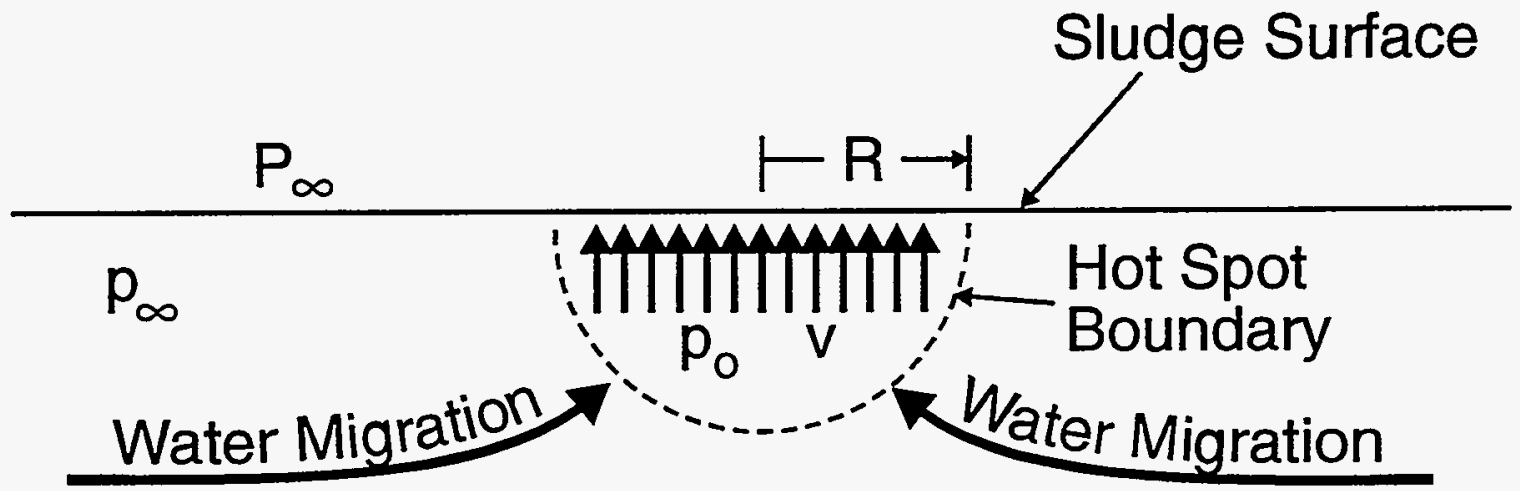

ME948053.CDR 8-24-94

Let $\mathrm{p}$ and $\mathrm{p}_{\infty}$ denote the pore-liquid pressures just beneath the evaporating surface and just beneath the sludge surface far from the evaporating surface (see Figure 6-8). From Darcy's law and potential flow theory one can show that the pore-liquid pressure difference required to produce a flow of velocity $v$ through a circular region of radius $R$ in the plane of an otherwise impermeable surface of a semi-infinite porous medium is 


$$
\mathbf{p}_{\infty}-\mathbf{p}_{0}=\frac{\mu_{\ell} v R}{\kappa}
$$

where $\mu_{\ell}$ is the viscosity of the liquid component of the sludge and $\alpha$ is the permeability of the sludge. Let $\sigma$ be the effective stress just below the evaporating surface. Then

$$
\boldsymbol{\sigma}=\mathrm{P}_{\boldsymbol{\alpha}}-\mathrm{p}_{\mathrm{o}}
$$

where $P_{\infty}$ is the applied atmospheric pressure. Since no consolidation takes place beneath the surface of the sludge far from the evaporation zone, the effective stress at infinity is zero and $\mathrm{p}_{\infty}=\mathrm{P}_{\infty}$. It follows, then from Equations (6-29) and (6-30) that

$$
\sigma=\frac{\mu_{e} \mathrm{vR}}{\mathrm{k}}
$$

or, from Equation (6-28),

$$
\sigma=\frac{\mu_{\ell} Q_{e v}}{\pi R \times h_{f g} \rho_{\ell}} .
$$

Equation (6-32) and the consolidation curve are sufficient to determine the water concentration at the evaporating interface. Consider the incredible situation in which $50 \%$ of the typical waste tank heat load, say, $Q_{e v}=10^{3} \mathrm{~W}$ is concentrated below the sludge surface and producing (from estimate in Section 6.3.1) evaporation from a surface area of radius $\mathrm{R}=1.0 \mathrm{~m}$. Assuming $\kappa=10^{-15} \mathrm{~m}^{2}$ (from estimate in Section 6.3.1), $\mathrm{h}_{\mathrm{fg}}=$ $2.2 \times 10^{6} \mathrm{~J} \mathrm{~kg}^{-1}, \mu_{\ell}=2.8 \times 10^{-3} \mathrm{~kg} \mathrm{~m}^{-1} \mathrm{~s}^{-1}$, and $\rho_{\ell}=10^{3} \mathrm{~kg} \mathrm{~m}^{-3}$ for the sludge and its liquid component, Equation (6-32) yields an effective stress $\sigma$ equal to $4.1 \times 10^{5} \mathrm{~Pa}$ (4.1 $\times 10^{3} \mathrm{~cm}$ water). The consolidation curve in Figure 6-4 for U Plant 1 simulant sludge indicates a water concentration at the evaporation surface of $55 \mathrm{wt} \%$. The predicted water content at the surface of In Farm 2 simulant sludge is $30 \mathrm{wt} \%$ (see Figures 6-2 and 6-3). Thus, in both cases the sludge surface is predicted to remain wet (saturated), even though the surface power is incredibly large and higher than the actual waste tank surface power by about a factor of 100 .

It should also be noted that the ability of the sludge to retain its moisture at the evaporation surface is probably underestimated by Equation (6-32). Recall from the laboratory observations discussed in Section 5.0 that surface cracks appear in the evaporation zone as a result of sludge shrinkage. The cracks greatly enhance the available surface area for evaporation and therefore relieve the effective stress by reducing the superficial liquid evaporation velocity $\mathrm{v}$ required to match the heat load. While other mechanisms may 
contribute to moisture transfer at the surface of the sludge, it is clear that water transport induced by sludge shrinkage or compression is capable of explaining the experimental results discussed in Sections 5.3 and 5.4.

The discussion above has shown that sludge undergoing strong local surface evaporation will provide an ample flow of water to keep the surface wet and avoid local dryout. However, it is worth noting that even if this water flow were postulated to be lacking or inadequate, local dryout would not proceed to the degree required to permit a propagating chemical reaction. As the moisture content of the sludge decreases, its vapor pressure falls, and an equilibrium is reached where no further evaporation occurs. This is discussed in more detail below.

The worst case for this is the In Farm 1 sludge, which has the highest concentration of ferrocyanide, $26 \mathrm{wt} \% \mathrm{Na}_{2} \mathrm{NiFe}(\mathrm{CN})_{6}$, when dry. The In Farm type sludge was added only to tanks C-108, C-109, C-111, and C-112. These tanks contain no saltcake on top of the ferrocyanide sludge. Only one of the 29 batches of ferrocyanide sludge added to these tanks had this 26 wt\% composition; the others contained less ferrocyanide. Furthermore, recent sludge samples from C-109 and C-112 showed ferrocyanide concentrations very much less than added ( $<2 \mathrm{wt} \%$ ), indicating depletion through aging reactions. Nevertheless, the maximum value of $26 \mathrm{wt} \%$ will be assumed here.

A concentration of $10 \mathrm{wt} \%$ free water has been found to be sufficient to prevent a propagating reaction in In Farm sludge containing $26 \mathrm{wt} \% \mathrm{Na}_{2} \mathrm{NiFe}(\mathrm{CN})_{6}$ (see Section 3.2).

The moisture content of In Farm simulant sludge in equilibrium air has been measured (see Section 2.4). Interpolation of these data gives a relative humidity of $49 \%$ in equilibrium with sludge containing $10 \mathrm{wt} \%$ free water and $85 \%$ in equilibrium with wet sludge (51 wt\% free water).

Consider tank C-112 as a worst case; it has the highest heat load (2.2 $\mathrm{kW})$ and the highest airspace temperature $\left(25^{\circ} \mathrm{C}\right)$ of any of the four tanks with In Farm sludge (Crowe 1993). Assume a localized hot spot giving a much higher than average surface heat flux and an elevated surface temperature. Because the temperature drop between surface and gas is small $\left(<1{ }^{\circ} \mathrm{C}\right)$ at normal heat flux, the surface temperature away from the hot spot may be taken as $25^{\circ} \mathrm{C}$. The requirement for equilibrium (no further evaporation from the hot spot) is that the vapor pressure of water in sludge at its peak surface temperature equals that of the sludge away from the hot spot. If the hot spot moisture content is equal to $10 \%$, as required to prevent a propagating reaction, then

$$
\mathrm{P}_{\mathrm{v}}=.49 \mathrm{P}_{\mathrm{T}}=.85 \mathrm{P}_{25}
$$

when $P_{v}=$ vapor pressure of water in head space

$\mathrm{P}_{25}=$ saturation vapor pressure of water at $25{ }^{\circ} \mathrm{C}=0.459 \mathrm{psig}$

$\mathrm{P}_{\mathrm{T}}=$ saturation vapor pressure of water at peak surface temperature. 
Therefore, $\mathrm{P}_{\mathrm{T}}=.796 \mathrm{psig}$

$$
\mathrm{T}=34.6^{\circ} \mathrm{C} \text {. }
$$

Therefore, if the hot spot is not severe enough to produce a surface temperature in excess of $34{ }^{\circ} \mathrm{C}\left(9^{\circ} \mathrm{C}\right.$ above normal), local evaporation cannot reduce the sludge moisture content sufficiently to permit a propagating reaction.

Next consider the local concentration of heat flux required to give such an elevation in surface temperature. Heat is transferred from the surface to the gas by natural convection and by radiation; there is no evaporation at the equilibrium conditions being considered. McAdams (1942) gives the following equation in British units for the natural-convection heat transfer co-efficient for upward-facing horizontal surfaces in air at ordinary temperatures and pressure.

$$
\begin{aligned}
\mathrm{h}_{\mathrm{c}} & =0.38(\Delta \mathrm{T}) 1 / 4 \\
\mathrm{~h}_{\mathrm{c}}=0.38[1.8(34-25)]^{1 / 4} & =0.76 \mathrm{Btu} / \mathrm{hr} / \mathrm{ft}^{2}{ }^{\circ} \mathrm{F}=4.3 \mathrm{~W} / \mathrm{m}^{2}{ }^{\circ} \mathrm{C} .
\end{aligned}
$$

The natural convection heat flux is then:

$$
\mathrm{Q}_{\mathrm{c}}=\left(4.3 \mathrm{~W} / \mathrm{m}^{2}{ }^{\circ} \mathrm{C}\right)\left(34-25^{\circ} \mathrm{C}\right)=39 \mathrm{~W} / \mathrm{m}^{2} .
$$

A small, surface hot spot radiates into a large cavity at $25^{\circ} \mathrm{C}$, which may be considered as a black body. For a sludge emissivity of 0.94 , the radiant heat transfer (McAdams 1942) is then:

$$
\mathrm{Q}_{\mathrm{R}}=5.67 \times 10^{-8} \mathrm{~W} / \mathrm{m}^{2} \mathrm{~K}^{4} .94\left[(307 \mathrm{~K})^{4}-(298 \mathrm{~K})^{4}\right]=53 \mathrm{~W} / \mathrm{m}^{2} .
$$

The total heat flux is thus:

$$
\mathrm{Q}_{\mathrm{T}}=39+53=92 \mathrm{~W} / \mathrm{m}^{2} .
$$

However, the average surface heat flux in tank $\mathrm{C}-112$, neglecting heat loss out the bottom and sides, is $2,200 \mathrm{~W} / 410 \mathrm{~m}^{2}=5.4 \mathrm{~W} / \mathrm{m}^{2}$. The heat flux at the hot spot required for a dryout of concern is thus 17 times the average heat flux. Since a hot spot within the sludge will lose heat radially and downward as well as upward, the areal concentration of heat generators would have to be even greater than this, particularly for the smaller hot spots. Such a large lateral concentration of heat generation is highly improbable.

\subsubsection{Internal Boiling}

The network of cracks that develops at an evaporation surface probably plays an important role in the cooling of hot spots submerged deep within the waste, which is the case discussed 
in Section 6.2. Cracks emanated from the rigid immersion heaters that were employed in the sludge boiling experiments described in Section 5.0. The high cooling capacity of the sludge in these tests was undoubtedly from the flow of steam away from the heater within cracks and the return flow of sludge water toward the heater through the particle-rich region between cracks. The cracks were observed to gradually increase in length and in number as the experiments progressed. This ensured that the latent heat removed by steam condensation within the cracks had adequate subcooling within the surrounding sludge. If it is assumed that the width of the cracks is large enough so that the steam flow away from the heater offers no resistance to the water migration process, a simple expression can be arrived at for the sludge cooling limit.

It is reasonable to assume that the flow of liquid through the sludge liquid-particle matrix is driven by sludge compression caused by shrinkage, much like the case treated above of liquid flow to an evaporating segment of the sludge surface. In fact, it can readily be shown that Equation (6-31) for the effective stress at the evaporating surface of the sludge can also be used to predict the effective stress at the surface of a submerged spherical heater of radius $R$. The velocity $\mathrm{v}$ is now the inward, radial superficial velocity of the sludge interstitial liquid at the surface of the heater where liquid is being converted to vapor. The heat fiux $q$ at the surface is related to $v$ via the energy balance

$$
q=\rho_{l} h_{f g} v \text {. }
$$

Eliminating $\mathrm{v}$ between Equations (6-31) and (6-33) yields the following expression between the surface heat flux and the effective stress

$$
q=\frac{k \rho_{\ell} h_{f g} \sigma(e)}{\mu_{f} R}
$$

Referring to the consolidation curve for U Plant simulant sludge in Figure 6-4 it is noted, by extrapolation of the curve to very high effective stress $\sigma$, that the saturated state at the evaporating surface cannot be maintained if $\sigma$ exceeds some critical value $\sigma_{\mathrm{cr}}$ which is approximately $10^{4} \mathrm{~cm}$ water $\left(10^{6} \mathrm{~Pa}\right)$. By substituting $\sigma_{\mathrm{cr}}$ into Equation (6-34), the theoretical "critical heat flux" $\mathrm{q}_{\mathrm{cr}}$ is obtained, which results in sludge dryout at the evaporating (heater) surface:

$$
q_{c r}=\frac{\kappa \rho_{l} h_{f_{g}} \sigma_{c x}}{\mu_{f} R} .
$$

The radius of the heater employed in the two-dimensional test section (see Section 5.3.5) was $\mathrm{R}=1.5 \times 10^{-3} \mathrm{~m}$. Substituting this value into Equation $(6-35)$, together with $\kappa=10^{-15} \mathrm{~m}^{2}$, $\rho_{\ell}=10^{3} \mathrm{~kg} \mathrm{~m}^{-3}, \mathrm{~h}_{\mathrm{fg}}=2.2 \times 10^{6} \mathrm{~J} \mathrm{~kg}^{-1}$, and $\mu_{\ell}=2.8 \times 10^{-3} \mathrm{~kg} \mathrm{~m}^{-1} \mathrm{~s}^{-1}$, gives 
$\mathrm{q}_{\mathrm{er}}=5.2 \times 10^{5} \mathrm{~W} / \mathrm{m}^{-2}$. The heat flux in the two-dimensional test with $\mathrm{U}$ Plant simulant material was $\mathrm{q}=5.4 \times 10^{4} \mathrm{~W} / \mathrm{m}^{-2}$, or one order of magnitude less than $\mathrm{q}_{\mathrm{er}}$. Clearly the sludge was capable of removing all the heater power generated by water-migration from the pore water pressure gradient caused by evaporation-induced sludge consolidation.

The model developed above may now be applied to a postulated hot spot in a waste tank. Suppose a spherical hot spot forms and raises the temperature of some local region of radius $\mathbf{R}_{\mathrm{HS}}$ above the boiling point of the sludge liquid and, simultaneously, a network of cracks develops which provides a path for steam condensation in the surrounding, cooler sludge. In this case, the steam-driven expansion illustrated in Figure 6-6 does not materialize and, instead, a spherical boiling zone containing a mixture of heat-generating saturated sludge and steam appears. Assuming that evaporation within the hot spot only occurs at its spherical boundary, Equation (6-35) when multiplied by $3 / \mathrm{R}_{\mathrm{HS}}$ gives the power density that must be exceeded before the return flow of sludge liquid to the hot spot fails to keep pace with the flow of steam from the hot spot and local dryout occurs; namely,

$$
Q_{c t}=\frac{3 \kappa \rho_{l} h_{\mathrm{fg}} \sigma_{\mathrm{cr}}}{\mu_{\ell} \mathrm{R}_{\mathrm{HS}}^{2}} .
$$

Dividing this expression by the average waste tank power $\mathrm{Q}_{\mathrm{avg}}$ yields the concentration of heat-generating material required to achieve local dryout:

$$
\frac{\mathrm{Q}_{\mathrm{cr}}}{\mathrm{Q}_{\mathrm{avg}}}=\frac{3 \mathrm{k} \rho_{l} \mathrm{~h}_{\mathrm{fg}} \sigma_{\mathrm{cg}}}{\mu_{l} \mathrm{R}_{\mathrm{HS}}^{2} \mathrm{Q}_{\mathrm{avg}}}
$$

A 4.0-cm-radius hot spot in a sludge with $\mathrm{Q}_{\mathrm{avg}}=5.0 \mathrm{~W} / \mathrm{m}^{-3}$ requires a concentration ratio of $3 \times 10^{5}$ before hot spot dryout is predicted. A large hot spot of radius $R_{\mathrm{Hs}}=0.5 \mathrm{~m}$ requires a concentration ratio of $1.9 \times 10^{3}$ before dryout can occur. Clearly, the amount of heat generating material that must be concentrated in a hot spot to achieve incipient dryout is much too large to be credible.

\subsection{POSSIBLE CONCENTRATION OF HEAT GENERATION IN TANKS}

The dryout mechanism discussed in Sections 6.2 and 6.4 would require very large concentrations of heat generation. It is appropriate, therefore, to consider how large a concentration of heat might be credible. The possibility that the heat-generating radionuclides might somehow become highly concentrated in some region of the tank has been investigated. Measurements of the distribution of ${ }^{90} \mathrm{Sr}$ and ${ }^{137} \mathrm{Cs}$, have been obtained for three ferrocyanide tanks. This work is summarized below. 
Concentration by gravitational settling has been considered by Dickinson et al. (1993). The ferrocyanide slurries added to the waste tanks were sufficiently mobile that they spread rapidly over the tank area before settling occurred. Preferential settling of particles containing radionuclides, especially ${ }^{90} \mathrm{Sr}$, is possible. However, sludge was added to the tanks in several batches that settled before the next addition. Hence, settling would produce concentration in several layers distributed over the sludge depth. More important, even concentration into a single horizontal Jayer would not produce temperatures approaching boiling; severe lateral concentration is needed. Heat transfer calculations show that the extreme case of all heat generation in a thin layer at the bottom of the tank would produce a peak temperature well below boiling.

Liquid waste containing dissolved ${ }^{137} \mathrm{Cs}$ was added on top of the settled ferrocyanide sludge in several tanks. Because $\mathrm{Na}_{2} \mathrm{NiFe}(\mathrm{CN})_{6}$ has a strong affinity for $\mathrm{Cs}$, this added ${ }^{137} \mathrm{Cs}$ may have been concentrated in a thin layer at the top of the ferrocyanide sludge. However, since this would be distributed over the tank area, it would be easily cooled and would give no problem.

Convection currents have been suggested as a possible mechanism for concentrating radionuclides. In general, however, convection currents would act to promote mixing and reduce high concentrations. Stringent conditions would have to be satisfied for convection currents to produce higher concentrations. Any transport of cesium or strontium will be limited by their low solubility. Both $\mathrm{Cs}$ and $\mathrm{Sr}$ in $\mathrm{C}-109$ and $\mathrm{C}-112$ were in insoluble form and they could be dissolved only with difficulty (Simpson et al. 1993a, 1993b). Because solubility generally increases with temperature, the expectation is for convection currents to dissolve radionuclides from warm regions and precipitate them in cooler regions, thereby alleviating any hot spots (McGrail 1994). Recent measurements have been made of the solubility of $\mathrm{Cs}_{2} \mathrm{NiFe}(\mathrm{CN})_{6}$ from 25 to $90^{\circ} \mathrm{C}$ at $\mathrm{pH}$ of 11 to 14 (Schiefelbein 1994). These show an increase of solubility with temperature.

The magnitude of convection currents that can develop is limited by the low permeability of the sludge [on the order of $10^{-14} \mathrm{~m}^{2}$, (Jeppson and Wong 1993)] and by the small driving force available from temperatures or concentration gradients.

A detailed analysis of the possible effects of convection currents in a ferrocyanide tank has been performed by McGrail et al. (1993) and McGrail (1994). Computer simulations of fluid, heat, and mass transport predict that fluid convection will occur in this waste because of density-gradients induced from chemical composition differences and/or thermal gradients. The predicted velocities were approximately $3 \mathrm{~m} / \mathrm{yr}$ for a sludge with $50 \%$ porosity, using a viscosity of $0.002 \mathrm{~Pa} \cdot \mathrm{s}$, permeability of $3.55 \times 10^{-14} \mathrm{~m}^{2}$, and assuming a $50 \%$ density difference between a fluid overlying the waste and the interstitial fluid. Convective velocities were much smaller for the case of thermal buoyancy-driven flow, approximately $10^{-5}$ to $10^{-2}$ $\mathrm{m} / \mathrm{yr}$ depending on the assumed heat generation rate and hydraulic conductivity of the waste. A model was developed to determine the extent of redistribution of ${ }^{137} \mathrm{Cs}$ as a result of diffusion and convection in the waste over a 30-year period. For an increasing solubility for $\mathrm{Cs}_{2} \mathrm{NiFe}(\mathrm{CN})_{6}$ as a function of increasing temperature, the results show that ${ }^{137} \mathrm{Cs}$ partially 
redistributes in a thin layer at the colder top of the tank. The effect of the mass redistribution is to lower the predicted centerline tank temperature by about $10^{\circ} \mathrm{C}$ over the case where the ${ }^{137} \mathrm{Cs}$ is assumed to be uniformly distributed.

McGrail (1994) also considered the case of a retrograde dependence of solubility on temperature. Even for this case, which recent solubility measurements have shown to be not true for $\mathrm{Cs}_{2} \mathrm{NiFe}(\mathrm{CN})_{6}$, the buoyancy-driven convective flow gave peak ${ }^{137} \mathrm{Cs}$ concentrations only 10 times tank average and a $5{ }^{\circ} \mathrm{C}$ increase in peak temperature. McGrail concludes that "redistribution of the ${ }^{137} \mathrm{Cs}$ as a result of aqueous diffusion and natural convection is of no concern in terms of generating a localized area or "hot spot" that could lead to a propagating exothermic reaction."

A distinction should be made between hot spots resulting from radionuclide distributions or other conditions that have existed for many years and those caused by presently changing conditions. The dominant radionuclides that contribute to heating $\left({ }^{137} \mathrm{Cs}\right.$ and ${ }^{90} \mathrm{Sr}$ ) have half-lives of about 30 years. The ferrocyanide additions were completed 35 years ago, and other additions about 17 years ago. Therefore, any hot spots created by these operations would now have only about 45 to $68 \%$ of their original heat generation, and would be unlikely to cause a problem now if they did not do so in the past. For runaway reactions to occur at present or future time, it would be necessary to have a concentration mechanism either take place at the present time or become initiated by future changes in tank conditions.

A measure of the distribution of heat sources in the tanks is obtained from the core samples taken from $241-\mathrm{C}-109, \mathrm{C}-112$, and T-107. These provide direct measurements of the distribution of ${ }^{90} \mathrm{Sr}$ and ${ }^{137} \mathrm{Cs}$. Cores were sampled through three risers in each tank and broken into subsegments to measure vertical variation. These data are summarized in Tables 6-2 through 6-4. The high concentrations of ${ }^{90} \mathrm{Sr}$ near the top of C-109 and C-112, is believed to result from later additions of strontium-rich waste from the Strontium Semiworks plant. These additions were made only to the C Farm ferrocyanide tanks. The bottom sample from each core may represent a heel of waste added to the tanks before ferrocyanide. Aside from these effects, the variations of ${ }^{90} \mathrm{Sr}$ and ${ }^{137} \mathrm{Cs}$ concentrations are generally modest. The vertical profiles of local ${ }^{137} \mathrm{Cs}$ concentrations have been measured in several ferrocyanide tanks by spectral gamma scans (Grigsby et al. 1992). These show ratios of peak to average concentrations of 1.2 to 3.1 . 
WHC-EP-0816

Table 6-2. Analyses of C-112 Core Samples, $\mu \mathrm{Ci} / \mathrm{g}$.

(Simpson et al. 1993a)

\begin{tabular}{||c|c|c|c|c|c|c||}
\hline \multirow{2}{*}{ Segment } & \multicolumn{2}{|c|}{ Core 34 } & \multicolumn{2}{c|}{ Core 35 } & \multicolumn{2}{c||}{ Core 36 } \\
\cline { 2 - 7 } & ${ }^{137} \mathrm{Cs}$ & ${ }^{90} \mathrm{Sr}$ & ${ }^{137} \mathrm{Cs}$ & ${ }^{90} \mathrm{Sr}$ & ${ }^{137} \mathrm{Cs}$ & ${ }^{90} \mathrm{Sr}$ \\
\hline 1 C (top) & - & - & - & - & 560 & 1,900 \\
\hline 1 D & 240 & 1,300 & 700 & 3,200 & 1,200 & 15 \\
\hline 2 A & - & - & - & - & 880 & 20 \\
\hline 2 B & 610 & 4,900 & - & - & 530 & 70 \\
\hline 2 C & 800 & 1,100 & - & - & 100 & 140 \\
\hline 2 D (bottom) & 510 & 2,500 & - & - & 40 & 200 \\
\hline
\end{tabular}

Table 6-3. Analyses of C-109 Core Samples, $\mu \mathrm{Ci} / \mathrm{g}$.

(Simpson et al. 1993b)

\begin{tabular}{||l|c|c|c|c|c|c||}
\hline \multirow{2}{*}{\multicolumn{1}{|c|}{ Segment }} & \multicolumn{2}{|c|}{ Core 47 } & \multicolumn{2}{c|}{ Core 48 } & \multicolumn{2}{c||}{ Core 49 } \\
\cline { 2 - 7 } & ${ }^{137} \mathrm{Cs}$ & ${ }^{90} \mathrm{Sr}$ & ${ }^{137} \mathrm{Cs}$ & ${ }^{90} \mathrm{Sr}$ & ${ }^{137} \mathrm{Cs}$ & ${ }^{90} \mathrm{Sr}$ \\
\hline 1 B (top) & 340 & 4,600 & 1,200 & 150 & 120 & 2,400 \\
\hline 1 C & 770 & 470 & 1,170 & 120 & 350 & 200 \\
\hline 1 D & 950 & 200 & 1,030 & 190 & 700 & 190 \\
\hline
\end{tabular}

Table 6-4. Analyses of T-107 Core Samples, $\mu \mathrm{Ci} / \mathrm{g}$. (Sasaki and Valenzuela 1994)

\begin{tabular}{||l|c|c|c|c|c|c||}
\hline \multirow{2}{*}{ Segment } & \multicolumn{2}{|c|}{ Core 50 } & \multicolumn{2}{c|}{ Core 51 } & \multicolumn{2}{c||}{ Core 52 } \\
\cline { 2 - 7 } & ${ }^{137} \mathrm{Cs}$ & ${ }^{90} \mathrm{Sr}$ & ${ }^{137} \mathrm{Cs}$ & ${ }^{90} \mathrm{Sr}$ & ${ }^{137} \mathrm{Cs}$ & ${ }^{90} \mathrm{Sr}$ \\
\hline 1 (top) & 7 & 32 & - & - & 11 & 165 \\
\hline 2 & 12 & 153 & 100 & 189 & 10 & 88 \\
\hline 3 & 6 & 125 & 16 & 222 & 9 & 57 \\
\hline 4 (bottom) & IS & IS & 16 & 127 & - & - \\
\hline
\end{tabular}


Some non-uniformities in the distribution of heat-producing radionuclides certainly exist in the ferrocyanide tanks. However, it does not appear to be credible that concentrations could reach the extreme levels required to heat the sludge locally to boiling.

The authors note that in the past, some nonferrocyanide Hanford Site waste tanks have shown temperatures above boiling. Five tanks have been identified as having had temperatures above $350^{\circ} \mathrm{F}\left(177^{\circ} \mathrm{C}\right)$, a limit of concern to the concrete, as listed in Table 6-5 (Richardson 1992).

Table 6-5. Historic High Temperatures in Hanford Waste Tanks.

\begin{tabular}{|c|c|c|}
\hline Tank & Peak Temperature, ${ }^{\circ} \mathrm{C}$ & Date of Peak Temperature \\
\hline A-101 & 204 & June 1961 \\
\hline A-102 & 216 & August 1962 \\
\hline A-104 & 221 & February 1963 \\
\hline A-106 & 312 & May 1963 \\
\hline SX-107 & 199 & February 1958 \\
\hline
\end{tabular}

These tanks had exceptionally high heat loads because they were filled, over a period of about one year each, with waste only about three months out of the reactor. The heat loads of these tanks at these times have been estimated at $5-10 \times 10^{6} \mathrm{Btu} / \mathrm{hr}$ or $1500-3000 \mathrm{~kW}$ (G. L. Borsheim, unpublished note, 1992). Temperatures in these tanks have since fallen to well below boiling. These tanks, then, had heat loads about $10^{3}$ times as high as the ferrocyanide tanks and contained no ferrocyanide sludge. The high temperatures observed in these tanks, therefore, do not contradict what is said above of the impossibility of exceeding the boiling point in the present ferrocyanide sludges. 
WHC-EP-0816

This page intentionally left blank. 


\subsection{CONCLUDING REMARKS}

In this report, three possible mechanisms were investigated to determine if any of them could dry out a portion of the ferrocyanide sludge and thus render it potentially reactive. These mechanisms are: 1) sludge drying by boiling of interstitial liquid in a "hot spot" of concentrated heat-generating radionuclides; 2) drainage of interstitial liquid via a tank leak or by pumping; and 3) local surface evaporation from higher local heat flux and surface temperature. As a result of a rather extensive laboratory program and present knowledge of water migration and water retention behavior in sludge-like materials (concentrated suspensions of fine particles), it has been concluded that none of these mechanisms are credible dryout mechanisms.

Sludge resists local dryout because the precipitate particles "suspended" in the sludge are small $(0.1-10.0 \mu \mathrm{m})$ and the microscopic forces, mainly electrostatic, holding the liquid and particles together are much stronger than the gravitational force and the interstitial (pore) liquid pressures that tend to separate the particles from their host liquid. As a result of the strong particle-particle forces, small water concentration gradients give rise to huge microscopic forces (stresses) for moving water down the concentration gradient, thereby keeping the sludge wet in the presence of an applied local heat source. The so-called "consolidation curve" gives the local "effective stress" produced as a function of the local water content. Consolidation (sludge shrinkage) curves for ferrocyanide simulant sludges are available and have been used in combination with the liquid momentum equation (Darcy's law) to explain the laboratory results and to make predictions for dryout phenomena in the actual waste tanks.

Conclusions from the laboratory program and the analyses are listed below for each dryout mechanism.

1) Hot Spot. The heat generated by any credible concentration of radionuclides can be removed by conduction without any temperature reaching the boiling point. In addition, laboratory observations of growing gas or vapor bubbles in simulant sludge show that both the liquid and solids are displaced by the growing bubble so that the interior of the bubble contains only vapor. Thus the original hot spot is converted to a thin, thermally stable annular region at the termination of the bubble growth process. Numerous small-scale experiments and one large-scale experiment were performed involving boiling of sludge off the surfaces of immersion heaters to simulate hot spots that, because of the presence of vent paths (cracks) for steam, may undergo internal boiling rather than conversion to a single bubble.

All of these experiments indicated very little moisture variation within and outside the heated volume. The high cooling capacity of the sludge material is found to be consistent with sludge consolidation theory. The theory was extended to the 
ferrocyanide waste tank application and shows that very large local concentrations of heat-generating material would be required to reach an incipient dryout condition.

2) Sludge Drainage. A small column of In Farm 2 simulant sludge with a filtered (open) bottom has drained for nearly two years. This experiment clearly describes the capability of sludge for retaining water against the pull of gravity and thereby resisting dryout by drainage. Starting with 53 wt\% water the sludge has reached 49 wt\% water and the measured drained liquid mass-time history indicates that the drainage process is essentially over. The drainage history is consistent with consolidation theory. The application of this theory to sludge drainage in an actual waste tank predicts that it should not be able to dry below about 30 to $40 \mathrm{wt} \%$ water at the final equilibrium condition, which could take many years to achieve depending on the "compressibility" of the sludge.

3) Sludge Surface Evaporation. Two experiments were performed, one small-scale and one large-scale, in which immersion heaters were placed just beneath the surface of the sludge. The diameter of the large-scale sludge tank was $0.9 \mathrm{~m}$ and the tank was covered with a plastic tent arrangement so that condensate would return to the edge of the tank and not the center, heated area. The experiments showed that surface dryout does not result from a local surface region of elevated temperature. The fact that water evaporated from the warm surface is easily replenished is explained in terms of consolidation theory. The theory is used to show that dryout via localized surface evaporation is highly unlikely in an actual waste tank.

As a result of the experiments reviewed and the analyses presented in this report, the authors conclude that the formation of a local dry region in the ferrocyanide sludge which could render all or part of the sludge reactive is highly unlikely. From the analyses presented in this report and analyses presented elsewhere, it is evident that the formation of a dry, global region of sludge is not possible. 


\subsection{REFERENCES}

Anderson, J. D., 1990, A History of the 200 Area Tank Farms, WHC-MR-0132, Westinghouse Hanford Company, Richland, Washington.

Armstrong, L., W. P. Freeman and J. L. Kovach, 1993, Ferrocyanide Simulant In Farm REV-25 Water Adsorption Isotherm, NUCON05NU189/01, Nuclear Consulting Services, Inc., Columbus, Ohio.

Bechtold, D. B., 1994, Particle Size Distribution of Kaolin Clay Samples; (internal memo 8E-110-PCL94-046 to D. W. Jeppson, June 15), Westinghouse Hanford Company, Richland, Washington.

Borsheim, G. L. and B. C. Simpson, 1991, An Assessment of the Inventories of the Ferrocyanide Watch List Tanks, WHC-SD-WM-ER-133, Rev. 0, Westinghouse Hanford Company, Richland, Washington.

Bouse, D. G., 1975, Thermal Conductivity of Hanford Waste Tank Solids and SX Tank Farm Soil Samples, ARH-CD-378, Atlantic Richfield Hanford Company, Richland, Washington (reprinted in McLaren 1993b).

Crane, P. J., 1992, Hydraulic Properties of Simulated Ferrocyanide Tank Waste, (internal memo 25330-PJC-92-114 to J. J. Wong, September 16), Westinghouse Hanford Company, Richland, Washington.

Creed, M. J. and H. K. Fauske, 1990, "An Easy, Inexpensive Approach to the DIERS Procedure," Chemical Engineering Progress, (March) p. 45.

Crippen, M. D., 1993, Barometric Pressure Variations, WHC-EP-0651, Westinghouse Hanford Company, Richland, Washington.

Crippen, M. D., 1994, Ferrocyanide Safety Program: Moisture Migration Test in Ferrocyanide Simulant, WHC-EP-0800, Westinghouse Hanford Company, Richland, Washington.

Crowe, R. D., M. Kummerer and A. K. Postma, 1993, Estimation of Heat Load in Waste Tanks Using Average Vapor Space Temperatures, WHC-EP-0709, Westinghouse Hanford Company, Richland, Washington.

Dickinson, D. R., J. M. McLaren, G. L. Borsheim and M. D. Crippen, 1993, Ferrocyanide Safety Program: Credibility of Drying Out Ferrocyanide Tank Waste by Hot Spots, WHC-EP-0648, Westinghouse Hanford Company, Richland, Washington. 
Epstein, M., 1988, "Buoyancy-Driven Exchange Flow Through Small Openings in Horizontal Partitions," Journal of Heat Transfer, vol. 110, p. 885.

Epstein, M., H. K. Fauske and R. J. Cash, 1993, Ferrocyanide Safety Program: Waste Tank Sludge Rheology Within a Hot Spot or During Draining Homogeneous Flow Versus Flow Through a Porous Medium), WHC-EP-0713, Westinghouse Hanford Company, Richland, Washington.

Epstein, M., H. K. Fauske and R. J. Cash, 1994, Conditions for Reaction Propagation in Dried Ferrocyanide/Nitrate-Nitrite Powders, WHC-SD-WM-TI-619, Rev. 0, Westinghouse Hanford Company, Richland, Washington.

Fauske, H. K. and J. C. Leung, 1985, "New Experimental Techniques for Characterizing Runaway Chemical Reactions," Chemical Engineering Progress, vol. 81, p. 39 (August).

Fauske, H. K., 1992, Adiabatic Calorimetry and Reaction Propagation Tests with Synthetic Ferrocyanide Materials Including U Plant 1, U Plant 2, In Farm 1, In Farm 2 and Vendor-Procured Sodium Nickel Ferrocyanide, WHC-SD-WM-RDT-054, Rev. 0, Westinghouse Hanford Company, Richland, Washington.

Fauske, H. K., 1993a, Adiabatic Calorimetry (RSST and VSP) Tests with Synthetic T Plant Flow Sheet Material, WHC-SD-WM-TI-621, Westinghouse Hanford Company, Richland, Washington.

Fauske, H. K., 1993b, Some Experimental Results on Dryout in Kaolin/Water Simulant Waste Heated Locally, (letter to R. J. Cash, December 9), Fauske \& Associates, Inc., Burr Ridge, Illinois.

Glasrud, G. C., R. C. Navarete, L. E. Scriven and C. W. Macosko, 1993, "Settling Behavior of Iron Oxide Suspensions," AIChE Journal, vol. 39, p. 560.

Grigsby, J. M., D. B. Bechtold, G. L. Borsheim, M. D. Crippen, D. R. Dickenson, G. L. Fox, D. W. Jeppson, M. Kummerer, J. M. McLaren, J. D. McCormack, A. Padilla, B. C. Simpson and. D. D. Stepnewski, 1992, Ferrocyanide Waste Tank Hazard Assessment - Interim Report, WHC-SD-WM-RPT-032, Rev. 1, Westinghouse Hanford Company, Richland, Washington.

Hanlon, B. M., 1993, Tank Farm Surveillance and Waste Tank Summary Report for April 1993, WHC-EP-0182-61, Westinghouse Hanford Company, Richland, Washington.

Hardee, H. C. and R. H. Nilson, 1977, "Natural Convection in Porous Media with Heat Generation," Nuclear Science and Engineering, vol. 63, p. 119. 
Jeppson, D. W. and J. J. Wong, 1993, Ferrocyanide Waste Simulant Characterization, WHC-EP-0631, Westinghouse Hanford Company, Richland Washington.

Jones, S. W., M. Epstein, S. G. Bankoff and D. R. Pederson, 1984, "Dryout Heat Fluxes in Particulate Beds Heated Through the Base," Journal of Heat Transfer, vol. 106, p. 176.

Jungfleisch, F. M., 1984, TRAC: A Preliminary Estimation of the Waste Inventories in Hanford Waste Tanks Through 1980, SD-WM-TI-057, Rockwell Hanford Operations, Richland, Washington:

Katsaros, B. K., W. T. Liu, J. A. Businger and J. E. Tillman, 1977, "Heat Transport and Thermal Structure in the Interfacial Boundary Layer Measured in an Open Tank of Water in Turbulent Free Convection," Journal of Fluid Mechanics, vol. 83, p. 311.

Klem, M. J., 1991, Vapor Space Sampling Criteria for Single-Shell Tanks Containing Ferrocyanide Waste, WHC-EP-0424, Rev. 0, Westinghouse Hanford Company, Richland, Washington.

Lilga, M. A., M. R. Lumetta and G. F. Schiefelbein, 1993, Ferrocyanide Safety Project Task 3, Ferrocyanide Aging Studies, FY 1993 Annual Report, PNL-8888, Pacific Northwest Laboratory, Richland, Washington.

McAdams, W. H., 1942, Heat Transmission, McGraw Hill Book Company, New York, New York.

McGrail, B. P., D. S. Trent, G. Terrones, J. D. Hudson and T. E. Michener, 1993, Computational Analysis of Fluid Flow and Zonal Deposition in Ferrocyanide Single-Shell Tanks, PNL-8876, Pacific Northwest Laboratory, Richland, Washington.

McGrail, B.P., 1994, Ferrocyanide Tank Safety Project - Computational Analysis of Coupled Fluid, Heat, and Mass Transport in Ferrocyanide Single-Shell Tanks: FY 1994 Interim Report, PNL-10163, Pacific Northwest Laboratory, Richland, Washington.

McLaren, J. M., 1991, Single-Shell Tank 104-BY Thermal Hydraulic Analysis, WHC-EP-0521, Westinghouse Hanford Company, Richland, Washington.

McLaren, J. M., 1993a, Ferrocyanide Safety Program: Heat Loads and Thermal Characteristics Determination for Selected Tanks, WHC-EP-0638, Westinghouse Hanford Company, Richland, Washington.

McLaren, J. M., 1993b, Ferrocyanide Safety Program: Updated Thermal Analysis Model for Ferrocyanide Tanks with Applications to Tank 241-BY-104, WHC-EP-0669, Westinghouse Hanford Company, Richland, Washington. 
McLaren, J. M., 1994a, Ferrocyanide Safety Program: Thermal Analysis of Ferrocyanide Tanks, Group I, WHC-EP-0729, Westinghouse Hanford Company, Richland, Washington.

McLaren, J. M., 1994b, Ferrocyanide Safety Program: Thermal Analysis of Ferrocyanide Watch List Tanks, Group II, WHC-EP-0794, Westinghouse Hanford Company, Richland, Washington.

Meacham, J. E., R. J. Cash and G. T. Dukelow, 1994, Quarterly Report on the Ferrocyanide Safety Program for the Period Ending June 30, 1994, WHC-EP-0474-13, Westinghouse Hanford Company, Richland, Washington.

Michaels, A. S. and J. C. Bolger, 1962, "Settling Rates and Sediment Volumes of Floculated Kaolin Suspensions," I\&EC Fundamentals, vol. 1, p. 24.

Ottewill, R. H., 1977, "Stability and Instability in Disperse Systems," J. Colloid and Int. Sci., vol. 58, p. 357.

Overbeek J. Th. G., 1977, "Recent Development in Understanding of Colloidal Systems," J. Colloid and Int. Sci., vol. 58, p. 408.

Postma, A. K., J. E. Meacham, G. S. Barney, G. L. Borsheim, R. J. Cash, M. D. Crippen, D. R. Dickinson, J. M. Grigsby, D. W. Jeppson, M. Kummerer, J. M. McLaren, C. S. Simmons and B. C. Simpson, 1994, Ferrocyanide Safety Program: Safety Criteria for Ferrocyanide Watch List Tanks, WHC-EP-0691, Westinghouse Hanford Company, Richland, Washington.

Richardson, D. C., 1992, Revision to Responses Provided to DNFSB on Questions Related to Safety Concerns by Sonja Anderson, (letter 92073178 R2 to R. E. Gerton, U. S. Department of Energy), Westinghouse Hanford Company, Richland, Washington.

Russel, W. B., 1980, "Review of the Role of Colloidal Forces in the Rheology of Suspensions," Journal of Rheology, vol. 24, p. 287.

Sasaki, L. M. and B. D. Valenzuela, 1994, Ferrocyanide Safety Program: Data Interpretation Report for Tank 241-T-107 Core Samples, WHC-EP-0796, Westinghouse Hanford Company, Richland, Washington.

Schiefelbein, G. F., 1994, Ferrocyanide Safety Project, April 1994 Monthly Report, (letter 9403417 to R. J. Cash, May 10), Pacific Northwest Laboratory, Richland, Washington.

Seinfeld, J. H., 1986, Atmospheric Chemistry and Physics of Air Pollution, John Wiley \& Sons, New York. 
Simpson, B. C., G. L. Borsheim and L. Jensen, 1993a, Tank Characterization Data Report: Tank 241-C-112, WHC-EP-0640, Rev. 1, Westinghouse Hanford Company, Richland, Washington.

Simpson, B. C., G. L. Borsheim and L. Jensen, 1993b, Tank Characterization Report: Tank 241-C-109, WHC-EP-0668, Westinghouse Hanford Company, Richland, Washington.

Tadros, Th. F., 1980, "Physical Stability of Suspension Concentrates," Adv. in Colloid and Int. Sci., vol. 12, p. 141.

Taylor, D. W., 1948, Fundamentals of Soil Mechanics, John Wiley \& Sons, New York.

Turner, J. S., 1973, Buoyancy Effects in Fluids, Cambridge University Press, Cambridge, Massachusetts.

Verway, E. J. W. and J. Overbeek, 1948, Theory and Stability of Lyophobic Colloids, Elsevier, Amsterdam, Holland.

Wong, J. J., 1992, Test Report on Characterization of Hydraulic and Thermal Properties of Synthetic Ferrocyanide Sludges, WHC-SD-WM-TRP-102, Westinghouse Hanford Company, Richland, Washington.

Yong, R. N., A. M. O. Mohamed and B. P. Warkentin, 1992, Principles of Contaminant Transport in Soils, Elsevier, Amsterdam, Holland. 
WHC-EP-0816

This page intentionally left blank. 


\section{DISTRIBUTION}

Number of copies

OFFSITE

6

U.S. Department of Energy

EM-36, Trevion II

12800 Middlebrook Road

Germantown, MD 20874

James V. Antizzo

Charles O'Dell (5)

1

EH-15, Trevion II

12800 Middlebrook Road

Germantown, MD 20874

Shirley Campbell-Grizzel

1

U.S. Department of Energy

Savannah River Operations Office

P.O. Box A

Aiken, SC 29808

Thomas C. Temple

1

Charles S. Abrams

1987 Virginia

Idaho Falls, ID 83404

1 David O. Campbell

102 Windham Road

Oak Ridge, TN 37830

1

Fred N. Carlson

6965 North 5th West

Idaho Falls, ID 83401

1

Billy C. Hudson

202 Northridge Court

Lindsborg, KA 67456 


\section{DISTRIBUTION (continued)}

\section{Number of copies}

\section{OFFSITE}

1

Arlin K. Postma

3640 Ballard Road

Dallas, OR 97338

1

William R. Prindle 1556 Crestline Drive

Santa Barbara, CA 93105

1

Alfred Schneider

5005 Hidden Branches Drive

Dunwoody, GA 30338

1

Air Products \& Chemicals, Inc. 7201 Hamilton Blvd

Allentown, PA 18195-1501

George E. Schmauch

1

Battelle Columbus Laboratories

505 King Avenue

Columbus, $\mathrm{OH}$ 43201-2693

James A. Gieseke

1

Brookhaven National Laboratory

Upton, NY 11973

Kamal K. Bandyopadhyay

1

Design Science, Inc.

163 Witherow Road

Sewickley, PA 15143

Gary Powers 


\section{DISTRIBUTION (continued)}

Number of copies

\section{OFFSITE}

Fauske and Associates, Inc.

16W070 W. 83rd St.

Burr Ridge, IL 60521

Hans K. Fauske

Mike Epstein

1

Florida State University

Department of Chemistry B-164

Tallahassee, FL 32306

Greg R. Choppin

1

Harvard University

295 Upland Avenue

Newton Highlands, MA 02161

Melvin W. First

1

Hazards Research Corporation

200 Valley Road, Suite 301

Mt. Arlington, NJ 07856

Chester Grelecki

3

Los Alamos National Laboratory

P.O. Box 1663

Los Alamos, NM 87545

Steve F. Agnew

Steve W. Eisenhawer

Thomas E. Larson

1

MIT/Department of Nuclear Engineering

77. Massachusetts Ave.

Room 24-102

Cambridge, MA 02139

Mujid S. Kazimi 
DISTRIBUTION (continued)

Number of copies

OFFSITE

1

Nuclear Consulting Services, Inc.

P.O. Box 29151

Columbus, OH 43229-0151

J. Louis Kovach

Oak Ridge National Laboratory

1

Emory D. Collins

P.O. Box 2008

7930, MS-6385

Oak Ridge, TN 37831-6385

1

Charles W. Forsberg

P.O. Box 2008

MS-6495

Oak Ridge, TN 37831-6495

1

Thomas S. Kress

P.O. Box 2009

9108, MS-8088

Oak Ridge, TN 37831-8088

1

Rice University

5211 Paisley

Houston, TX. 77096

Andrew S. Veletsos

2

Sandia National Laboratories

P.O. Box 5800

Albuquerque, NM 87185

Dana A. Powers, MS-0744

Scott E. Slezak, MS-0741 


\section{DISTRIBUTION (continued)}

Number of copies

\section{OFFITE}

Science Applications International Corporation

20300 Century Blvd, Suite 200-B

Germantown, MD 20874

Ray S. Daniels (3)

State of Washington - Department of Ecology

1

Michael T. Gordon

P. O. Box 47600

Olympia, WA 98504-7600

1

Alex Stone

1315 W. 4th Avenue

Kennewick, WA 99336

1

University of South Carolina

Department of Electrical and Computer Engineering

Swearingen Engineering Center

Columbia, SC 29208

Joseph S. Byrd

1

University of Washington

Center for Process Analytical Chemistry

Chemistry Department BG-10

Seattle, WA 98195

Bruce R. Kowalski

1

Vanderbilt University

P.O. Box 1596, Station B

Nashville, TN 37235

Frank L. Parker 


\section{DISTRIBUTION (continued)}

\section{Number of copies}

\section{OFFSITE}

1

Waste Policy Institute

555 Quince Orchard Road, Suite 600

Gaitherburg, MD 20878-1437

Donald T. Oakley

1

Dartmouth College

Thayer School of Engineering

8000 Cummings Hall

Hanover, NH 03755-8000

Graham B. Wallis

\section{ONSITE}

12

U.S. Department of Energy, Richland Operations Office

R. F. Christensen (4)

S7-54

R. E. Gerton (4)

A. G. Krasopoulos

A4-81

Public Reading Room

$\mathrm{H} 2-53$

RL Docket File (2)

\section{Pacific Northwest Laboratory}

S. A. Bryan

P7-25

A. R. Felmy

K6-82

B. M. Johnson

$\mathrm{K} 1-78$

M. A. Lilga

P8-38

B. P. McGrail

$\mathrm{K} 2-38$

R. D. Scheele

P7 -25

G. F. Schiefelbein

P8-38

C. S. Simmons

K6-77

D. M. Strachan

$\mathrm{K} 2-44$

Hanford Technical Library

P8-55 


\section{DISTRIBUTION (continued)}

Number of copies

ONSITE

Westinghouse Hanford Company

H. Babad $\quad$ 57-30

J. B. Billetdeaux

D. C. Board $\$ 1-57$

G. L. Borsheim H5-27

S. R. Moreno B3-06

R. J. Cash (2) S7-15

M. D. Crippen L5-31

D. R. Dickinson $\quad$ L5-31

G. T. Dukelow $\quad$ S7-15

J. M. Grigsby H4-62

M. E. Huda R3-08

M. N. Islam R3-08

D. W. Jeppson L5-31

N. W. Kirch R2-11

C. A. Kuhlman B3-30

M. Kummerer H4-62

J. M. McLaren H0-34

J. E. Meacham $57-15$

N. J. Milliken H4-62

M. A. Payne $\quad$ S7-14

F. R. Reich L5-63

C. P. Schroeder L7-06

B. C. Simpson R2-12

H. Toffer H0-38

D. A. Turner $\quad$ S7-15

W. T. Watson H0-38

W. D. Winkelman L5-55

D. D. Wodrich $\quad$ S7-84

Central Files L8-04

Document Processing and Distribution (2) L8-15

EDMC H6-08

OSTI (2) L8-07

$\begin{array}{ll}\text { TFIC } & \text { R1-20 }\end{array}$ 